\title{
KIPS
}

\section{KILOWATT ISOTOPE POWER SYSTEM}

\section{"KIPS CONTROL SYSTEM SELECTION"}

TOPICAL REPORT
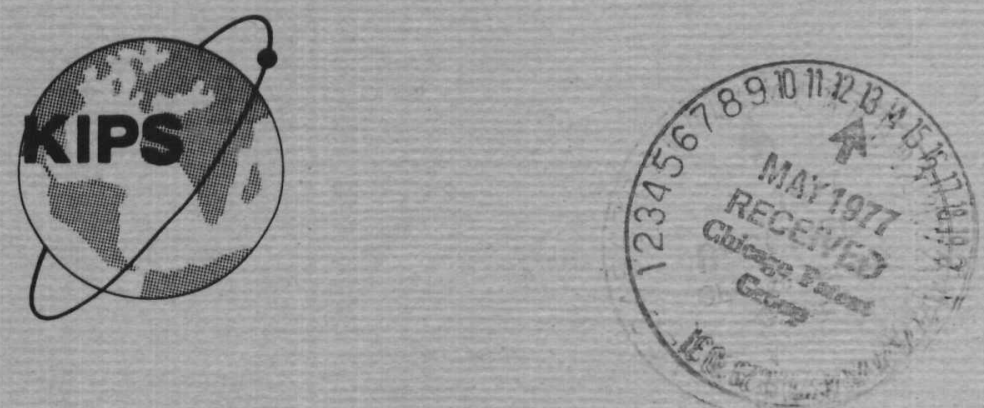


\section{DISCLAIMER}

This report was prepared as an account of work sponsored by an agency of the United States Government. Neither the United States Government nor any agency Thereof, nor any of their employees, makes any warranty, express or implied, or assumes any legal liability or responsibility for the accuracy, completeness, or usefulness of any information, apparatus, product, or process disclosed, or represents that its use would not infringe privately owned rights. Reference herein to any specific commercial product, process, or service by trade name, trademark, manufacturer, or otherwise does not necessarily constitute or imply its endorsement, recommendation, or favoring by the United States Government or any agency thereof. The views and opinions of authors expressed herein do not necessarily state or reflect those of the United States Government or any agency thereof. 


\section{DISCLAIMER}

Portions of this document may be illegible in electronic image products. Images are produced from the best available original document. 


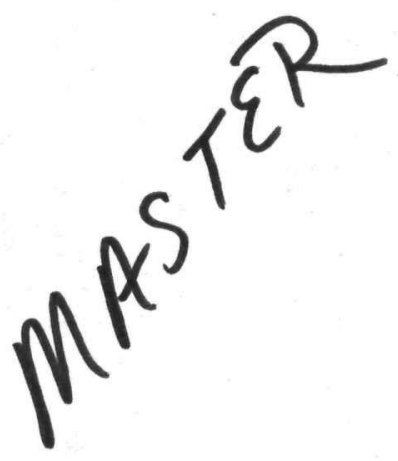

\author{
KIPS \\ KILOWATT ISOTOPE POWER SYSTEM
}

"KIPS CONTROL SYSTEM SELECTION"

TOPICAL REPORT

\begin{abstract}
Prepared for the
U.S. ENERGY RESEARCH AND

DEVELOPMENT ADMINISTRATION

UNDER CONTRACT EX-76-C-16-3071
\end{abstract}

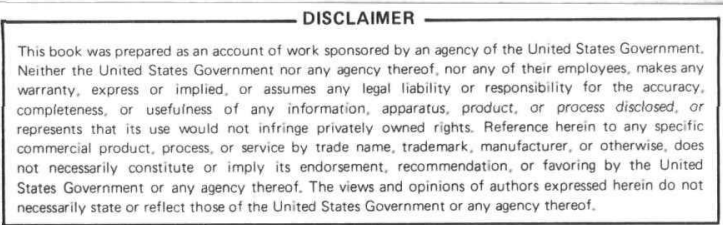

Prepared by: Sundstrand Advanced Technology Group 


\section{NOTICE}

"This report was prepared as an account of work sponsored by the United States Government. Neither the United States nor the United States Energy Research \& Development Administration, nor any of their employees, nor any of their contractors, subcontractors, or their employees, make any warranty, express or Implied, or assumes any legal liability or responsibility for the accuracy, completeness or usefulness of any information, apparatus, product or process disclosed, or represents that its use would not infringe privately-owned rights". 


\section{TABLE OF CONTENTS}

$\underline{\text { PAGE }}$

SUMMARY : 1

1.0 KIPS Control System Requirement 2

1.1 Turbine Inlet State Point Control 2

1.2 CRU Speed Control 5

1.3 Electrical Output Control 7

1.4 Heat Rejection Control 10

2.0 Control System Selection

3.0 Comparative Tradeoff Study Electromechanical vs. Hydromechanical Flow Control Valve

3.1 Uninteruptable Power Supply For Electromechanical Valve

3.2 Temperature Sensors For Electromechanical Valve

3.3 Electronic Controller Design Approach

For Both Systems

3.3.1 Controller For Mechanical Valve

3.3.2 Controller For Electrical Valve

3.3.3 Comparison of Block Diagrams For Both Systems

3.4 Reliability Comparison

3.4.1 Electronic Component Operating Temperature and Derating

3.4.2 Nak Sensor and Bellows Data

3.4.3 Nak Thermal Sensor Corrosion 
TABLE OF CONTENTS (CONTINUED)

\section{PAGE}

\subsubsection{Review of Mechanical Valve Reliability}

\section{Appendices}

A Control System Selection As Presented For Design Review \#3 (Revision A)

B Corrosion of Thermal Sensor Materials By Nak 


\section{LIST OF FIGURES}

$\underline{\text { PAGE }}$

1. Speed Control Systems 12

2 Temperature Control Systems $\quad 14$

3 Power Conversion System Block Diagram 18

4 Electromechanical Flow Control Valve 20

5 Electro Valve Flow Characteristics 21

6 Mechanical Flow Control Valve 22

7 Electro Valve Controller Block Diagram 28

8 Mechanical Valve Controller Block Diagram 29

9 Valve Functional Comparison $\quad 30$

10 Reliability Block Diagram Electromechanical 31 Valve

11 Reliab1lity Block Diagram Hydromechanical 32 Valve

12 NAK Filled Temperature Sensor Experience 38

13 Reliability Estimation for Mechanical Valve 43

14 Pressure Motor Bellows Redundancy 44

15 Thermal Sensor Bellows Redundancy 45

TABLES

1 KIPS Controller Temperatures vs. Recommended Limits 
SUMMARY

This Control system topical report covers basic control requirements, selection of control system and a recent review of an electromechanical approach to the flow control valve.

Section I covers the basic control requirements for Organic Rankine cycle systems, particular requirements for an isotope fueled space power system, and special requirements imposed by launch, Shuttle deployment and spacecraft requirements. Various control devices which can be used to meet system requirements are discussed.

In Section II, various combinations of control functions and devices are presented with comments as to the suitability of each for the intended application. This is essentially a review of the selection process used to pick the present rIPS control system. The formal trade-off matrix, component description, and system selection, as prepared for Design Reviews 2 and 3 , is included as Appendix A to the report.

Section 3 covers the recently completed design of an electronicelectromechanical flow control valve and compares this approach to the thermal bulb-hydro-mechanical flow control valve baseline. The results of this comparative study indicate that the present configuration is preferable to an electrical valve. 


\subsection{KIPS Control System Requirements}

The KIPS control system must be designed to accommodate a wide variety of requirements. Some of these are fundamental control functions required on any Organic Rankine cycle system, some are necessitated by the particular requirements of the changing heat rate of the isotope heat source used in the KIPS System, and additional functions are necessitated by spacecraft requirements. These control system requirements are discussed in the following sub-sections. Those noted by (A) are primary control functions required of any $O R C *$, those designated (B) are imposed by the isotope heat source and those designated (C) are additional but no less important requirements imposed by the ground and space environments, launch load considerations, and spacecraft torque requirements.

\subsection{Turbine Inlet State Point Control}

\subsubsection{Basic Requirements (A)}

A Rankine cycle system needs to have some control system to maintain turbine inlet conditions at the selected state point. Keeping turbine inlet conditions relatively close to the design point insures that the system will be able to produce the required power and that the turbine will always be supplied with superheated vapor to avoid erosion damage from partially vaporized working fluid. The flow rate through the turbine nozzles is proportional to turbine inlet pressure and inversely proportional to the square root of temperature. Thus, for constant turbine nozzle area, only two of the three parameters, flow, temperature and pressure need to be controlled. 
l'he necessity for flow control can best be illustrated by assuming that all other parameters of the system are held constant and noting the effects of a temperature perturbation on the system stability if no flow control is usea.

A slight decrease in turbine inlet temperature increases the vapor density at the turbine inlet and permits greater flow through the turbine nozzles. Increased flow through the constant heat rate heater results in a further decrease of vapor temperature and even higher nozzle flow. This process cascades until the turbine is flooded with liquid and can produce no power.

A positive temperature perturbation starts a cascading process in the opposite direction, resulting in a system overtemperature shutdown.

For the KIPS ORC system where there is only a small variation in system heat input due to isotope decay, sufficient control on turbine inlet conditions can be achieved by throttling flow and permitting the small corresponding change in pressure to occur. A pressure control or a flow limiter can provide constant flow rate, but will not provide adequate turbine inlet temperature control because the $7 \%$ decay in heat source input is of the same order of magnitude as the working fluid superheat. Small variations in heat input lead to large changes in temperature. Therefore, if a flow limiter or pressure regulator is used as the primary means of turbine inlet state property control, supplemental temperature control is also required. This supplemental control can be achieved by using heat pipes or shutters to control heat input rate or by diverting working fluid within the loop to shunt excess heat to the radiator. 
1.1.2 Temperature Control Requirements for Isotope Decay (B)

As the isotope heat source decays, less heat is delivered to the KIPS boiler. There are basically two approaches to the problem of maintaining constant turbine inlet temperature as the isotope decays. In the first approach, flow is kept constant and heat is diverted. In the second, flow is permitted to vary to absorb all available heat.

It is possible to keep the flow rate constant at a value corresponding to EOL* condition and control turbine inlet temperature, via shutters, thermal shunts, or heat pipes on the isotope heat source. This approach limits the PSC* output power to EOL conditions even when additional heat is available. It also means that the isotope heat source will have additional thermal losses throughout the heat source life due to the presence of the thermal shunt device, further reducing PCS output power. An alternate method for dissipating lexcess heat at BOL* condition is to shunt fluid around the regenerator. The regenerator connects the flow loop to the heat rejection loop so excess heat can be dissipated through the regeneratorcondenser interface.

One technique for accomplishing the regenerator short circuit is to divert vapor flow around the regenerator. The vapor flow can be taken from a point either before or after the turbine. It is also possible to accomplish the same result by diverting the regenerator liquid flow around the regenerator, thus causing the regenerator to operate at a higher temperature and shunting excess heat via the higher regenerator vapor outlet temperature.

* EOL End of Life

PCS Power Conversion System

BOL Beginning of Life 
The second approach consists of using all of the available heat at all times and adjusting boiler flow rate as required to maintain constant turbine inlet temperature. This approach permits maximum possible power output at all times and is, therefore, preferred if it can be easily accomplished.

\subsection{CRU* Speed Control (C)}

CRU speed control is not a primary requirement for a system with D.C. output power as alternator frequency is not critical. The speed control requirements are imposed by two conflicting requirements associated with the KIPS missions.

It is desirable to operate at a high rotative speed during launch shock and vibration loads.

Analysis of the CRU bearings indicated that extra bearing capacity would be required to handle launch and orbital transfer shock and vibration loads. The jet condenser jets also required extra pressure to achieve higher velocities and deflect less under these conditions. Bullding in extra capacity in these components was deemed undesirable since this extra capacity was normally not required and would result in higher parasitic losses and lower system efficiency.

By letting the CRU speed vary as load changes, the CRU seeks a speed which limits turbine input power to that required by the system and removes the need for active control of turbine power. The frequency wild system also aids in the system acceptance of full load on transients since the speed is high at part load and the CRU inertia can be used to insure that overload transients can be applied without substantial voltage drop due to speed variations. 
Spacecraft torque minimization requirements prohibit the use of frequency wild operation once orbit has been attained. Reasonably close control of $\mathrm{CRU}$ speed is required to insure that the spacecraft remains stable. The KIPS control system must then provide a dual mode feature, i.e. frequency wild or high speed operation for launch and speed control at best efficiency point for sustained spacecraft use. Speed can be controlled either by adjusting the CRU input power or its output power. Since turbine inlet temperature is usually kept constant to maintain superheated vapor conditions, turbine input power is controlled by adjusting flow or pressure ratio. Flow can be adjusted directly by varying turbine nozzle area or diverting some flow past the turbine. Flow can also be adjusted indirectly by a throttling valve which reduces turbine inlet pressure and causes a reduction of flow rate through fixed area turbine nozzles. A throttling valve at the turbine outlet will cause a power reduction by backpressuring the turbine and reducing the available turbine pressure ratio.

If a flow throttling valve is used to control temperature, the speed control function can be accommodated indirectly by bypassing the flow on the liquid side of the regenerator when excess power is available and speed begins to increase. As liquid is bypassed, boiler inlet temperature drops, turbine inlet temperature drops and flow is reduced by the temperature control valve to bring turbine inlet temperature back up to the desired value. This flow reduction reduces turbine power and prevents further speed increase.

Turbine speed can be also controlled by adjusting the CRU output power. An electrical load bank can be used to dissipate excess power. This technique removes excess heat from the power producing loop by converting the heat into work and converting the work back into heat 
outside of the loop on a high temperature radiator. The same effect is accomplished by loading the CRU hydraulically by means of the system pump or a separate hydraulic drag disc. However, the heat produced by this means must be rejected by the system radiator.

\subsection{Electrical Output Controls}

\subsubsection{Voltage Regulation (C)}

A voltage regulator is required to maintain the output voltage within required limits. Voltage regulation is typically accomplished by controlling alternator field current. Several types of voltage regulator circuits can be used.

PROPORTIONAL VOLTAGE REGULATORS: Shunt and series regulators are simple with low parts count, but have the major drawback that they are dissipative. Dissipation causes higher losses in semiconductors and resistors lowering reliability. Therefore, dissipative proportional voltage regulators were avoided because of their low reliability.

MAGNETIC AMPLIFIER REGULATOR: The magnetic amplifier acts as a phase controlled switch on the rectified AC field supply voltage to supply a variable DC voltage to the exciter field. The magnetic amplifier can be considered a switch in series with the exciter field that can be turned on at various phase angles of the rectified input voltage half sine waves, thus producing a variable DC. This regulator is simple with few parts; its drawback is the weight of the magnetic amplifier which must handle the total field current.

PULSE WIDTH MODULATED REGULATORS: The pulse width modulating regulators can be put into two classes, forced and Bang-Bang Modulation. 


\subsubsection{Continued}

a) Pulse Width Modulation: In pulse width modulation

a switch in series with the field is operated at either the ripple frequency of the field power source or at a selected frequency derived from an oscillator. The duty cycle of the modulation frequency is varled by voltage error to maintain the output voltage. This regulator is more complicated than the others considered and is more applicable to systems requiring exceptionally good voltage regulation.

b) Bang-Bang Pulse Width Modulation: In the Bang-Bang system the switch in series with the field is allowed to modulate at the system natural frequency and have a duty cycle dependent on the loop dynamics. This is a simple regulator with voltage regulation characteristics less refined than the forced pulse width modulation scheme.

\subsubsection{Overload Protection (C)}

Provision must be made in the control system to prevent an electrical overload from occurring. With any type of P.C.S. an electrical overload can cause control problems by the attempt to operate outside the expected operating range. When the system heat input is fixed an attempt to extract more power than is thermodynamically possible can cause severe system disruptions.

In the case of the ORC system, an electrical overload causes the CRU to slow down in an attempt to match turbine torque with the increased torque requirements of the alternator. This speed decrease will eventually reduce feed pump pressure to a point where the turbine flow is reduced. The system will then overheat, causing the PCS system to shutdown. 


\subsubsection{Continued}

Overload prevention can be achieved by design of the alternator such that it saturates and cannot deliver excess power. An attempt to overload the system results in rapid voltage drop which limits the power so that an overload cannot occur. This approach usually compromises the generator efficiency at design conditions, and cannot easily be used when several design power levels are required from the same generator.

With a constant output voltage P.C.S. as required for the KIPS system, current limiting can be used to provide overload protection. Current sensors can be incorporated into the generator controls to limit the current to the design value or to provide short circuit protection by disconnecting the load when an overload occurs. Current limiting can also be used to partially unload the generator in the event of a CRU underspeed condition caused by a partial fallure of some other system component. If the maximum alternator field current is just sufficient to carry full load at rated speed and output current is limited to that required to provide rated power at rated voltage, a decrease in speed below minimum design speed will result in a linear decrease in voltage and output power. The turbine power does not decrease as rapidly with speed as the generator output, so a lower speed balance point can be attained and the system will continue to supply some electrical power instead of shutting down.

The major drawback to the use of current limiting for KIPS is the varying output power capability with time as the isotope heat source decays. A fixed current linear setting. would always limit the electrical output to E.O.L. conditions. An adjustable current IImit would require some means of determining what the maximum load 


\subsubsection{Continued}

capablitiy of the PCS is at any set of operating conditions and setting the current limit appropriately. Current limiting is accomplished by cutting back on alternator field current as required to maintain constant output current during electrical overloads. Thus output voltage will drop and CRU speed will increase. Thus current limiting violates the requirement for constant speed operation.

CRU speed is an excellent indicator of system overload. As excessive load is applied and the speed sags, the underspeed signal can be used to reduce or cut off alternator field current to limit the output capability of the alternator and thus prevent continued speed reduction. In this way overloads are prevented from harming the PCS and constant speed is maintained.

\subsection{Heat Rejection Control (C)}

The primary means of P.C.S. heat rejection is via the system radiator. The radiator must be large enough to refect BOL waste heat at full load and the highest heat sink temperature. At other operating conditions the radiator is oversized and it is desirable to Iimit the heat rejected to maximize P.C.S. efficiency; this capability is particularly desirable at E.O.L. when the P.C.S. output power is lowest.

It is also very desirable to have some means of controlling radiator outlet temperature when the radiator auxilliary cooling loop is used for system heat rejection when the P.C.S. is installed in the Shuttle Bay. P.C.S. control of the radiator temperature eliminates the need for active shuttle control of the cooling temperature.

A third function of the radiator heat rejection control is to permit subcooling of the radiator metal to act as a heat sink when the KIPS system is launched using a Titan vehicle. This heat 


\subsection{Continued}

sink permits the KIPS system to continue running during the critical launch period when the radiator is shrouded.

\subsection{Control System Selection}

It can be seen from the description of control requirements In section 1 that there are many possible techniques to provide each of the control requirements. The objective in selecting a control system is then to perform all of the control system functions with a minimum number of devices. The following discussion is an attempt to step through the requirements to show what types of controls are most likely to lead to a simple system.

A good starting point is the requirement that the PCS must operate both with the speed controlled for spacecraft stability and frequency wild for launch. The speed wild capability should be arranged so that it is also a viable backup operating mode in the event of a speed control system failure. Since the change from speed wild to constant speed mode must be made after orbital transfer, a remote electrical signal must be used to provide mode switching. Figure 1 shows the various techniques for providing speed control with comments on the effects of each technique on system performance. The electrical load bank becomes the obvious choice when tight speed control is required and has the other advantages of easiest remote switching, minimal effect on E.O.L. performance and ease of adding required overload protection. The electric load bank was therefore selected as the means of system speed control. 


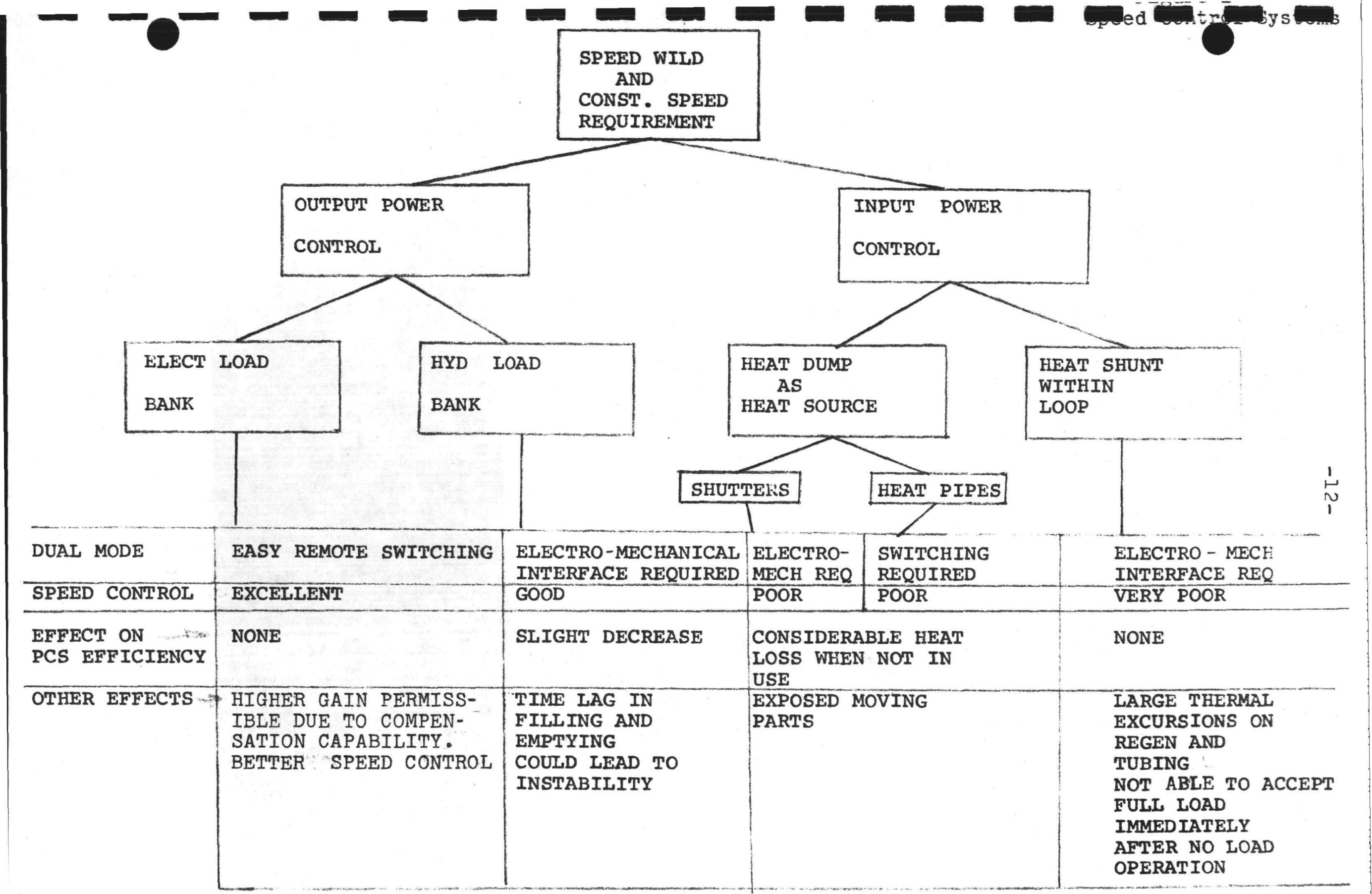


The electric load bank speed control sub-system consists of a speed detection circuit, a means of switching power to the load bank, and the load bank resistors.

Two frequency discriminator circuits were studied, a passive tuned circuit and an integrated circuit discriminator. The passive tuned clrcult was selected based on lower parts count, lower weight, and higher reliability.

Three types of PLR* loading circuits were considered, an AC power switchingcircuit using SCR's, a Bang-Bang DC power switching circuit using transistor switches, and a pulse width modulated DC power switching circuit using transistor switches. The first option was unsuitable because of the low reliability of the SCR's. The second option was eliminated due to excessive speed variation which creates undesirable torque effects on the spacecraft. The selected PWM circuit has a high modulating frequency so speed variations are of a low amplitude and high frequency.

System turbine inlet temperature control was then investigated using the chart of Figure 2. As discussed in section 1.0, direct control of temperature by throttling flow will produce inherently adequate control of turbine inlet pressure and can be designed to control temperature to any desired operating range. The other approach, using a flow limiter or pressure regulator for gross control during frequency wild operation and some means of shunting excess heat by use of a diverter valve, or shutter, provides distinctly inferior temperature control because of component thermal lags, and prevents the system from accepting full load immediately when operating at no load in the speed wild mode.

No simplification of the mechanism is evident from the use of PLR: Parasitic load resistor 


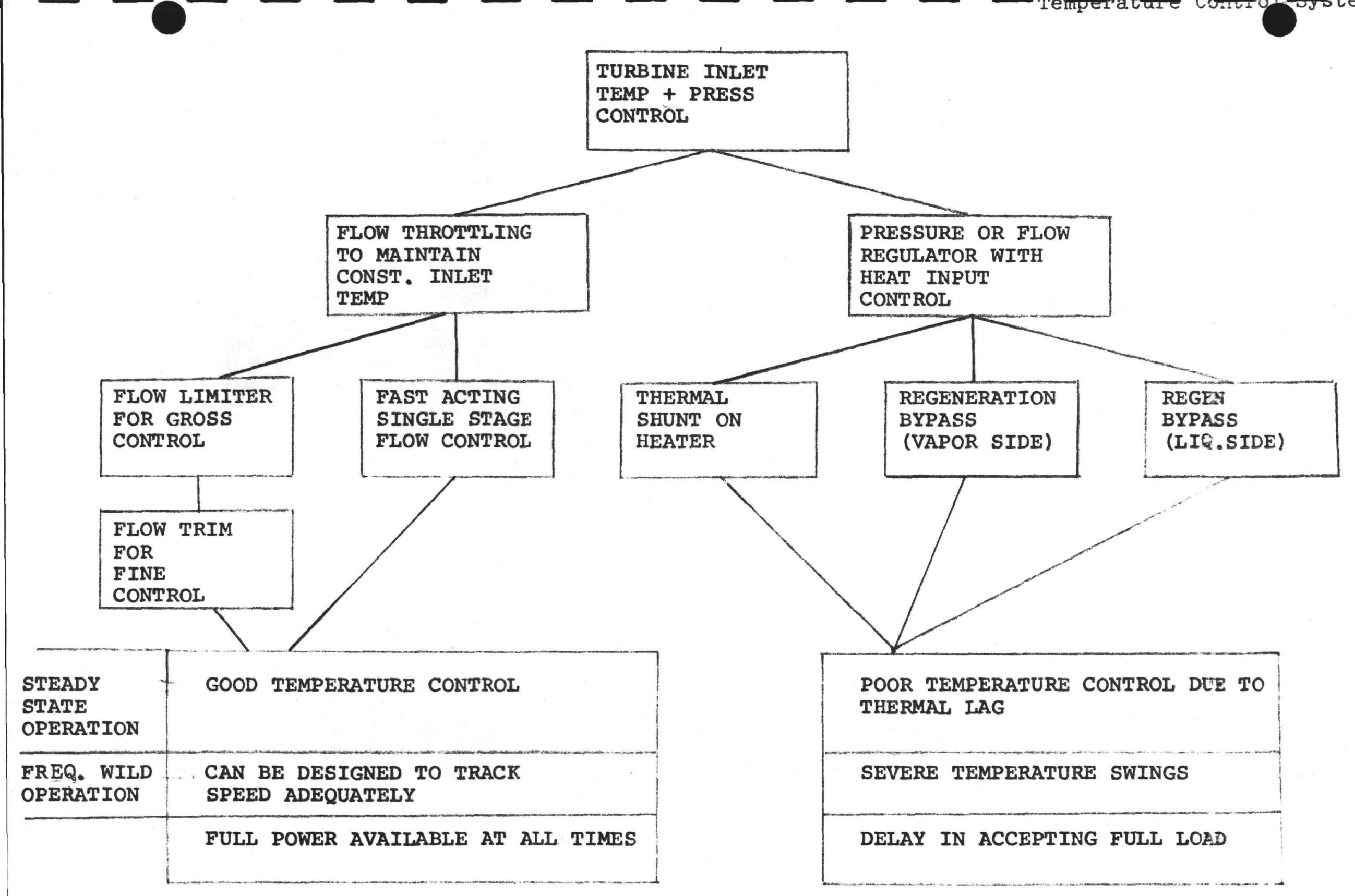




\subsection{Continued}

the latter technique so a flow throttling valve was selected to provide temperature control.

Varlous flow control valves were investigated during the early months of the KIPS program to insure that the valve would be as simple and reliable as possible. Electrically operated valves were eliminated early in the studies because of the expected low reliability of the long chain of components required. The electrical valve requires a thermal sensor, electronic control circuits, an amplifier to produce valve drive current, and an electro-mechanical valve. The temperature control function is then also dependent on a continuous and uninterruptable supply of electrical power. Section 3 of this report covers a more recent re-examination of the use of an electrical temperature control valve.

A fluidic temperature control valve appeared to be quite attractive and within the state of the art. The fluidic valve should require no moving parts if temperature sensing is accomplished via a fluid viscosity sensitive capillary tube. This approach was pursued in confuction with Harry Diamond Laboratories. As the KIPS detalled model of the steady state operating points for the system was completed an operating map of detailed requirements for the fluldic valve revealed that higher valve gain and faster response than originally anticipated were required. As additional amplifier stages were added the valve passages became more complicated, heat losses through the temperature sensor increased and valve pressure drop increased. In addition it was found that to properly start and shut down the system a check valve must be added to the fluidic valve vent line. Alternate valves were then investigated in which direct thermal expansion of bimetallic discs or hydraulic displacement of a liquid 


\subsection{Continued}

fllled thermal bulb could be used to provide flow throttling.

The trade-off and selection process used to pick the best valve conflguration prepared and presented in the Data Pac for KIPS Design Review No. 2 (Ref. 1). Further evaluation of the selected valve design was included in Design Review No. 3. (Ref. 2).

The revised selection matrix and discussion is included in this report as Appendix A.

As the result of these trade-off studies a 2 stage flapper valve was selected for temperature control. The first stage uses a redundant bellows assembly to. actuate a flow limiting flapper nozzle and the second stage uses redundant liquid metal ( $\mathrm{NaK}$ ) fllled temperature sensors to actuate a reference setting flapper nozzle. The valve is able to respond rapidly via the flow limiter to keep turbine flow constant under all operating conditions and can make gradual corrections to the flow setting to keep turbine inlet temperature constant.

During the second Design Review, reservations were expressed concerning several features of the valve design. The primary concern was the NaK filled thermal sensors. It was suggested that Sundstrand take a fresh look at an electrically driven valve to evaluate the potential benefits of static electronic components and a simple valve as opposed to the dual flapper, bellows, and NaK filled sensor of the current design. This recent trade-off is covered in Section 3.

Having selected a parasitic load bank for speed control with provision for underspeed alternator unloading to prevent output electrical faults from affecting the P.C.S., and a flow throttling valve to control turbine inlet temperature, the basic system controls are complete. The system can operate elther frequency w1ld or at constant speed as desired by switching off the speed control circuit and turbine inlet temperature is controlled under all 


\subsection{Continued}

operating conditions. To complete the control system a voltage regulator and heat rejection control device are required.

Voltage control is provided by the voltage regulator which controls alternator field current. The voltage regulator responds rapidly to load transients to maintain close control of output voltage even with rapid load fluctuations. Frequency wild operation mandates the use of a voltage regulatorto control output voltage. Alternator power output capability increases with speed so as speed increases, alternator field current must be decreased to maintain voltage control. A straight forward switching regulator circuit was selected over a proportional regulator due to the fact that switching regulators dissipate much less power than proportional regulators and lower power dissipation increases reliability.

Solid state switching components were compared to a system using a saturable reactor to perform the switching function. Solid state switching provided advantages in both reliability and weight. Details of the electronic controller trade-off studies are contained in Appendix A.

A radiator bypass valve was selected as the best method of controlling system heat rejection. The valve provides radiator outlet temperature control during a Titan launch, Space Shuttłe Bay operation, and deployed spacecraft operation. The valve has the very desirable feature of failing "safe" 1.e. In the closed position so that a failure does not greatly reduce PCS Output power capability; a 40 watt electrical output reduction occurs if the bypass valve fails closed. The selection process for the bypass valve is covered in Appendix A.

A PCS system block diagram showing the type and location of the various controls is shown in Figure 3. 


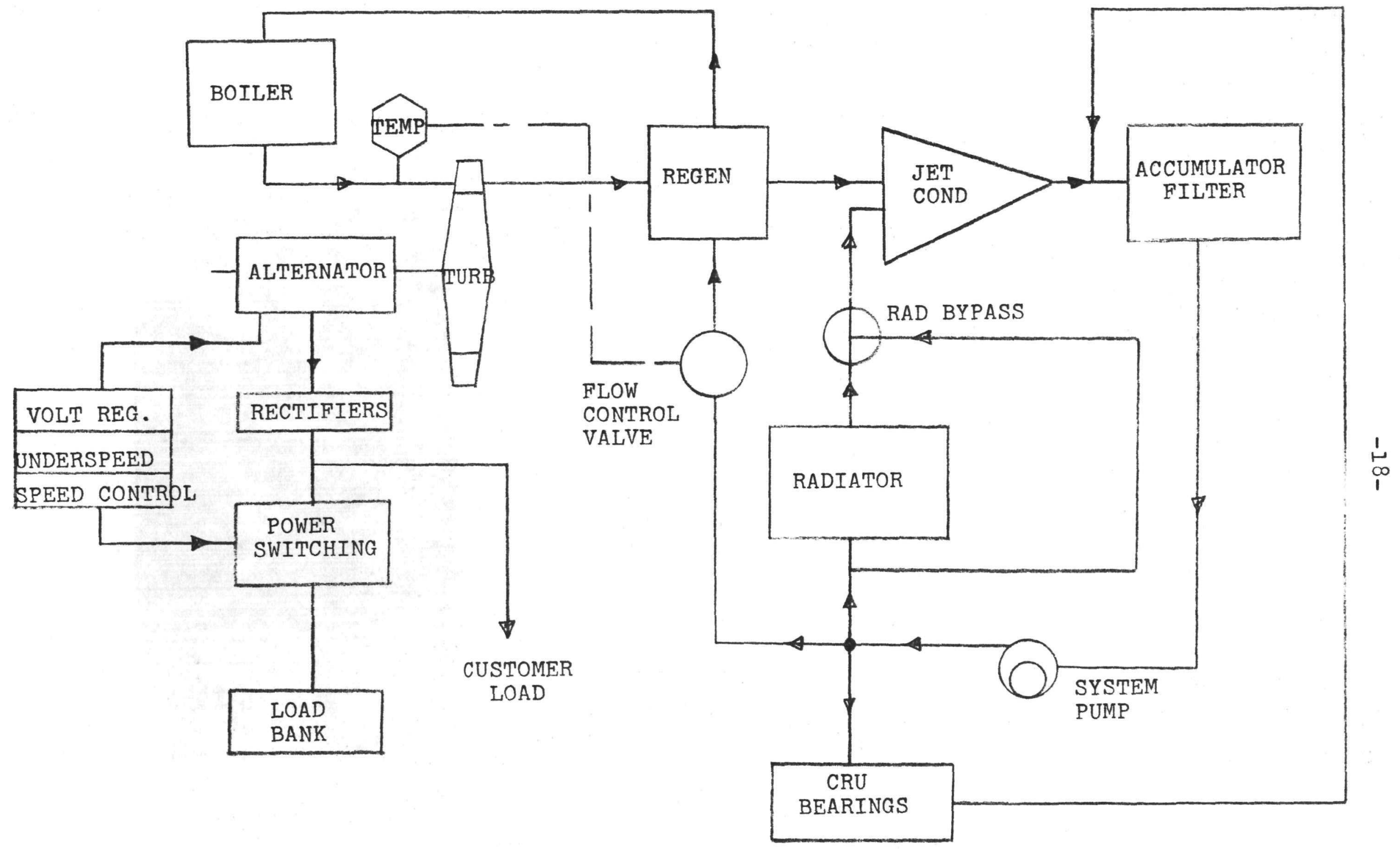

FIGURE 3 KIPS PCS BLOCK DIAGRAM 
3.0 Electronic vs. Mechanical Flow Control Valve

The purpose of this section is to compare an electromechanical

flow control valve with the present hydromechanical flow control valve design to see $1 \mathrm{f}^{\circ}$ a rellabll1ty advantage can be achieved by changing to an electrical control system.

The major advantage of an electrical control system is in the simplification of the valve mechanism, particularly deletion of the NaK filled sensor and the bellows assemblies. Accordingly a simple single stage flapper valve was designed using a flexure pivot and a dry coll to achieve the simplest possible throttle valve. This valve is shown in Figure 4. Flow characteristics are displayed on Figure 5. It is immediately obvious that the mechanical part of the electrically driven valve is considerably less complicated and therefore more reliable than the present mechanical valve of Figure 6. The critical questions are whether the added mechanical rellability is sufficient to cover the rather complicated electrical drive circuit and temperature sensing electronics package associated with the electrical valve, and the provision of an uninterruptable power supply for the electrical valve.

The second question is of particular importance for the KIPS power system. Any KIPS flow control valve must be continuously operating to maintain correct turbine inlet temperature. During system start up it is assumed that external electrical power is available to run the electrical temperature control valve until the C.R.U. Is up to speed and providing power. In the event of a user short circuit after the system has been placed in operation, the KIPS alternator output voltage drops and control power is lost. With an electrical temperature control valve the P.C.S. will become unstable during a short circuit and will shut down either due to excessive 

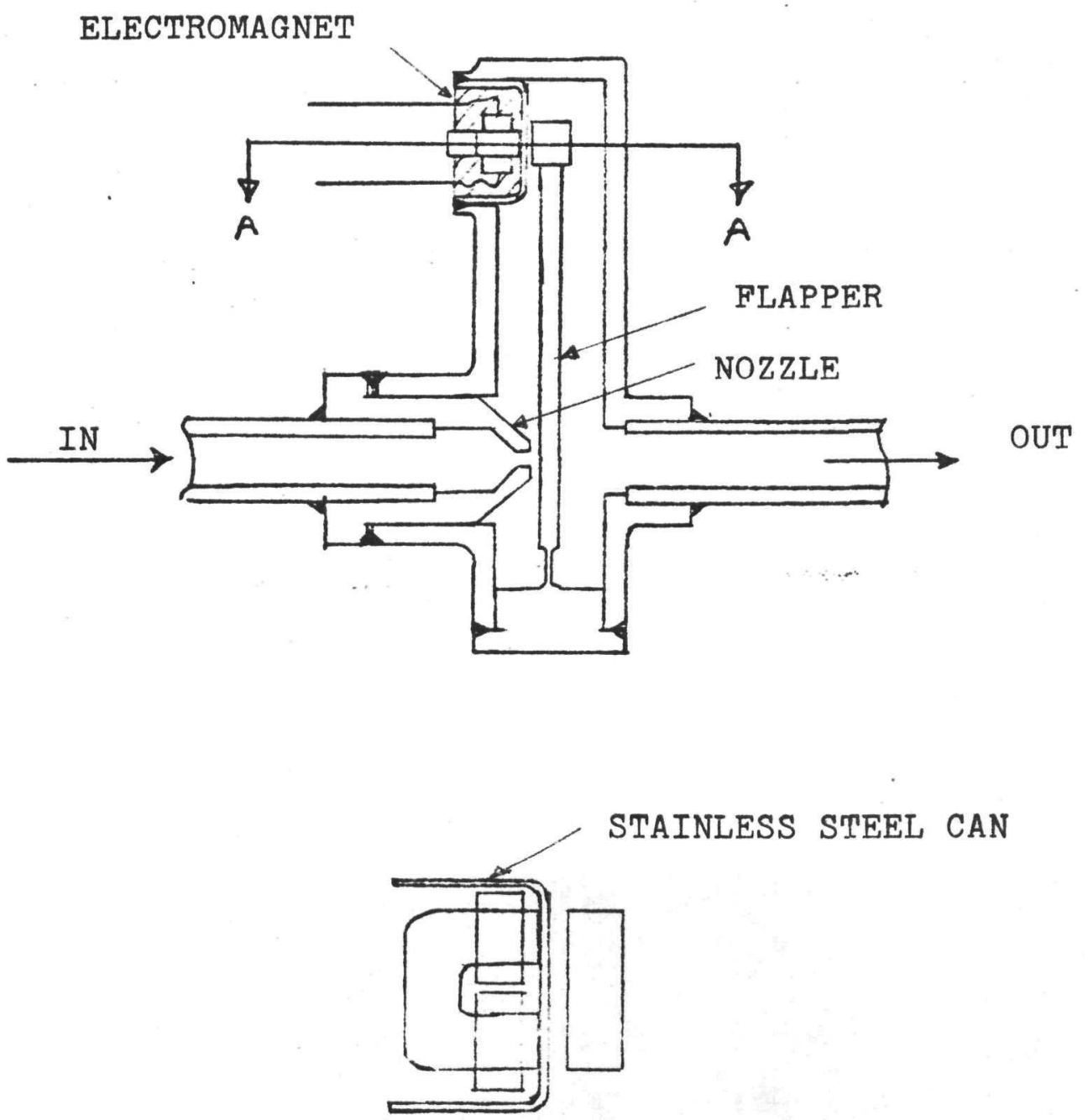

SECT ION A-A

- ELECTRO-MECHANICAL FLOW CONTROL VALVE

FIGURE 4 


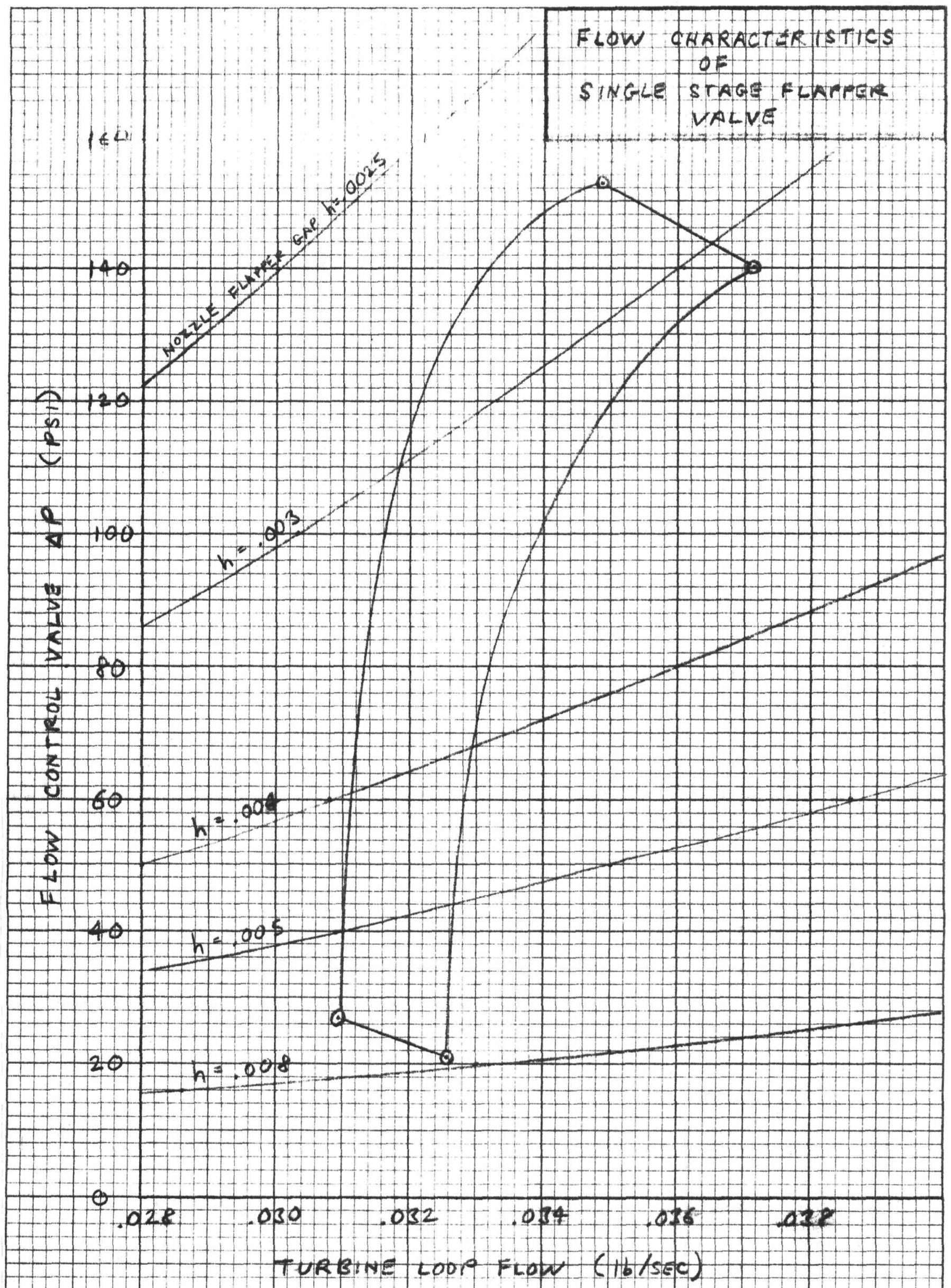




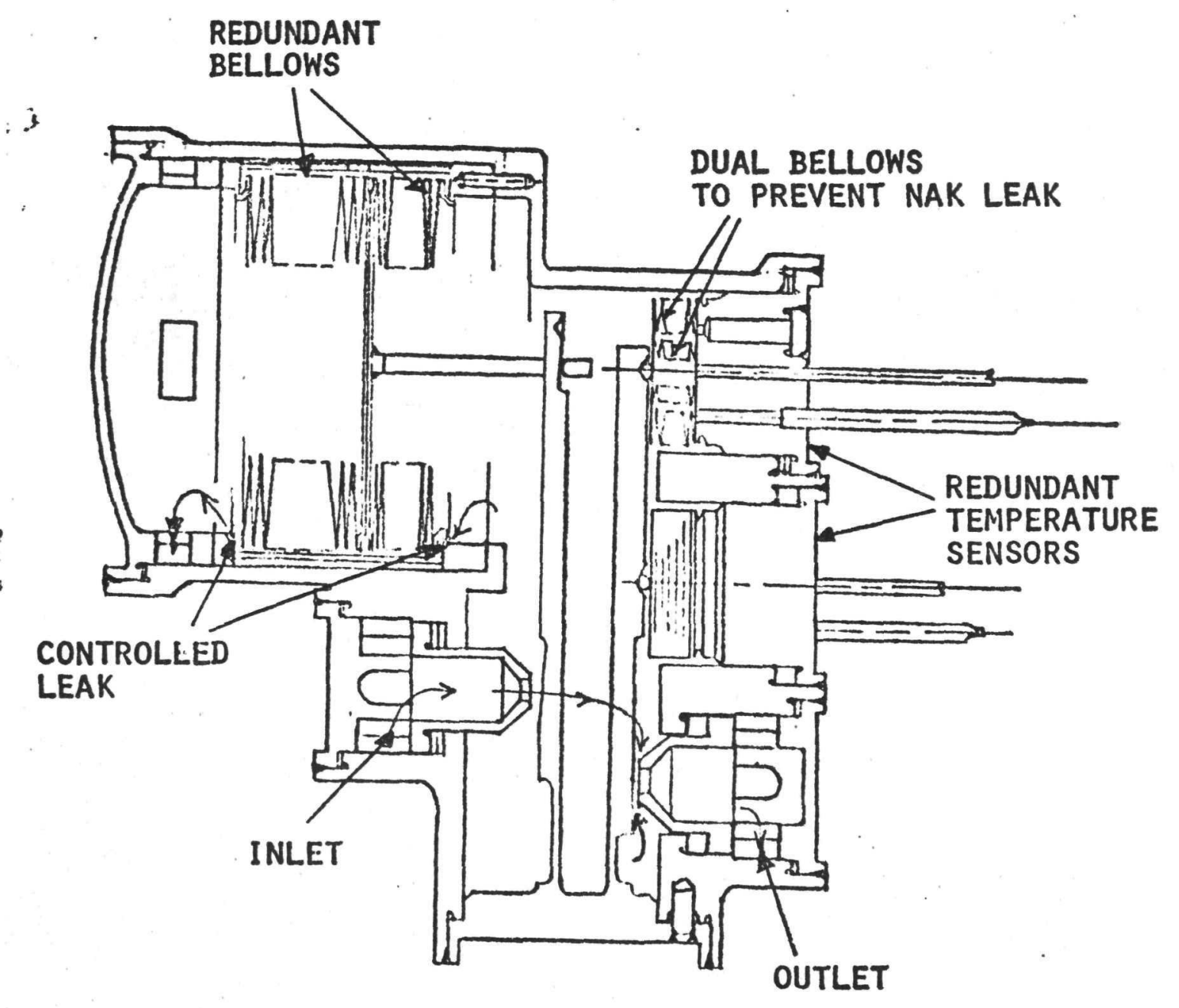

KIPS FLIGHT SYSTEM FLOW CONTROL VALVE 


\subsection{Continued}

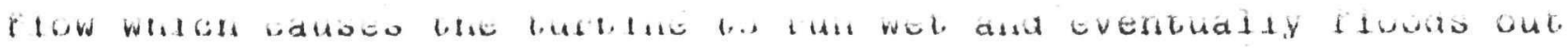

the jet condenser or due to insufficient flow which causes an overtemperature shutdown.

Similar problems occurs in the event of a user electrical overload. As the overload causes the CRU to slow down, the existing controller sheds load by removing field excitation current from the alternator. Alternator output power then goes to zero until the CRU speeds up and residual magnetism is sufficient to re-energize the alternator field. If the overload is still present, the CRU slows down and the field is again de-energized. No electrical output power to operate the control valve is available when the alternator field current is shut off. The electrical valve is therefore incompatible with the present KIPS control system because the present system does not provide uninterruptable power. Three possible ways of providing independent temperature control power were investigated.

3.1 Uninterruptable Power Supply For Electromechanical Valve One approach is to add a battery to the system to provide temperature control power during electrical bus faults. A brief Investigation (Ref. 3, 4, 5) into battery life and reliability revealed that a battery was totally unsuitable as a means of providing backup power for the controller.

A silver-zinc battery could be stored in the unactivated state for long periods but would require an electrical signal and time to actuate and would not be easily reusable in the event of a second fault several months or years later.

Ni-Cad batteries are often used on spacecraft and considerable developement has gone into the design of high reliability batteries. 


\subsection{Continued}

Reference $I$ states that "the average service life of a Ni-Cad battery can approach five years", not an encouraging statement for a system with a 7 year mission life. In addition N1-Cd batterles cannot be operated at temperatures as high as the lowest KIPS fluid temperature so additional battery thermal conditioning would be required. The battery could not be floated on the 28 VDC bus but would require a constant current power supply for trickle charging and a state of charge sensing circuit for recharging the battery after use.

A second possiblity for providing uninterrupted power to the temperature controller is to redesign the CRU to add a permanent magnet generator which would operate independently of the main alternator to supply control power. This option, although far better than a battery, adds additional complexity to the system.

The third possibility requires a controller redesign to disconnect the user from the Power bus in the event of a short circuit or overload. Current transformers could be used to sense user current and switches used to disconnect the power in the event of a short circuit. Mechanical switches are not desirable because the number of moving parts will most likely exceed those of the mechanical valve we are trying to replace.

A large transistor could be used as a switch but no JANTXV transistors of the required 50-70 amp capacity are available. Transistors this large have been built but have unknown reliability. An SCR could also be used as the switch but they have a 1.2 volt voltage drop when "on" resulting in a 55 watt power loss for a 1300 watt system. This not only amounts to a constant $4 \%$ reduction in available output power but also necessitates active cooling of the 


\subsection{Continued}

$\mathrm{SCR}$. $S C R^{\prime} \mathrm{S}$ in general have inadequate reliability for a large life mission, particularly at these high current levels.

of these possible sources for uninterruptable power for the electric valve, the P.M.G. Is the most feasible and was used in making up the electrical temperature control valve block diagram.

\subsection{Temperature Sensors For Electromechanical Valve}

The electrical temperature sensor used to sense turbine inlet temperature for the electromechanical valve was selected from three possible types. Thermistor, thermocouple, and resistance temperature devices were considered.

The first device to be considered, the thermistor, has a maximum temperature limitation of $200^{\circ} \mathrm{C}$ or $392^{\circ} \mathrm{F}$ which is far short of the $650^{\circ} \mathrm{F}$ turbine inlet temperature. The thermistor was judged not sultable and not given further consideration.

The thermocouple does not suffer from this temperature limitation. It is however, a thermoelectric device generating a millivolt level electrical signal proportional to the temperature. The thermocouple can be modeled as a voltage source in series with a large value resistor. The input amplifier must therefore have a very high input impedance to prevent loading down the thermocouple output. This combination of low level signals with high input impedance makes the circuit very susceptible to nolse. This noise susceptiblilty and the other problems associated with the high input impedance make the thermocouple sensor undesirable for this application.

The third device to be considered was the platinum resistance temperature device, commonly referred to as a platinum RTD. It is a coll of platinum wire whose resistance changes as a function of 


\subsection{Continued}

temperature. It is a resistance device like the thermistor rather than a thermoelectric device like the thermocouple, and is useable at temperatures exceeding 12000F. From considerations of operating environment and circuit noise susceptibility, the platinum RTD is the most sultable electrical temperature sensor.

Investigation revealed that platinum resistance temperature devices (RTD's) are suitable in space for periods of 10 years or more (Ref. 3). The RTD used with the electro-mechanical valve is assigned

a fallure rate of 2.0 fallures per million hours based on data supplied by manufacturers. This data Iists a minimum fallure rate of 5 fallures per mililon hours for a commercial aircraft application. Conservatively, a factor of 2.5 is used for a fallure rate of 2.0 failures per million hours.

\subsection{Electronic Controller Design Approach For Both Systems}

\subsubsection{Electronic Controller for Mechanical Valve Schematic}

Reliability of the KIPS electronic controller was of prime Importance in 1ts design. Two design concepts were explored in an effort to maximize reliability while keeping equipment cost, weight and size reasonable. The first used a triple redundant design for all circuits with two of the three required to be operating for success. This resulted in a controller with a reliability greater than .99 for five years. This reliability was achieved at the expense of increased cost, welght and size.

The second method used a minimum parts design approach. The circuits were simplifled and all parts were carefully selected and derated. Redundancy was retained in the parasitic load resistors (PLR's) and their transistor switches. The use of three PLR's 


\section{1 .1 Continued}

slzed for 0.5 PU load reduces the switching transistors' current by a factor of two and provides redundancy in the PLR's which have the h1ghest assigned fallure rate in the control system. Th1s system provides a rellability of .982 while keeping the cost, welght and size of the controller reasonable. For a completely triple redundant system the cost, weight and size would be roughly three times as large.

\subsubsection{Electronic Controller For Electromechanical Valve}

The KIPS controller for the electro-mechanical valve option employs redundancy in two areas. The parasitic load resistor and switching transistor circuitry is the same configuration used in the mechanical valve version. Three identical circuits are provided with two of the three required to be operating for system success. The second area to employ redundancy is the temperature control circuitry. Because of the high failure rate of the platinum resis-

tance temperature device (2 fallures $/ 10^{6}$ hours), redundancy is required if a controller rellability greater than 0.9 for five years is to be achieved. The configuration used has three identical temperature control circuits with two of the three required for system success. Using redundancy in these two areas a controller rellabllity of .9599626 for five years is achieved.

\subsubsection{Comparison of the Block Diagrams For the 2 Valve Approaches}

The resulting block diagrams for the electromechanical and hydromechanical systems are shown in Figures 7 and 8 respectively.

A list of the significant differences between the two systems is presented in Figure 9. The hydromechanical valve has a pressure regulator function to maintain flow control during speed transcents 


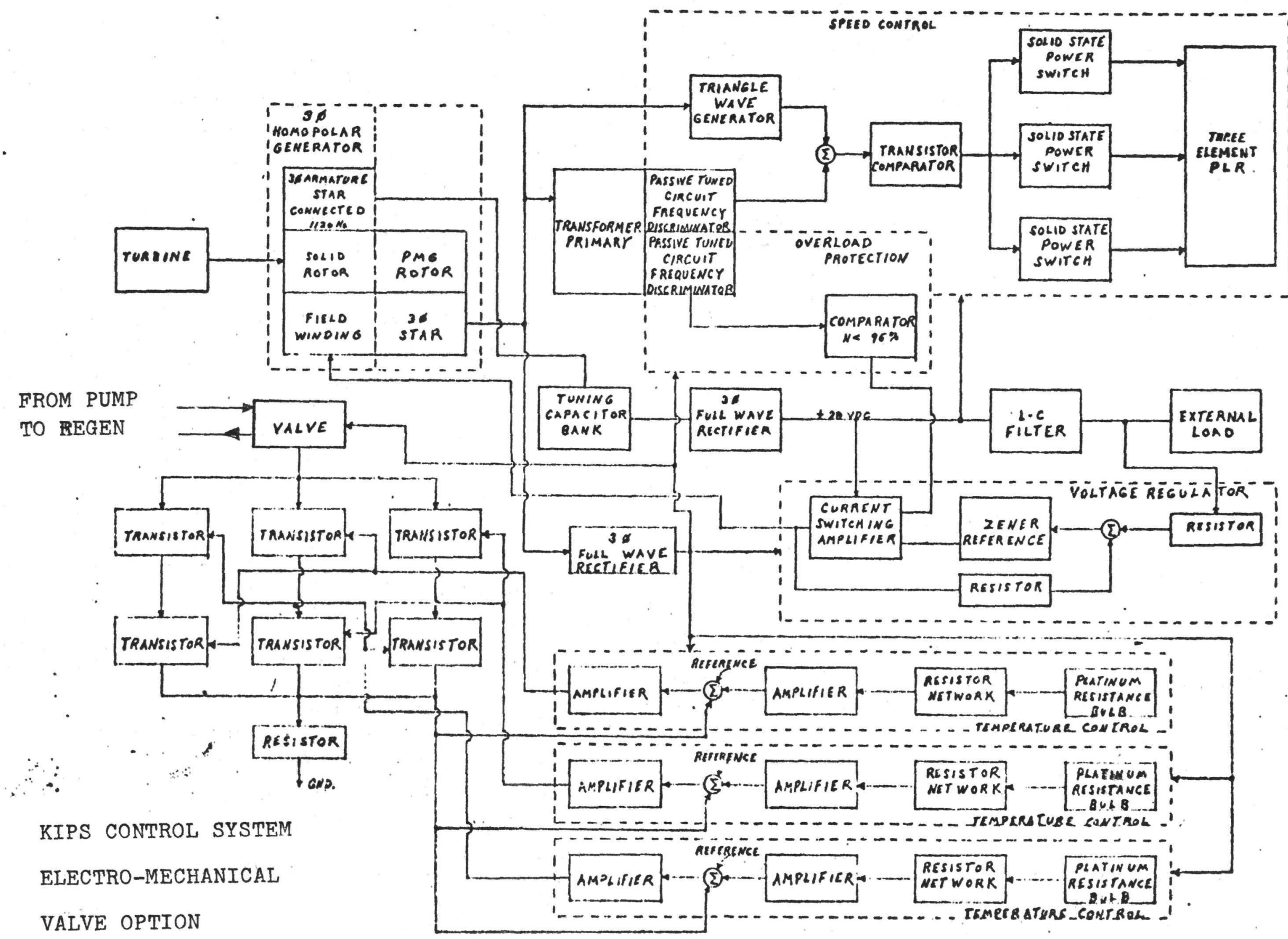




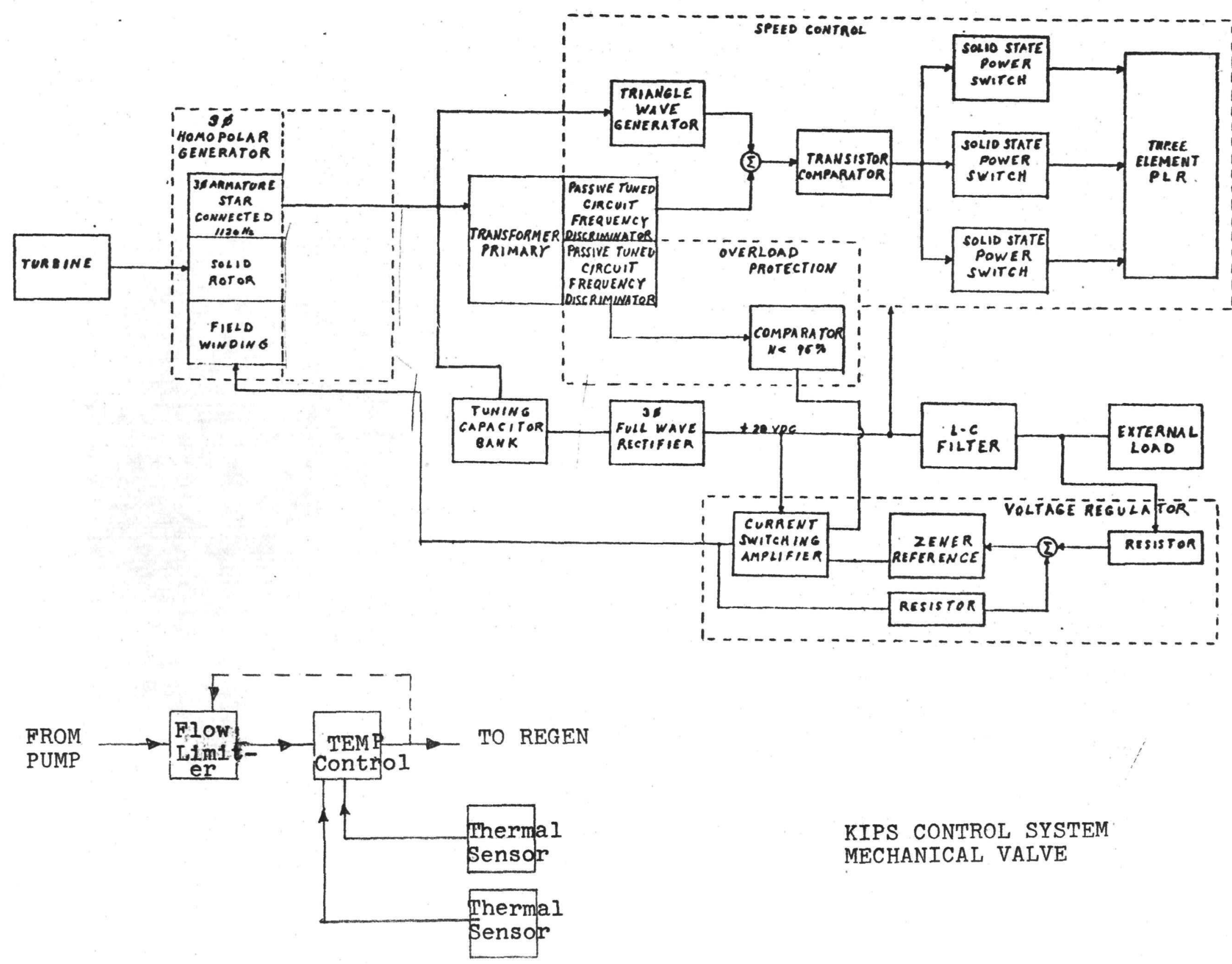




\begin{tabular}{|c|c|c|}
\hline Function & Hydromechanical & Electromechanical \\
\hline Temp. Sensing & Double Redundant NaK Filled Bulbs & $\begin{array}{l}\text { Triple Redundant } \\
\text { Platinum Resisting } \\
\text { Bulbs }\end{array}$ \\
\hline Motive Power & $\begin{array}{l}\text { NaK Expansion For Temp. Portion } \\
\text { Fluid Feedback on Double Re- } \\
\text { dundant Bellows For Gross Flow } \\
\text { Limiting }\end{array}$ & $\begin{array}{l}\text { Single PMG Triple } \\
\text { Redundant Drive Circuits } \\
\text { Single Electromagnet } \\
\text { on Flapper Nozzle }\end{array}$ \\
\hline $\begin{array}{l}\text { Cooling } \\
\text { Requirement }\end{array}$ & None & Cold Plate (Existing) \\
\hline $\begin{array}{l}\text { Power } \\
\text { Consumption }\end{array}$ & None & 10 Watts \\
\hline $\begin{array}{l}\text { Response Time } \\
\text { Constant For } \\
\text { Speed Pertura- } \\
\text { bation }\end{array}$ & Milliseconds & No Valve Response \\
\hline $\begin{array}{l}\text { Response Time } \\
\text { Constant For Temp. } \\
\text { Perturbation }\end{array}$ & 10 Seconds & $2-3$ Seconds Minimum \\
\hline Type of Flow Control & Flow Limit With Temp. Bias & $\begin{array}{l}\text { Direct Temp Control } \\
\text { of Flow }\end{array}$ \\
\hline System Stability & Good & Presumed Adequate \\
\hline
\end{tabular}


RELIABILITY BLOCK DIAGRAM

electromechanical flow control valve

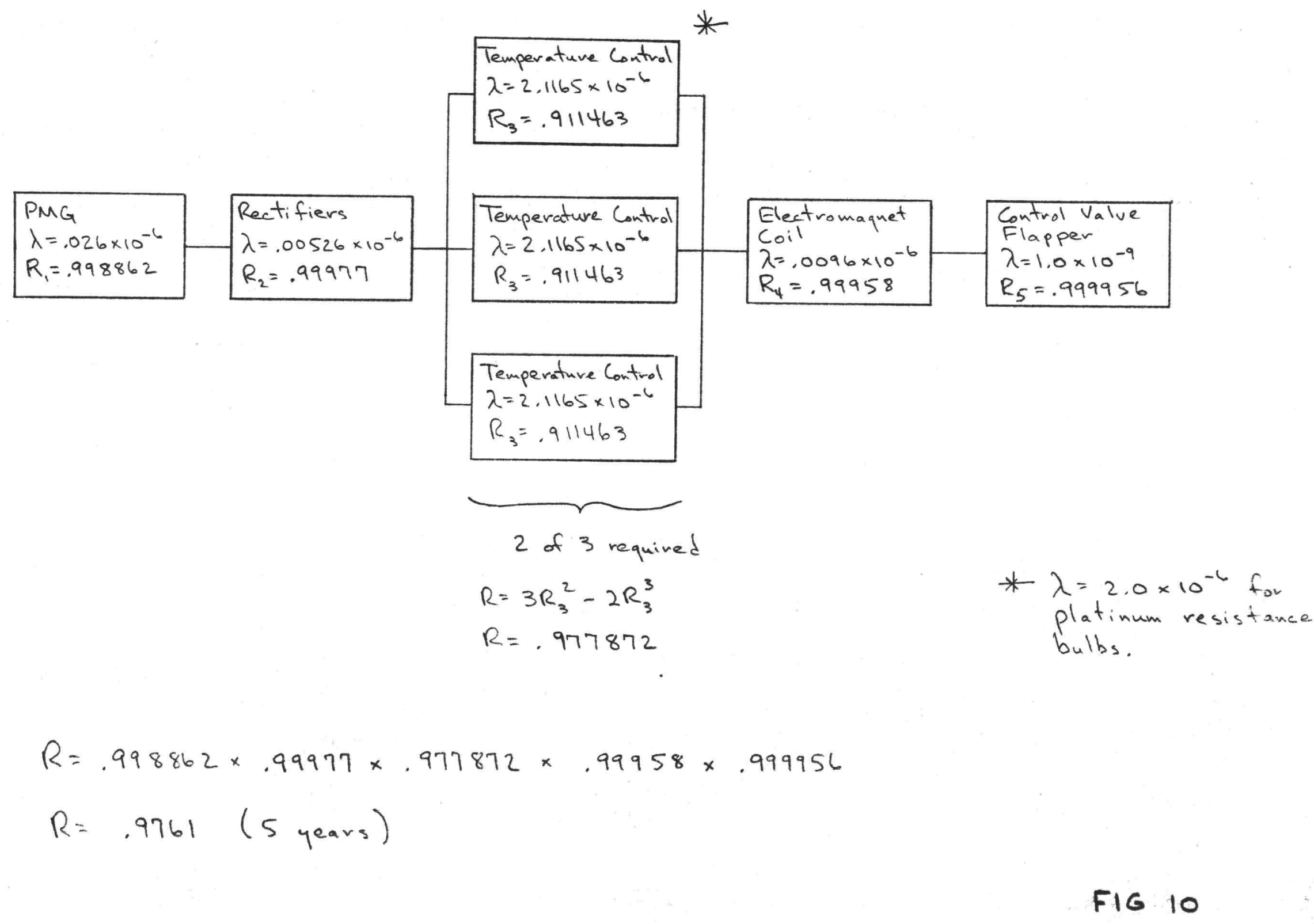




\section{ReliabILITY Block DIAGRAM}

mechancal flow contra valve

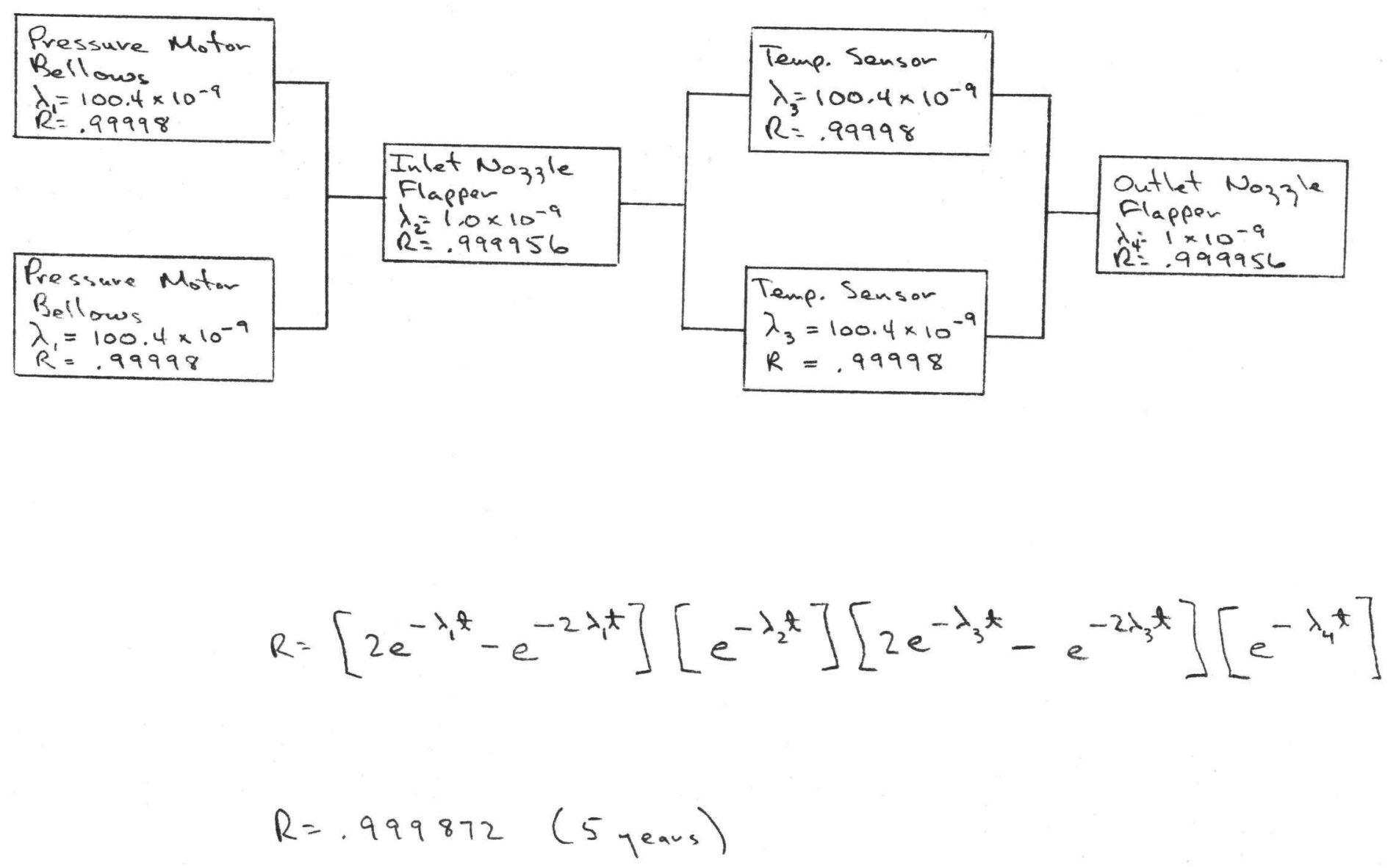




\subsubsection{Continued}

and a relatively slow responding temperature control function. The electromechanical valve does not have the pressure regulator function. It is assumed that the more rapid temperature response of the electrical temperature sensor can make flow corrections sufficiently fast so that instability does not occur during speed wild operation.

The increased circuitry required for the electro-mechanical valve option slightly increases the controller size, weight, cost, and power consumption. Increase in size, weight and cost is estimated to be 10 to 20\%. Power consumption increase for the temperature control circuit and electro-mechanical valve is estimated to be on the order of 10 watts, evenly divided between the two.

\section{4 Reliability Comparison of Both Systems}

Figures 10 and 11 show the reliability block diagrams for the electro-mechanical valve and controls and the mechanical valve. The fallure rates for the mechanical valve are as presented in the Design Review \#3 data package (See section 3.4 .1 of this report). The fallure rates for the electro-mechanical valve controls and electro-magnetic coll are MIL-HDBK-217B rates, except for the platinum bulb rate which is not listed in MIL-HDBK-217B. Rationale for selection of an appropriate failure rate for the platinum RTD is discussed in section 3.2 .

The lesser reliability of the electro-mechanical valve and controls is due primarily to the relatively high fallure rate estimated for the platinum resistance bulbs. However, even if the platinum bulb reliability was unity $(\lambda=0)$ the reliability of the remainder of the electro-mechanical valve and controls would be .99809 which is less 


\subsection{Continued}

than the .99987 reliability calculated for the mechanical valve.

The hydromechanical valve is therefore preferred for inclusion

in the KIPS Flight system.

Additional supporting data on the reliability of the bellows, NaK filled sensor, and the operating temperature of the electronic controller has been collected and is discussed in the following subsections.

\subsubsection{KIPS Component Operating Temperature and Derating}

Because of coolant temperature limitations, the KIPS controller will be operating at an ambient temperature of approximately $75^{\circ} \mathrm{C}$. This is well below the maximum operating temperature of all controller components. Some questions have been raised about the effect of this temperature on semiconductor and IC reliability.

A review of some of the avallable literature was made to determine what temperature derating guidelines are commonly used for high reliability spacecraft applications. The NASA funded "Long-Iife Assurance Study for Manned Spacecraft Long-L1fe Hardware", NASA-CR-128908 lists the temperature derating criteria shown in Table 1 for IC's, transistors, and diodes. The $75^{\circ} \mathrm{C}$ operating ambient temperature is within the $85^{\circ} \mathrm{C}$ limit of Marshall Space Flight Center (MSFC) for IC's. Likewise the $102^{\circ} \mathrm{C}$ maximum transistor junction temperature Is below the $110^{\circ} \mathrm{C}$ IImit of MSFC, GSFC, and Motorola and well below the $130^{\circ} \mathrm{C}$ Iimit of Martin. The maximum KIPS diode junction temperature of $104^{\circ} \mathrm{C}$ does exceed the $100^{\circ} \mathrm{C}$ Iimit recommended by MSFC, GSFC, and Grumman but is below the maximum of $110^{\circ} \mathrm{C}$ recommended by motorola and $130^{\circ} \mathrm{C}$ recommended by Martin. It should be remembered that these are recommendations only and not absolute limits which $1 f$ exceeded, w1ll result in sudden loss of rellability. 
3.4.1 Continued

\begin{tabular}{l|r|r|r|r|c|c|}
\cline { 2 - 4 } & KIPS & MSFC & Martin & Motorola & Grumman & GSFC \\
\hline I.C. - T ambient Max. & $75^{\circ} \mathrm{C}$ & $85^{\circ} \mathrm{C}$ & - & - & - & - \\
\hline Transistor-T, Max. & $102^{\circ} \mathrm{C}$ & $110^{\circ} \mathrm{C}$ & $130^{\circ} \mathrm{C}$ & $110^{\circ} \mathrm{C}$ & - & $110^{\circ} \mathrm{C}$ \\
\hline Diode - T Max. & $104^{\circ} \mathrm{C}$ & $100^{\circ} \mathrm{C}$ & $130^{\circ} \mathrm{C}$ & $110^{\circ} \mathrm{C}$ & $100^{\circ} \mathrm{C}$ & $110^{\circ} \mathrm{C}$ \\
\hline
\end{tabular}

Table 1 - KIPS temperature vs. limits of varlous space agencies and contractors. 


\subsubsection{Continued}

To further reinforce this statement that the reliability of the KIPS controller is adequate with a cold plate temperature of $75^{\circ} \mathrm{C}$, reliab1l1ty predictions were made at $75^{\circ} \mathrm{C}$ and $40^{\circ} \mathrm{C}$ for comparison. MIL-HDBK-2I7B, "Reliability Prediction of Electronic Equipment" was used for both predictions. The component fallure rates in MIL-HDBK-217B are based on component internal or junction temperature which are derived from case temperature and electrical stress. For most controlier components case temperature will be equal to cold plate temperature. Because of higher power levels and thermal resistance from case to cold plate, the actual case temperatures of the PLR switching transistors, and rectifier diodes will be higher than the cold plate. Actual case temperatures of these components were used in both cases. These yielded reliabilities of .98647836 and 98194596 for $40^{\circ} \mathrm{C}$ and $75^{\circ} \mathrm{C}$ respectively. The increase in reliability at the lower temperature is small, less than $0.5 \%$.

\subsubsection{Nak Sensor Data}

A data base search has been conducted to support the use of NaK filled temperature sensors in the KIPS mechanical valve. Use of NaK fllled temperature sensors has been found in commercial and industrial applications. NaK filled pressure sensors, somewhat similar to the mechanical valve temperature sensor, were found to be used in reactor component experimental loops. Also found were data for bellows liquid metal seals used in reactors and reactor experiments. The temperature and pressure sensor and bellows data is presented in the following paragraphs. Also presented are the results of a Sundstrand study concerning corrosion of thermal sensor materials by $\mathrm{NaK}$.

Sundstrand has contacted several manufacturers who use NaK 
3.4.2 Continued

filled capillary temperature sensors in commercial and industrial applications. Figure 12 describes the NaK temperature sensors, their applications and experience.

References 6,7 , and 8 discuss the use of NaK filled capillary pressure transducers in high temperature alkall metal test loops at General Electric, The pressure transducer described in these references contain a slack diaphram which separates the process fluid from the Na filled capillary tube. The pressure of the process fluid is transmitted across the slack diaphram through the NaK filled capillary tube to a bourdon tube. This capillary is 316 stainless, 0.125 inch $O D \times 0.050$ ID $\times 25$ feet long. In comparison the capillary for the KIPS temperature sensor is 304 stainless, 0.062 inch $O D \times 0.026$ inch ID $\times 7$ inches long.

The transducers accumulated 72,650 hours during the referenced loop tests. Operating times and approximate operating temperatures for the transducers are as follows:

Number of Transducers

Cb-IZr Pumped Sod1um Loop

(Ref. 6)

Cb-IZr Rankine System Corrosion Test Loop

(Ref. 7)

T-111 Rankine System

Corrosion Test Loop

(Ref. 8)
Loop Time Transducer

(Hours) Temp. (OF)

2,650

650

1

4

5,000

2000

1840

1350
800

5

10,000

2000

1925

1350

800

800 


\section{APPLICATION}

Honeywell Controls, Models T683 \& T654

Temperature Controllers

General Electric Appliance Division, Self-Cleaning Ovens

\section{SENSOR DESCRIPTION}

S.S. capillary, .025 ID, .093 O.D. Copper bellows. Silver brazed and heliarc welded throughout. $\mathrm{NaK}$ sensors used up to $1200^{\circ} \mathrm{F}$.

304 SS capillary, .020 ID, .062 OD. Oven cleaning temperature is $880^{\circ} \mathrm{F}$

\section{EXPERIENCE}

\section{5 years}

300 units/year

Field Experience:

6 years

3/4 million units/year

$$
\begin{aligned}
& \text { Test Experience: } \\
& \text { 1000 hours @ } 900 \mathrm{~F} \\
& 3500 \text { hours cycling } \\
& 350 \text { - } 450{ }^{\circ} \mathrm{F}
\end{aligned}
$$

Diaphram with 321 SS capillary .020 ID, 18 - 45 in. length. Sensor is set for $1300-1400^{\circ} \mathrm{F}$ Sensors experience temp. change from $500^{\circ} \mathrm{F}$ to $1300^{\circ} \mathrm{F}$ dally.

Sensor produced by

Essex International,

Mansfield, Ohio

50,000 sensors shipped to England since 1972.

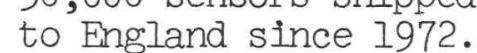

Used in brick heating ovens to heat bricks

overnight at low electric rates for daytime heat supplys. No service problems

reported by sales/service concern.
When tested above $1000^{\circ} \mathrm{F}$, capillary plugging was experienced. 


\subsubsection{Continued}

The reference 6 loop transducer was filled with commercially pure $\mathrm{NaK}$ (analysis of NaK sample indicated $5 \mathrm{ppm}$ oxygen level). The reference 7 loop transducers were filled with high-purity NaK (analysis of two $\mathrm{NaK}$ samples indlcated an average $3.8 \mathrm{ppm}$ oxygen level). A sample of Nak used to fill the reference 8 transducers was analyzed to contain less than 3 ppm oxygen.

Operation of the pressure transducers in the three loops is described as trouble-free.

Additional information about $\mathrm{NaK}$ filled capillary pressure sensors was obtained from Westinghouse (Ref. 9). Westinghouse uses $\mathrm{Na}$ filled sensors for pressure measurement in high temperature sodium streams. Approximately 10 pressure sensors, manufactured by Taylor Instrument Company, have been used for about 10 years. An estimated 20,000 total hours have been logged for the transducers, with the high time transducer having about 3,000 hours. The capillaries are stainless steel, 0.058 inch ID $\times 25 \mathrm{ft}$. long. The transducers are used at up to $1200^{\circ} \mathrm{F}$. The only failures have been capillary breaking due to handling damage.

Reference 10 presents the results of a literature search for information about the design and operating experience of bellows in liquid metal systems. Examples are cited of metallic bellows in a molten metal environment in a number of reactors and reactor experiments. With the exception of one example of a hydraulically formed structural bellows, all other examples are for edge welded type bellows. The report (Ref. 10) states that bellows requiring long stroke and/or low spring rate are virtually always of the welded type. In general, the bellows described in the report are unlike the NaK sensor bellows in size and environment. Most of the example 


\subsubsection{Continued}

bellows seals described were exposed to sodium vapor at up to $11500 \mathrm{~F}$

a Ilquid sodium at $1200^{\circ} \mathrm{F}$. However, one bellows of interest is incorporated in the expansion compensator units of the SNAP IOA Nuclear Power Unit. These bellows are welded metallic bellows. They use 0.010 in, thick metallic discs, are of AM-350 steel and see liquid $\mathrm{NaK}$ at $750^{\circ} \mathrm{F}$ in service. No experience data is provided in the report. The KIPS temperature sensor bellows is of AM-350, but is immersed in a fluid at approximately $220^{\circ} \mathrm{F}$. A primary value of the reference 10 report is that it provides an extensive bibliography of references relating to design and operating experience of bellows In Iiquid metals.

This bibliography may be useful for locating additional operating experience data, particularly for the SNAP 10A expansion compensator bellows.

\subsubsection{Thermal Sensor Corrosion}

A study was conducted concerning the corrosion of thermal sensor materials by $\mathrm{NaK}$. The conclusion of the study was that corrosion of thermal sensor materials should not present problems in achleving the seven year Iffe. Details of this study are presented in Appendix B.

The following is also provided as supplementary information, based on telephone conversation and correspondence.

J. H. Devan, Oak Ridge National Lab, advised that there would be no compatab1lity problem between AM-350 stainless steel and $\mathrm{NaK}$ between $220^{\circ} \mathrm{F}$ and $650^{\circ} \mathrm{F}$. Mr. Devan also advised that dissolution of precipitate in $\mathrm{NaK}$ occurs at about $800^{\circ} \mathrm{C}\left(1472^{\circ} \mathrm{F}\right)$.

Correspondence with W.E. Reuther, Argonne National Lab, on the 


\subsubsection{Continued}

topic of the effects of NaK on stainless steel bellows, advised that Nak would not bo expected to interact in any algnifloant way with stalnless steel bellows at $110^{\circ} \mathrm{C}\left(230^{\circ} \mathrm{F}\right)$.

B. C. Huguelet, Argonne National Lab, advised that there are no appreciable corrosion or embrittlement problems with NaK and stainless steel at $700^{\circ} \mathrm{F}$ as long as the welds are good and free from impurities; corrosion starts at about $600^{\circ} \mathrm{C}\left(1112^{\circ} \mathrm{F}\right)$. 
Figure 13, which is extracted form the Design Review \#3 data package, shows the reliability estimation for the KIPS mechanical control valve.

Figure 14 shows the block diagram for the pressure motor bellows seals. Either bellows seal may fail with only minor consequences.

Figure 15 shows the thermal sensor. Either thermal sensor bellows may fall without leaking $\mathrm{NaK}$ into the working fluid loop. Two temperature sensors are contained in each control valve so that, in the event of a primary (inner) bellows failure in one sensor, the other temperature sensor will carry the control valve function. 


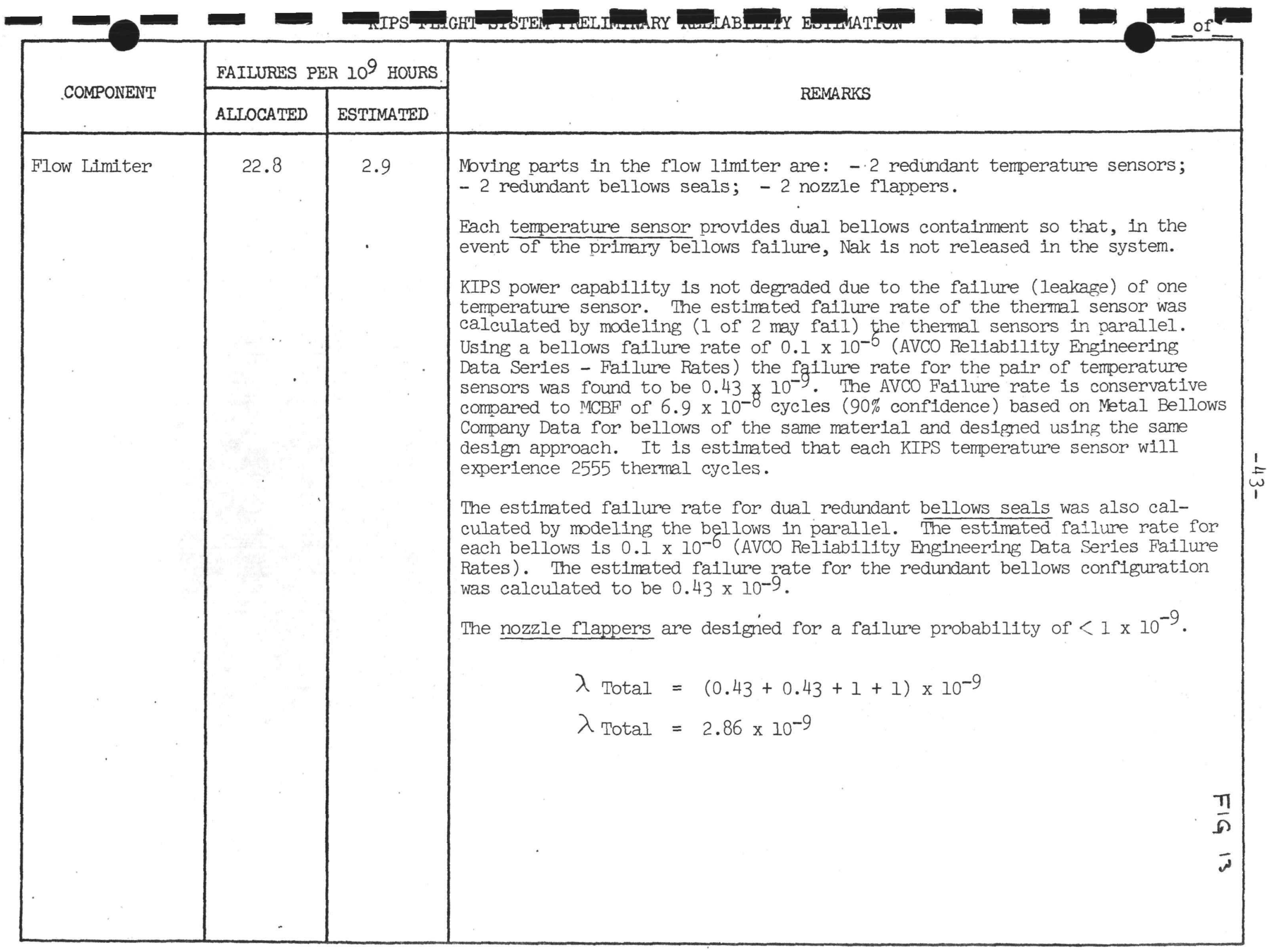




\section{PRESSURE MOTOR BELLOWS REDUNDANCY}

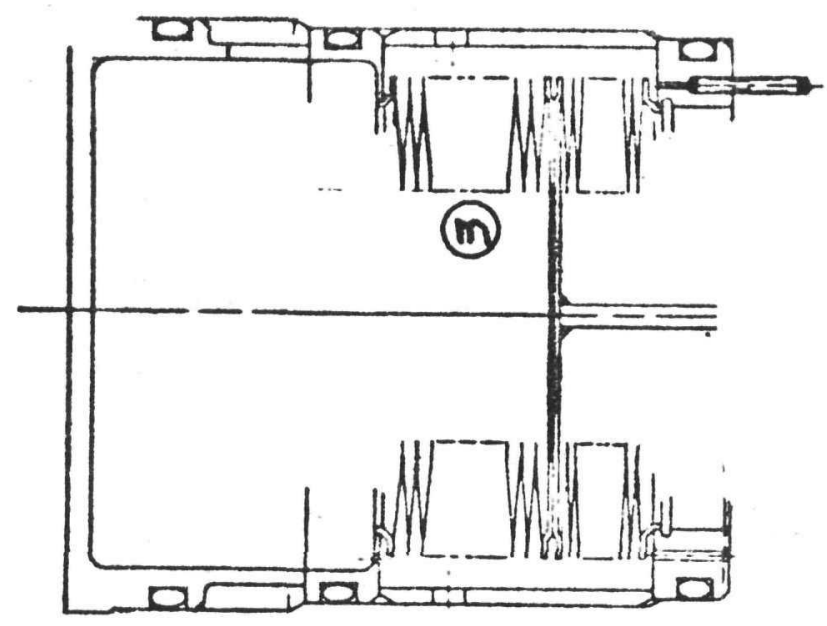

- Either bellows may fail with only minor consequences.

- System tolerant of minor bellows leakage.

- Access to both sides of bellows for cleaning.

- Helium leak check of bellows assembly.

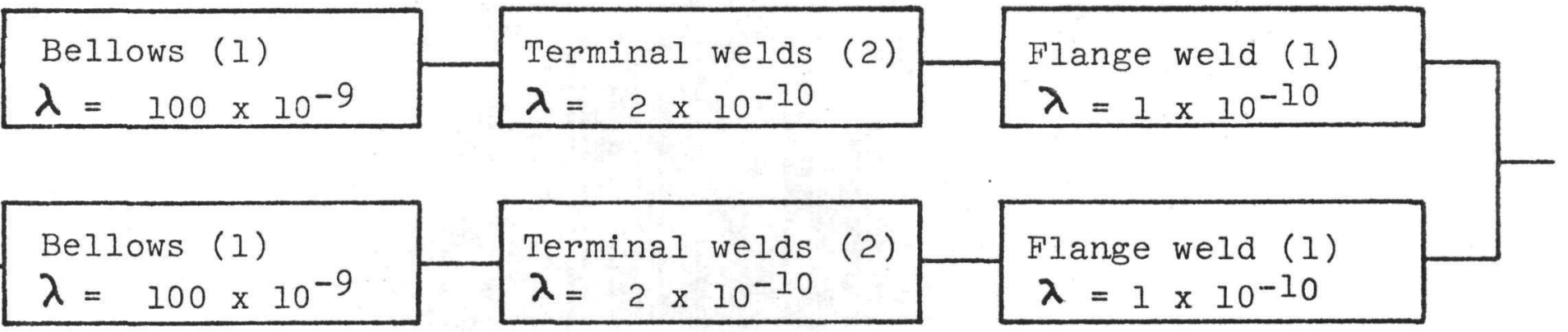

$$
\begin{aligned}
& R_{T}=2 e^{-\lambda t}-e^{-2 \lambda t}=e^{-\lambda_{T} t} \\
& \lambda_{T}=0.43 \times 10^{-9} \text { faizures per hour }
\end{aligned}
$$




\section{THERMAL SENSOR BELLOWS REDUNDANCY}

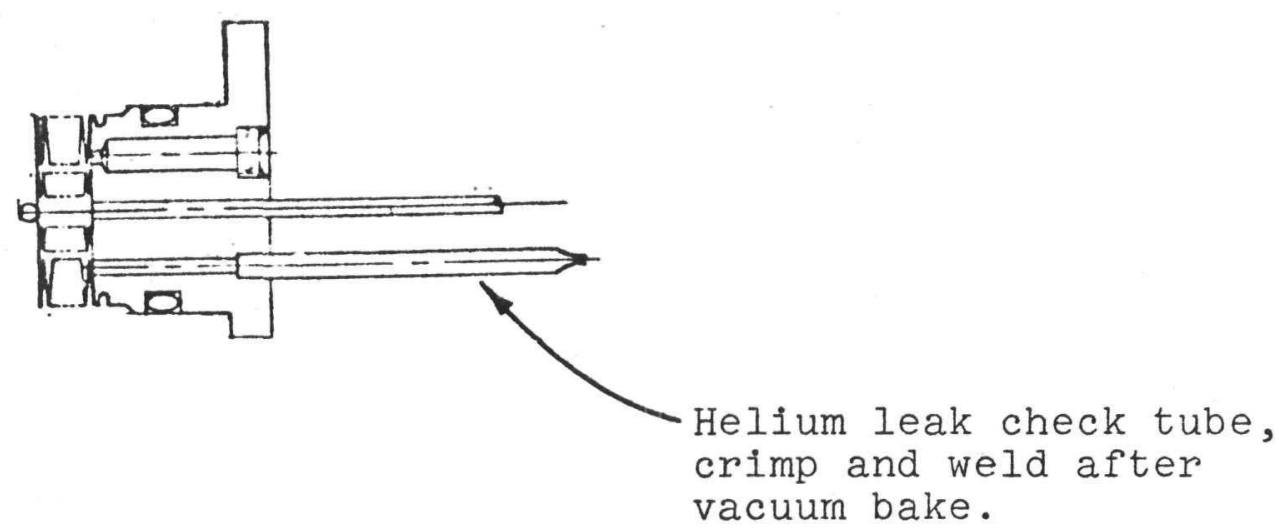

- Analysis shows no NaK corrosion problem with sensor parts.

Thermal sensor Reliability $=e^{-\lambda t}=.9956$ ( 5 years)

$$
=100.4 \times 10^{-9} \text { failures per hour }
$$

(Redundant thermal sensor will allow continued system operation.)

System Reliability Impact (no NaK in fluid lcop) $=2 e^{-\lambda t}-e^{-2 \lambda t}$

$$
\begin{aligned}
& =.99998 \text { ( } 5 \text { years }) \\
\text { equivalent } \lambda & =.43 \times 10^{-9} \text { failures per hour }
\end{aligned}
$$


REFERENCES

1. Data Package, KIPS Des1gn Review \#2, Sundstrand Energy Systems, Sept. 1976, Vol. I Section 3, 4.

2. Data Package, KIPS Design Review \#3, Sundstrand Energy Systems, Nov. 1976, Vol. I Section 3, 4.

3. Burrows, R. W., Long Life Assurance Study, Martin Marietta Corp., NASA CR-128907 Section XII - 5.

4. James H. Masson, Telephone Conversation RE NiCd and Silver Zinc Batteries, Viking Program Experience.

5. Ken Hughes, Jim Bene: Langley Research Center, Telephone Conversation RE: Life, Reliability, Storage, Charging, Etc. of Nicd Batteries.

6. Hoffman, E. E. and Holowach, J., Cb-IZr Pumped Sodium Loop, NASA CR-1135, Sept. 1968.

7. Hoffman E. E. and Holowach, J., Cb-lZr Rankine System Corrosion Test Loop, NASA CR-1509, June, 1970.

8. Harrison, R. W., Hoffman, E. E. and Smith, J. P., T-11l Rankine System Corrosion Test Loop, NASA CR-134816, June, 1975.

9. Telecon 3/3/76 with R. Smith, Large Loop Program Manager, Westinghouse Electric Corp., Advanced Reactor Division, Madison, Pennsylvania.

10. Aungst, R. C., Bellows Seals For Liquid Metal Systems Literature Search For Fabrication and Operational Experience, BNWL-905, Battelle Memorial Institute, Pacific Northwest Laboratory, Richland Washington, December 10, 1968. 
APPENDIX A

Control System Selection as Presented For Design Review \#3

3.0 ELECTRICAL CONTROLS (PDR)

3.1 Tradeoffs - Block Diagrams, Reliability, Performance Welght, Single Point Fallure Considerations

3.2 Baseline Components

3.3 FSCD and GDS Selection (Similarity and Differences)

3. 4 Breadboard Test Results

3.5 Further Study and Test Plans

3.6 Margins of Safety and Reliabil1ty

3.7 Generator Terminal Block

3.8 Critical Characteristics

\subsection{FLUID CONTROLS (PDR)}

4.I Turbine Flow/Temperature Control Valve

4.1.1 Function

4.1.2 Tradeoffs

4.1.3 Selected Design, Analysis

4.1.4 Similarity to Filght System

4.1.5 Test Plan

4.1.6 Reliability

4.1.7 Quality Control, Cleaning, Critical Characteristics

4.1.8 Appendix

4.2 Radiator Bypass Valve

4.2.I Function and Need

4.2.2 Tradeoffs

4.2.3 Selected Design and Analysis

4.2.4 Similarity to Flight System

4.2.5 Test, Plans

4.2.6 Filter

4.2.7 Reliability

4.2.8 Quality Control, cleaning, Critical Characteristics

4.2.9 Appendix 
3.0 ELECTRICAL CONTROLS (PDR)

3.1 TRADEOFFS

Tradeoffs were made between various controller configurations. Our intent was to determine the least complex controller that has a probability of greater than .99 of achieving the mission life of 5 years. This reliability criterla was pursued rather than a no single point fallure philosophy because it produced a less complex and lower weight system with an acceptable mission risk. Block diagrams of various configurations that were reviewed are discussed below. The reliability numbers that are given are the probability of achieving the 5 year mission life.

\subsubsection{SPEED CONTROL}

1. The baseline voltage regulator of $\mathrm{Fig}$. I has one frequency discriminator, one comparator, three power switches and three PLR's. If the PLR's are sized such that all three are re- 
quired for full load the reliability is .8739218 . If the sizing is changed such that any two PLR's are capable of full load then the reliability is increased to .99265277 . 2. Fig. 2 shows a speed control where each PLR is driven by a separate frequency discriminator, comparator, and power switch combination. Two PLR's are capable of handing the full load. The reliability is .994073.

3. The speed control of fig. 3 has three parallel connected frequency discriminators driving three sets of parallel connected comparators which control three sets of series connected power switches. Two PLR's are capable of full load. The reliability is .994644 .

4. Fig. 4 shows three parallel connected frequency discriminator and comparator combinations, each capable of ariving two PLR's through series connected power switches. Two PLR's are capable of full load. The reliability is .994192

\subsubsection{VOLTAGE REGULATOR}

1. The baseline voltage regulator with overload protection is shown in figure 5. The reliability is .99737289.

2. The voltage regulator of figure 6 consists of two of the baseline voltage regulators connected in parallel with only one regular required for proper operation. The reliability is .9956431.

3. Fig 7 shows a voltage regulator which consists of three baseline voltage regulators, with each one driving a separate field in the generator. Only two of the fields, and associated circuitry, are required for proper operation. The reliability is .999104 . 
3.1.3 TUNING CAPACITOR

Figure 8 shows the baseline tuning capacitors and a tuning capacitor system that could be used for a no single point failure philosophy.

Reliabilities are:

Baseline .999999

Fused Redundant .9999412

\subsubsection{RECTIFIER}

The baseline rectifier and other rectifier configurations that could increase rectifier reliability are shown in fig 9. The reliabilities are as follows:

$$
\begin{array}{lc}
\text { Baseline } & .999107 \\
\text { Redundant } & .9999994 \\
\text { Fused Redundant } & .99988461 \\
\text { Combination } & .9999922
\end{array}
$$

\subsubsection{CONCLUSIONS}

The desired controller must have an overall reliability of 99. Since the PIR's individually have been assumed to have the lowest reliability of all the controller compo- . nents, the first step in increasing the baseline controller reliability is to choose the configuration where the PLR's are sized such that two PLR's are capable of full load. With this change, the baseline controller will have a reliability of .990045 . Any additional changes that would significantly increase controller reliability would also significantIy increase system weight. A description of the block diagrams for the baseline system appears in the following section. 
3.2.1 BASELINE SPEED CONTROL

A block diagram of the speed control is shown in fig. 1 . This concept relies on the turbine being capable of accelerating a load slightly less than 1.0 per unit (P.U.) through the rated frequency of $1122 \mathrm{~Hz}$, and also that a load slightly greater than the 1.0 P.U. will be too great for the turbine to hold at that frequency. Consequently, whenever the generator output frequency exceeds $1122 \mathrm{hz}$, a load of at least 1.0 P.U. is added to the load. The turbine speed will start to decelerate, regardless of the actual useful load. The parasitic load is removed once the generator output frequency is less than the rated frequency of $1122 \mathrm{hz}$. The parasitic load is comprised of three parasitic load resistors (PLR's) each drawing .5PU load such that two PLR's are capable of providing full load. Having three PLR's with any two capable of handing full load greatly increases the reliability of the system since a short circuited PLR is unlikely.

The frequency discriminator consists of a passive tuned circuit which produces a DC output voltage proportional to system frequency near the resonant frequency of the tuned circuit. Figure 10 shows the general form of the frequency discriminator transfer characteristic. The system operates slightly to the right of the $f_{0}$ point. The comparator is set to switch at the voltage proportional to $1122 \mathrm{~Hz}$. This comparator turns the power switches on or off, appiying or removing power to the PLR's. 


\subsubsection{BASELINE VOLTAGE REGULATOR}

A block diagram for the voltage regulator is shown in

figure 5. This voltage regulator is a switching type to minimize the regulating losses. Overload protection is included to prevent an excessive load condition from causing the turbine to decrease in speed to a point where the system would cease operation. The switching point of the regulator is set by the zener reference and bias circuit. When the output voltage is low, the switching amplifier is on, causing maximum field current to flow in the field winding, increasing the generator voltage. When the output goes higher than the set point, the switching amplifier is turned off, allowing the field current and generators output voltage to start to decay. The overload protection uses a frequency discriminator similar to the speed control frequency discriminator, and a comparator to detect when turbine speed falls below 95\%. When this is detected, the switching amplifier is turned off, decreasing the generator output voltage and lowering the generator load. The generator output voltage will not decrease below a small residual voltage which is sufficient to operate the frequency discriminator, comparator, and switching amplifier. The reduction in generator load prevents the system from ceasing operation. 


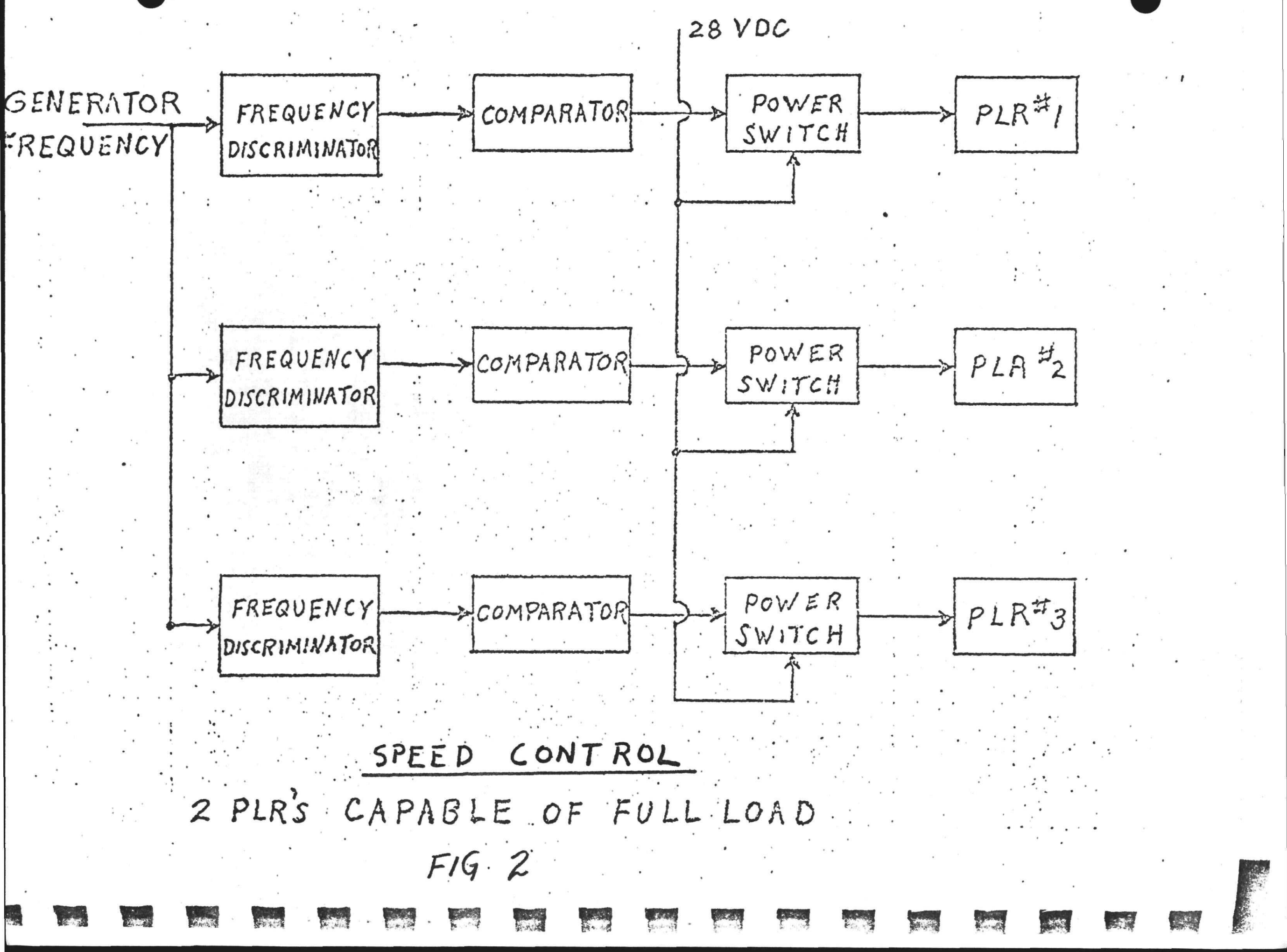




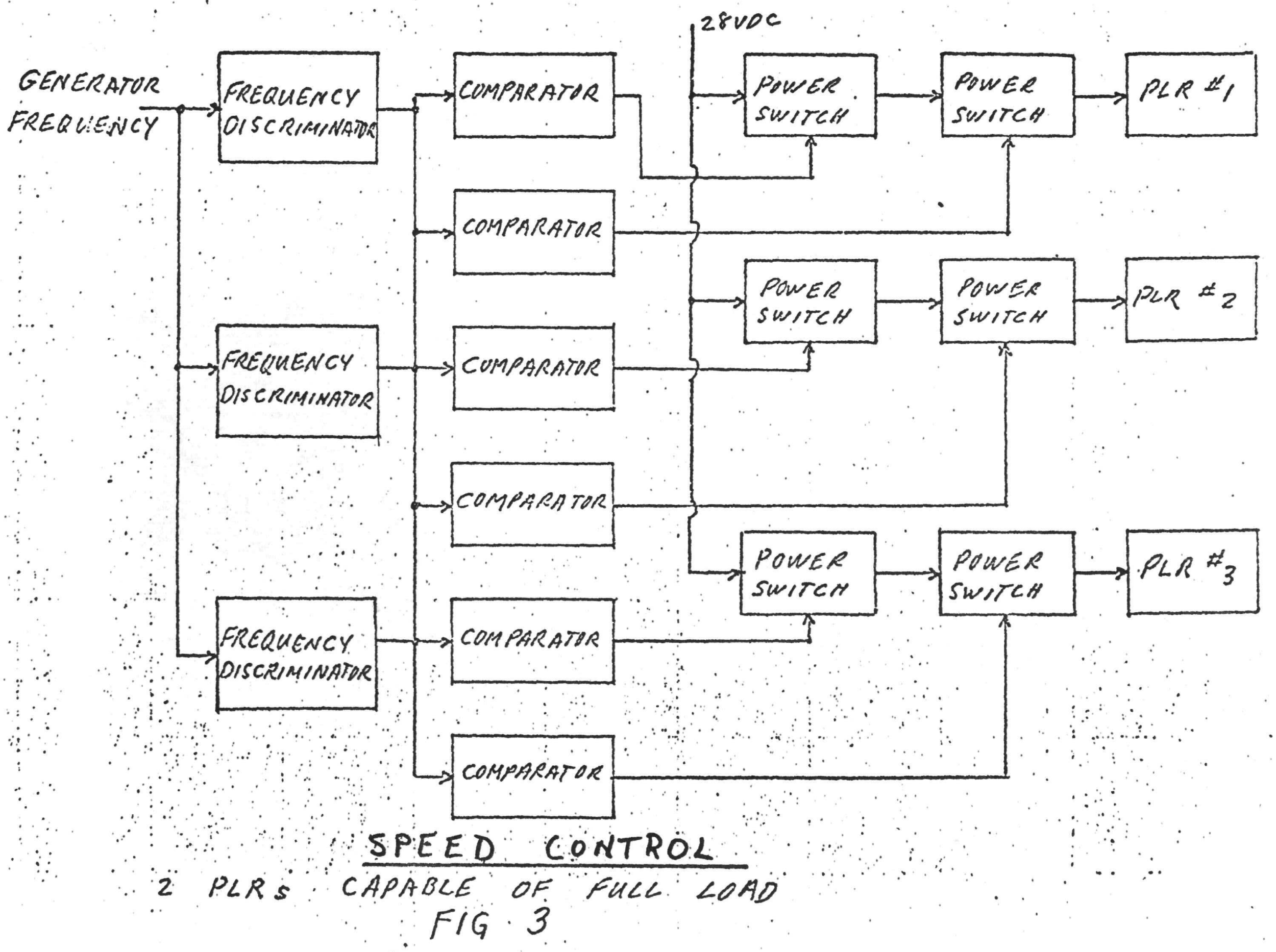




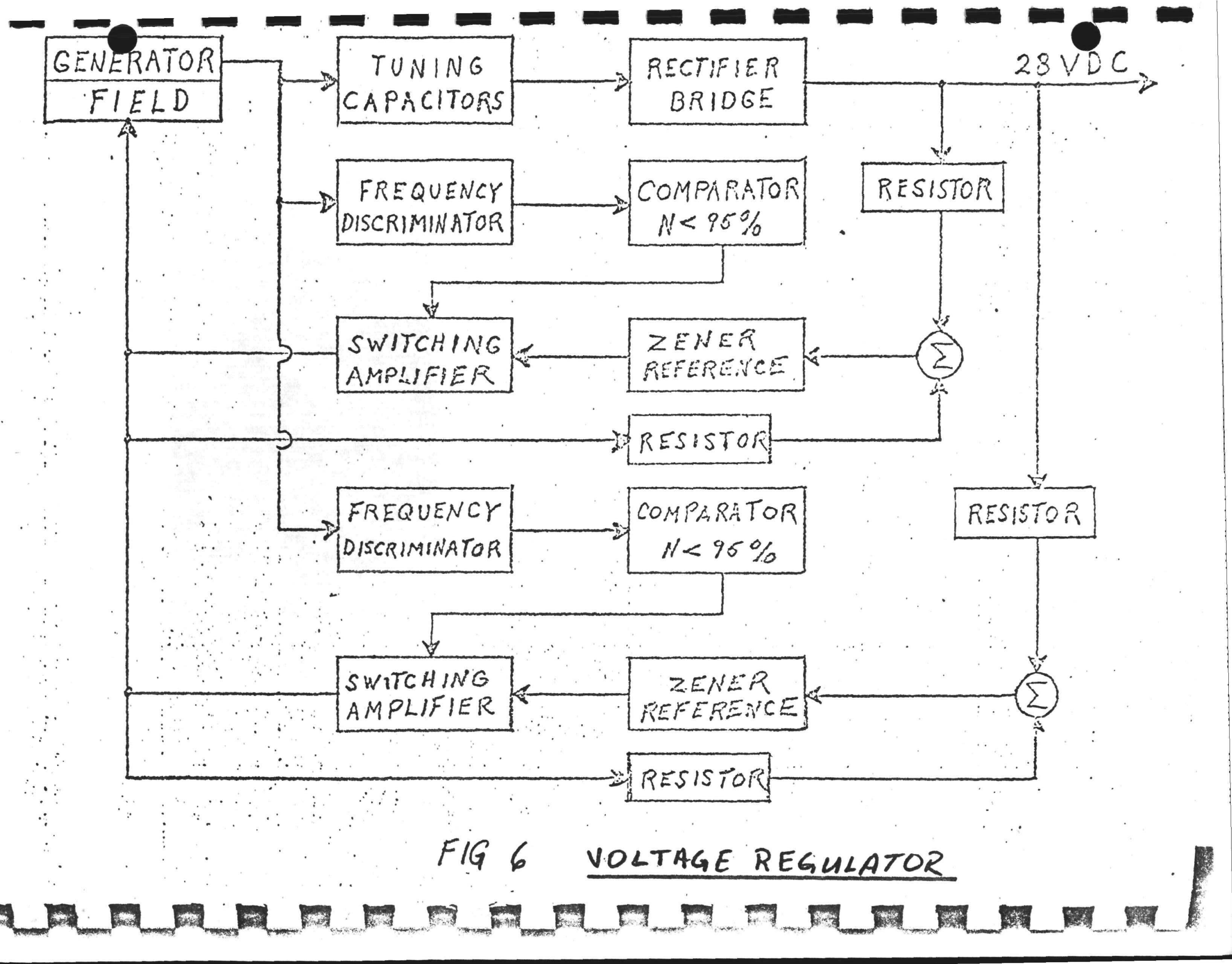




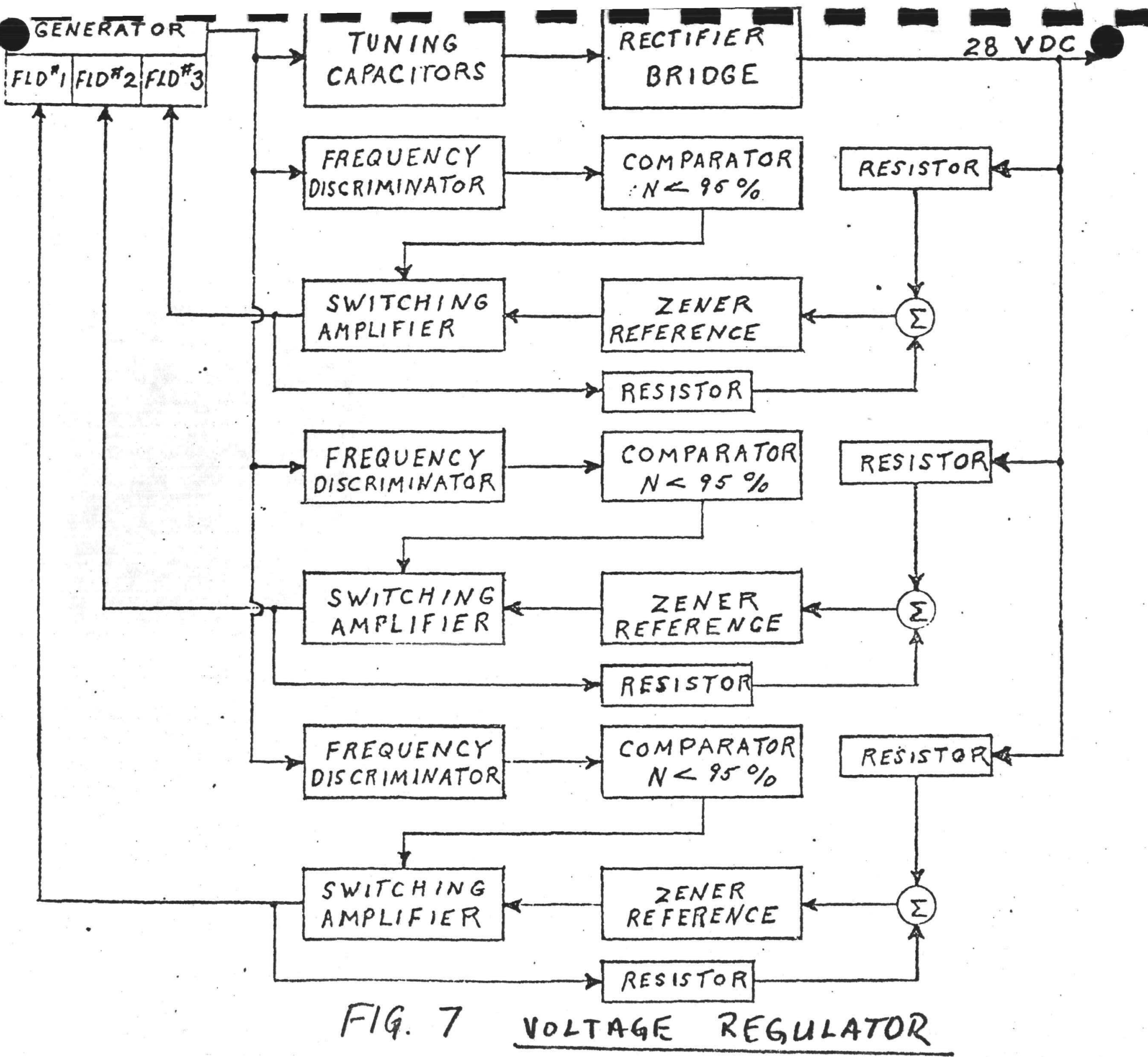




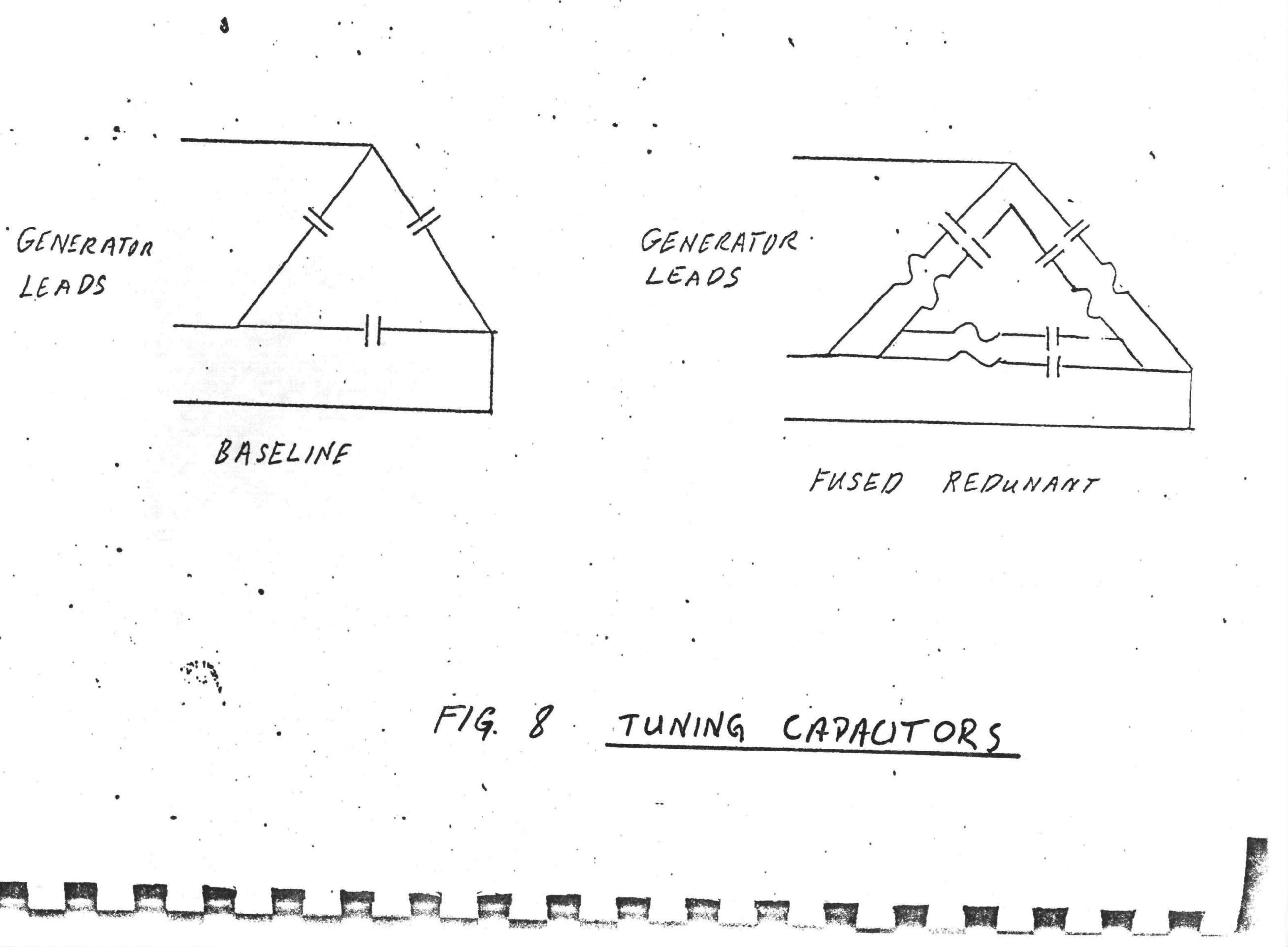




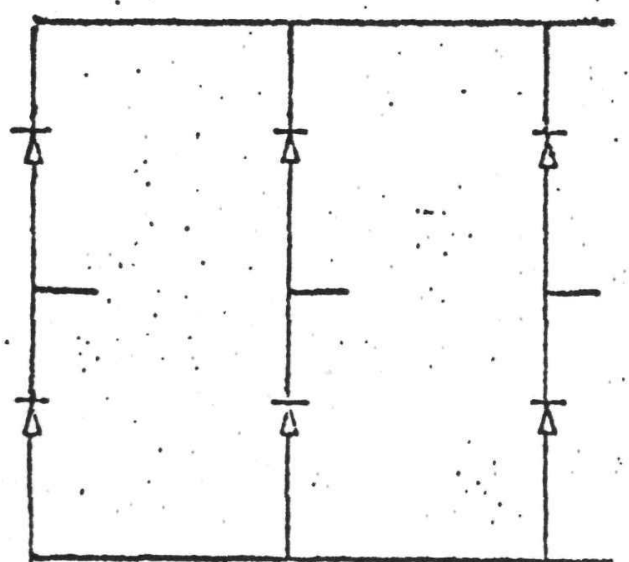

BASELINE

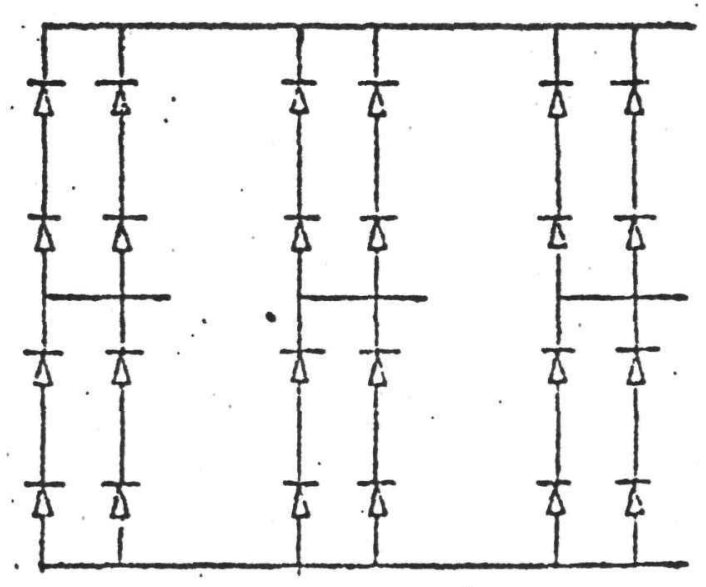

REDUNDANT

RECTIFIER

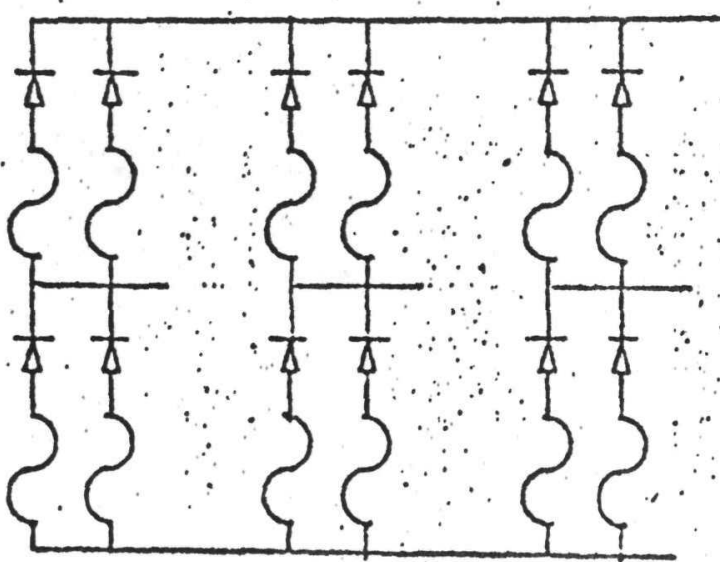

FUSED REDUNDANT.

FIG 9

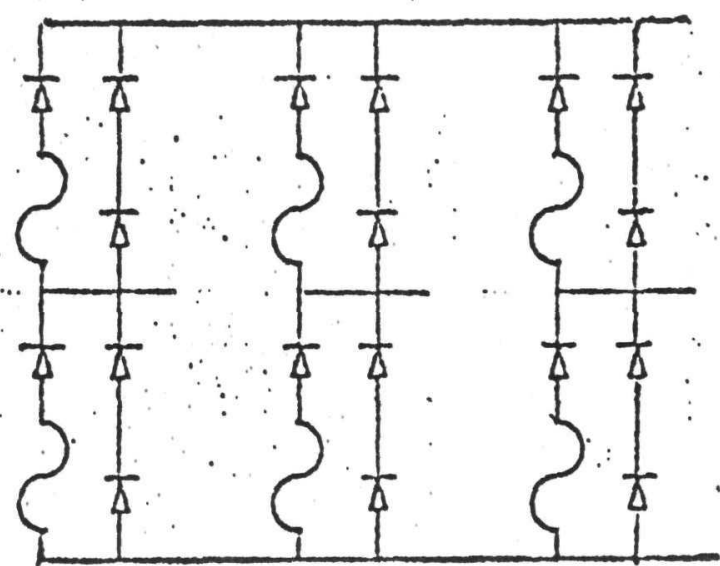

COMBINATION 


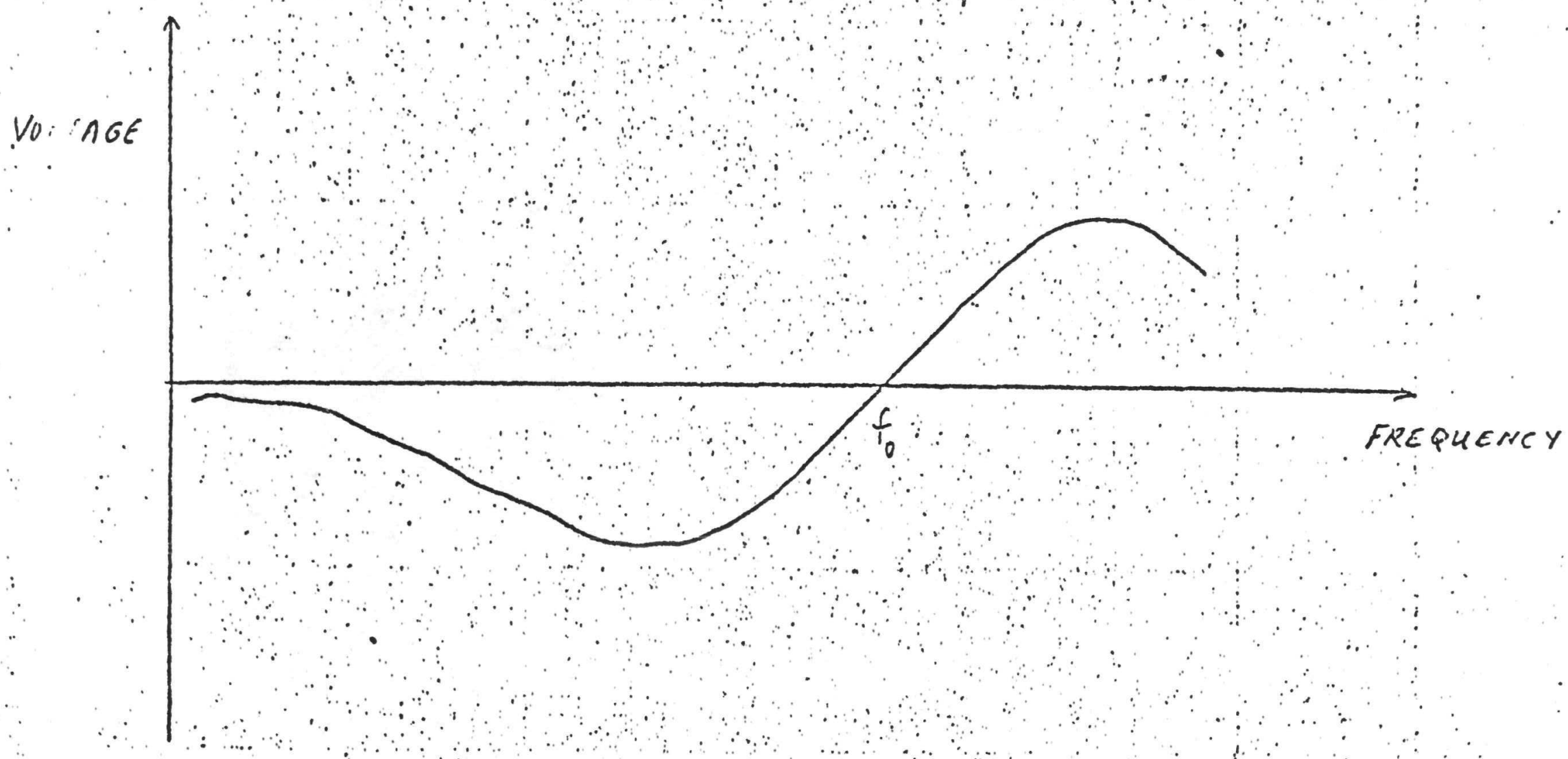

FREQ UENCY DISCRIMINATOR TRANSFER CHARACTERISTICS FIG 10 
Rev. A

3.2 .3

CIRCUIT SCHEHATIC

The present schematic of the controller is shom in Figure 1l. Recent testing of the controller with the KIPS alternator showed that several adjustments to the circult design, as presented in the PDR data package, were necessary.

1. A pulse-width-modulation (PWI) technique is now incorporated in the speed control. This helps to stabilize the output voltage.

2. An LC filter is used for additional smoothing of the output voltage waveform.

3. Inductors are used to speed the switching times of the PLR drive transistors.

4. Both speed detectors are driven from a single transformer to save space. 
Figure 11

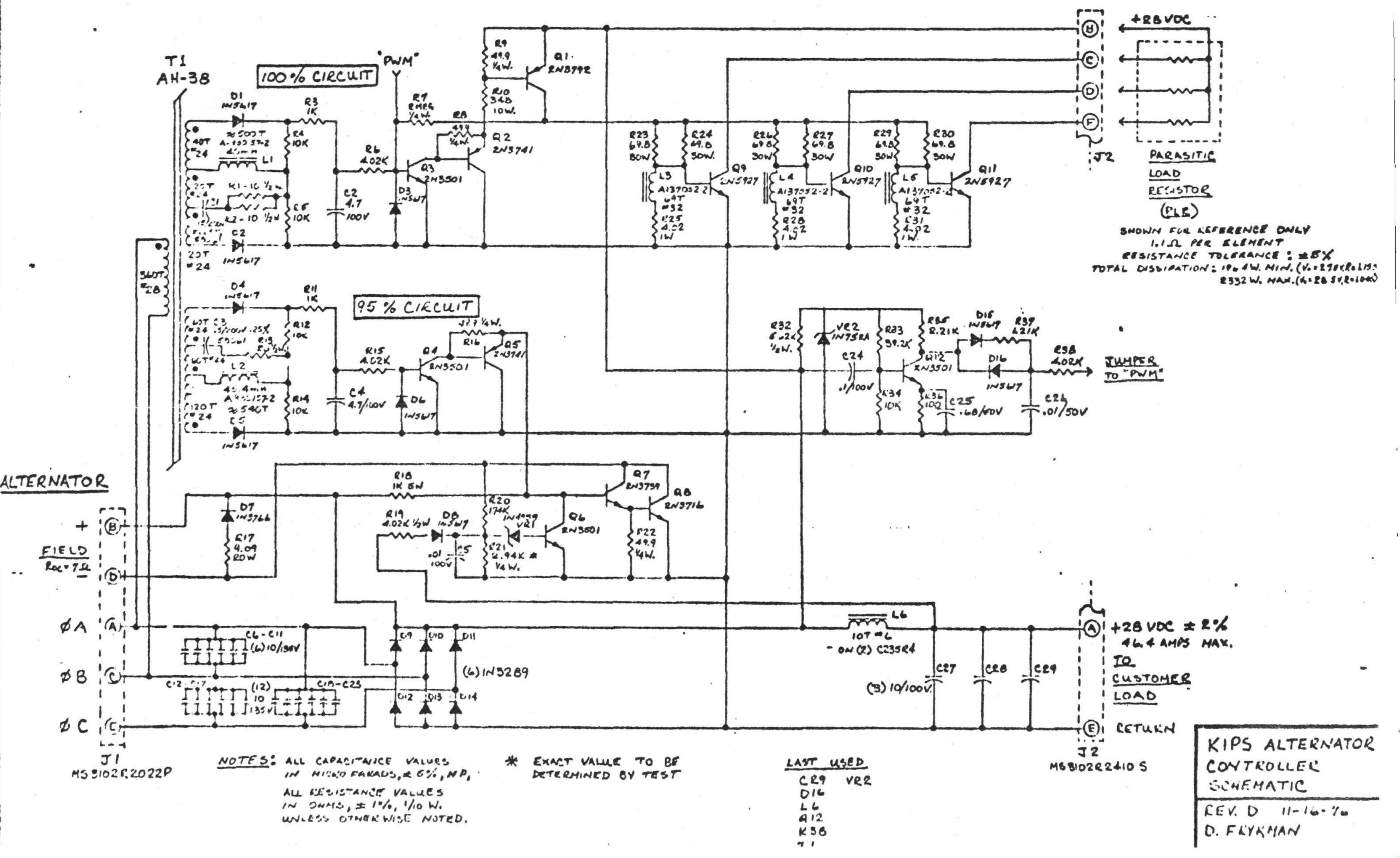


Rev. A

FLIGHT SYSTEM COICEPMUAL DESIGN AID GROUND DEMOHSTRATION SYSTEM SELECIION

A major guideline for the GDS controlier design is its similarity to the FSCD controller. The GDS electrical circuit will be identical to the flight circuit in function, performance, and redundancy. One desirable difference is the addition of two GDS test connectors that provide access to circuit test points. These are necessary to measure circuit operation, efficiency, and to allow optimization of the speed control and voltage regulator under closed-loop conditions. These test connectors and additional wiring increase the package size and weight slightly.

The PLR for the GDS is likely to be a convective breadboard unit of wirewound resistors rather than the radiative titanium unit which wil be used for the filght units.

The reliability levels of the GDS electrical components will be as close as possible to the flight design levels. In each case, the GDS component wiIl have the same basic part number (such as IN3766) as the flight component, but its reliability level may be lower as forced by long procurement lead times.

\subsection{BREADBOARD TEST RESULTS}

The KIPS breadboard controller, corresponding to the PDR circuit design, has been tested with the KIPS alterrator. whe voltage regulation, with no speed control, is very stable and produces a nearly ideal output waveform. The field current is switched on the 
ripple that exists on the output voltage.

The speed control, as originally proposed, causes severe voltage transients as the PLR switches on and off. This action also disturbs the voltage regulation. To solve this problem a pulse-width-modulation (PWM) approach was tried. It was found that PWI at a high frequency $(6700 \mathrm{~Hz})$ can reduce the ripple voltage and the value observed was 4.5 volts (RIS). A filter will be added to attenuate the ripple to about 2 volts (RIIS). Final testing of the complete controller, as shown by the Figure II schematic, has not been done.

The PLR used for this testing is a resistive load bank that dissipates heat by convection.

The tuning capacitors have produced several desirable features. The residual voltage, when the field current is zero, is increased due to the capacitance. This is shom in Figure 12. The high voltage at the 95\% speed point aids the speed detector operation when the speed is below that point since the field is kept off. Also, the voltage $\left(V_{L-L}\right)$ waveform is smoothed significantly. A power factor of .87 has been measured with an alternator load of 1200 watts.

A worst case analysis will be made for the electrical circuits. Proper operation will be assured for the expected range of component parameters after a five year mission. 


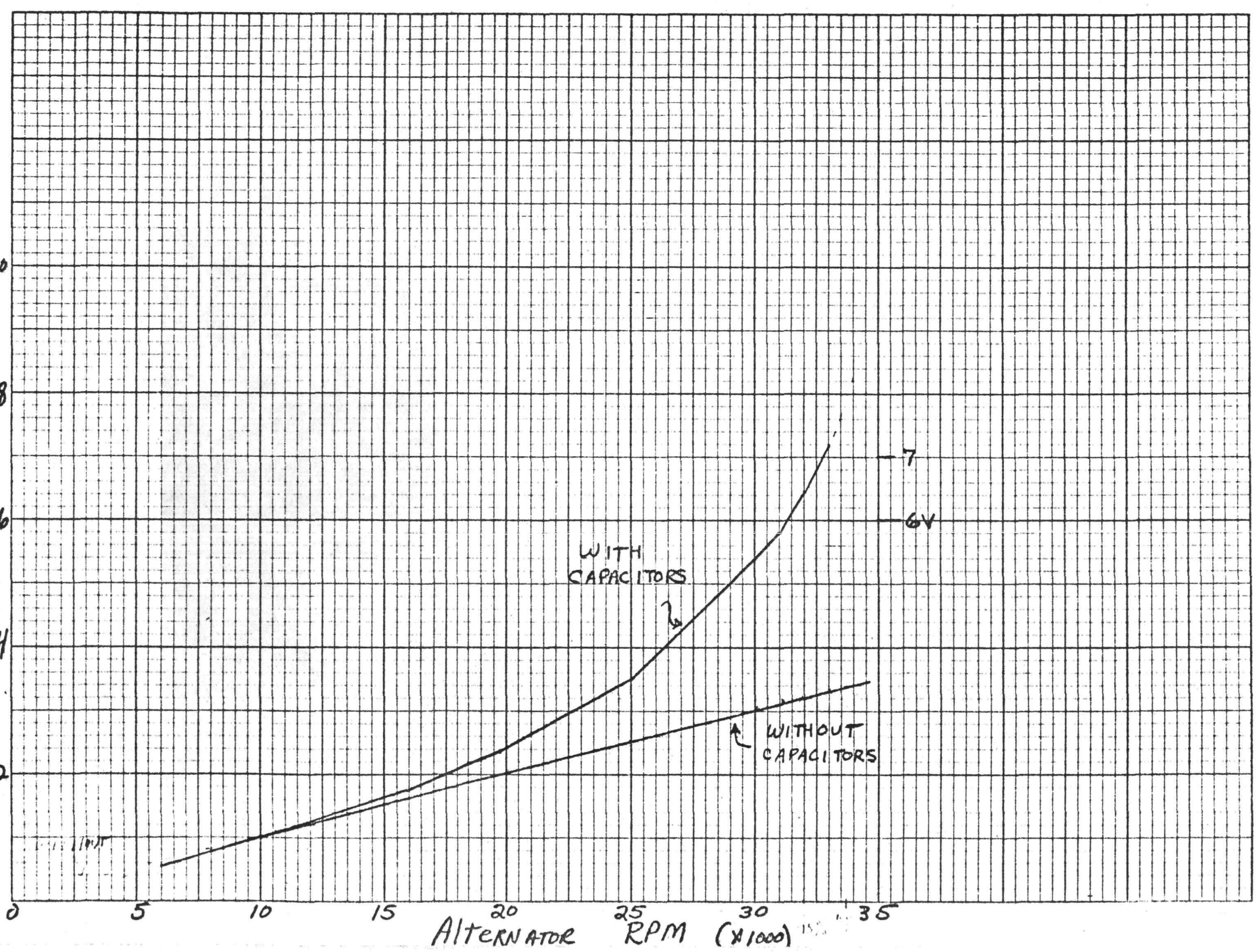


All components that are used in the controller have stress levels that are well below the rated stress. Fol example, the resistors will never have over $50 \%$ of their rated power dissipation and typically will be less than 25\%. The capacitors are operated at a third or less of their rated working voltage. The wire sizes are selected for about 2000 Amperes/inch ${ }^{2}$ (hax) which is a conservative figure. The semiconductor devices are also operated well below their rated stress levels.

Using the expected stress levels during system operation and MIL-HDBK$217 \mathrm{~B}$ as a guide for the fallure rates of the components, the controller reliability has been calculated to be .987 for the flve year mission life.

3.7 GENERATOR TERMINAL BLOCK

The generator terminal block provides for termination of both control and output power leads. Glass and metal construction forms a hermetic seal. Threaded fastners provide clamping force to make the electrical connections.

External connections are isolated by separators which provide electrical insulation. 
Rev. A

3.7 .1

MATERIALS AND PROCESSES, CONTROLLER

The controller for GDS will be fabricated with brazed aluminum. Brazing will also attach the cooling tubing to the package.

The FSCD units' materials and processes will be selected after GDS development testing.

3.8

CRITICAL CHARACTERISTICS

Nearly all of the electronic components have corresponding Military Speciffcations that cover the necessary characteristics. Each device is inspected by either the vendor or Sundstrand to neet or exceed these detailed characteristics. In this vay, the circuit elements are described to a high degree. The parts list is given in Figure 13. 
VENDOR PART NO.

JANTXV?:H 3501

JANTX 2N3739

J AivTXVEN $37 ! 1$

JMNTXV2N 3716

JANTX 2N3792

58060

JANTX 2 N5927

JAN'TXVIN5617

JANTX 1113766

JAIITXVIII 4959

JAlJ 1113289

JANTXVIN752A

$2^{\text {* }}$

DIODL:

REC'PIFIER

ZEHIS DIODE IIV 5\%

RECTIFILR

ZENER DIOUE $5.6 \mathrm{~V} 5 \%$

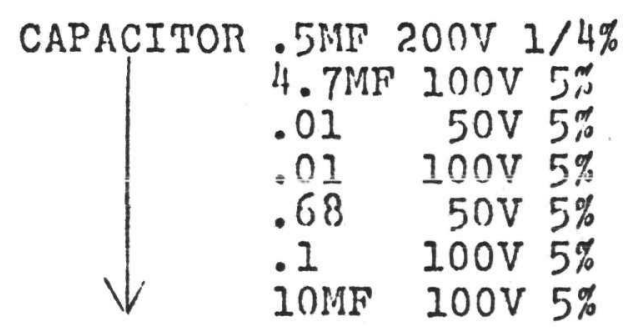

TRANSFORMER

$$
58059-1
$$$$
58058
$$$$
\text { 58059-2 }
$$

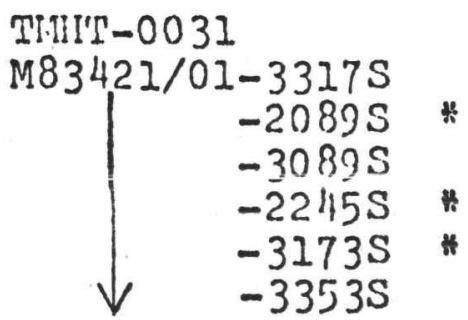

INDUCTOR, PRECISION

$39.95 \mathrm{MH} 1 / 2 \%$

INDUCTOR

$45.43 \mathrm{MII} 2 / 2 \%$

$+$

INDUCTOR, FILTER
MILIT

SPECIFICATIONS

MIL-S-19500/366A 1402

1441

$1408 B$

$/ 379 \mathrm{~B}$

1440

MIL-S-19500/411

$1297 \mathrm{~A}$

13563

12460

$1127 \mathrm{~F}$

MIL-C-8342I

MIL-T-27

A930157-2 CORE AI37\%52-2 CORE

* PWM Circuit: Preliminary Quant1ty

Figure 13

+ To Be Determined 

The location of the valve in the system is illustrated in Fig. 4.1. Figure 4.2 presents data for the speed governed mode of operation that illustrates the dependence of turbine inlet temperature on turbine loop flow. A large change in turbine inlet temperature results from a small change in turbine loop flow. The three curves presented represent different levels of heat flow from the isotope heat source at different times in the life of the unit. It is evident from the figure that some means of indexing flow during the life of the unit is required. If no means of flow biasing were available, the unit would drop off in turbine inlet temperature as the isotopes decayed. The drop off in turbine inlet temperature would result in the unit running wet and a premature shut down of the unit.

The requirement that the unit run non-speed governed compounds the turbine loop flow control problem. The data presented on Fig. 4.3 is for the non-speed governed case and illustrates the range of flows and throttling pressure drops the valve must control over. Once again the information is presented at three levels of isotope heat input. The curves presented are for a turbine inlet temperature of $650^{\circ} \mathrm{F}$. Around each of these lines is a small band (not shown) representing the acceptable range of operating temperatures. The size of this band can be estimated from Figure 4.2. Speed varies along each of the curves as a function of the load applied. In order to stay within the acceptable range of operating temperatures under all these conditions some sort of closed loop temperature controller is required.

Alternate mechanisms were considered, however, it must be remembered that only approximately five percent of the heat input is into superheat. As a result turbine inlet temperature decreases rapidly as flow increases. Conversely a relatively small decrease in flow causes a relatively large increase in turbine inlet temperature. Thus, for a given level of heat input, flow must be kept within a narrow band. Alternative mechanisms considered to control flow could not meet the system requirements and were therefore discarded.

Figure 4.3 defines the flow and pressure drop envelope that the valve is required to stay within. The valve must be able to control flow over the approximate range of $.027 \mathrm{lbm} / \mathrm{sec}$. to $.037 \mathrm{lbm} / \mathrm{sec}$. and vary pressure drop over the range of $20 \mathrm{psi}$ to $130 \mathrm{psi}$. The range which the valve must hold temperature within was independently defined as $637^{\circ} \mathrm{F}-670^{\circ} \mathrm{F}$. The temperature range was chosen in order to preclude running wet at the low temperature extreme and to minimize degradation of the working fluid at the high temperature extreme. 
K.I.P.S. FIUID LOOP CONTROUS

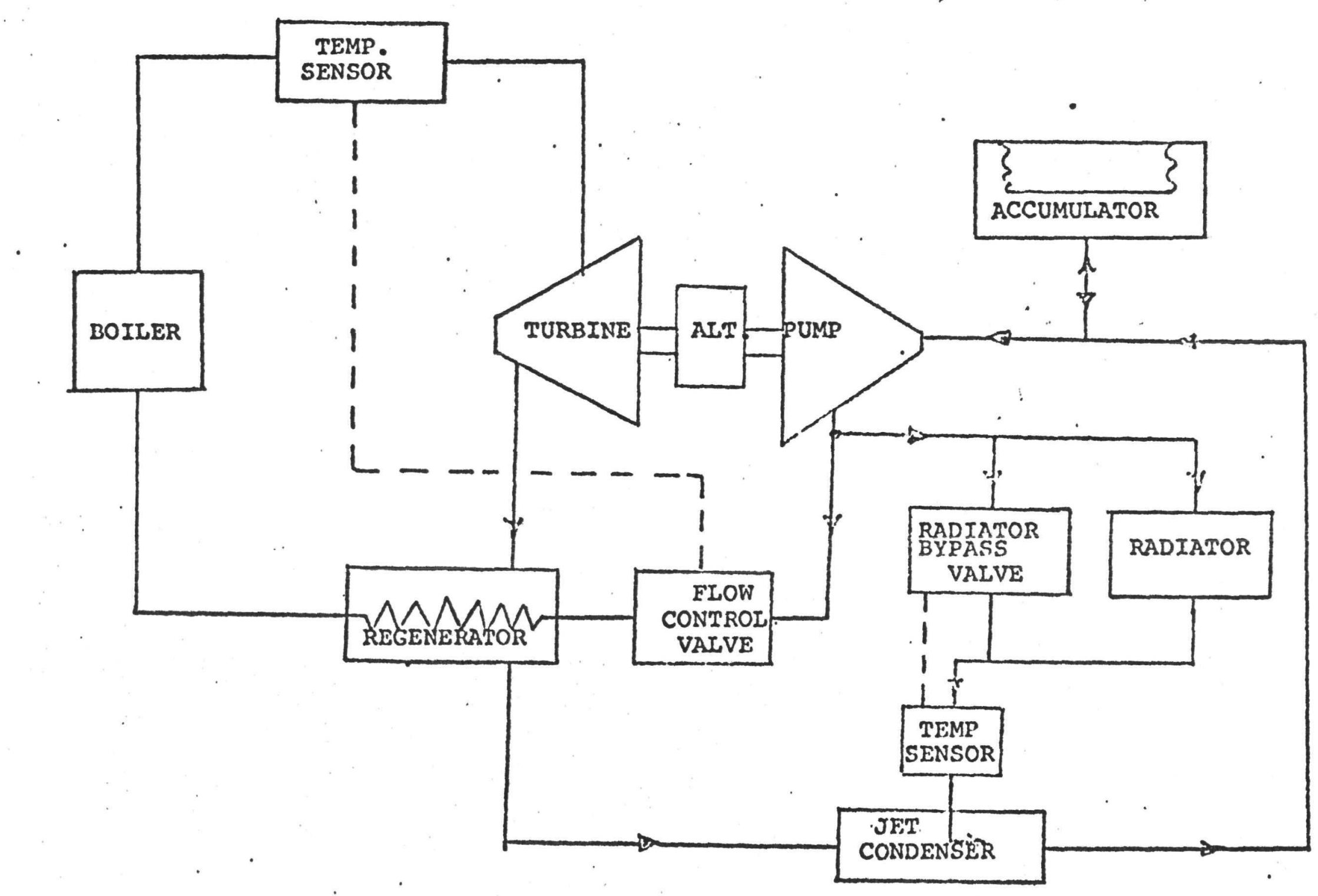

FIG. 4.1 
KIPS FLOW CONTROI REQUIREMENTS

Turbine Inlet Temp. vs Turbine Loop Flow at Constant Speed

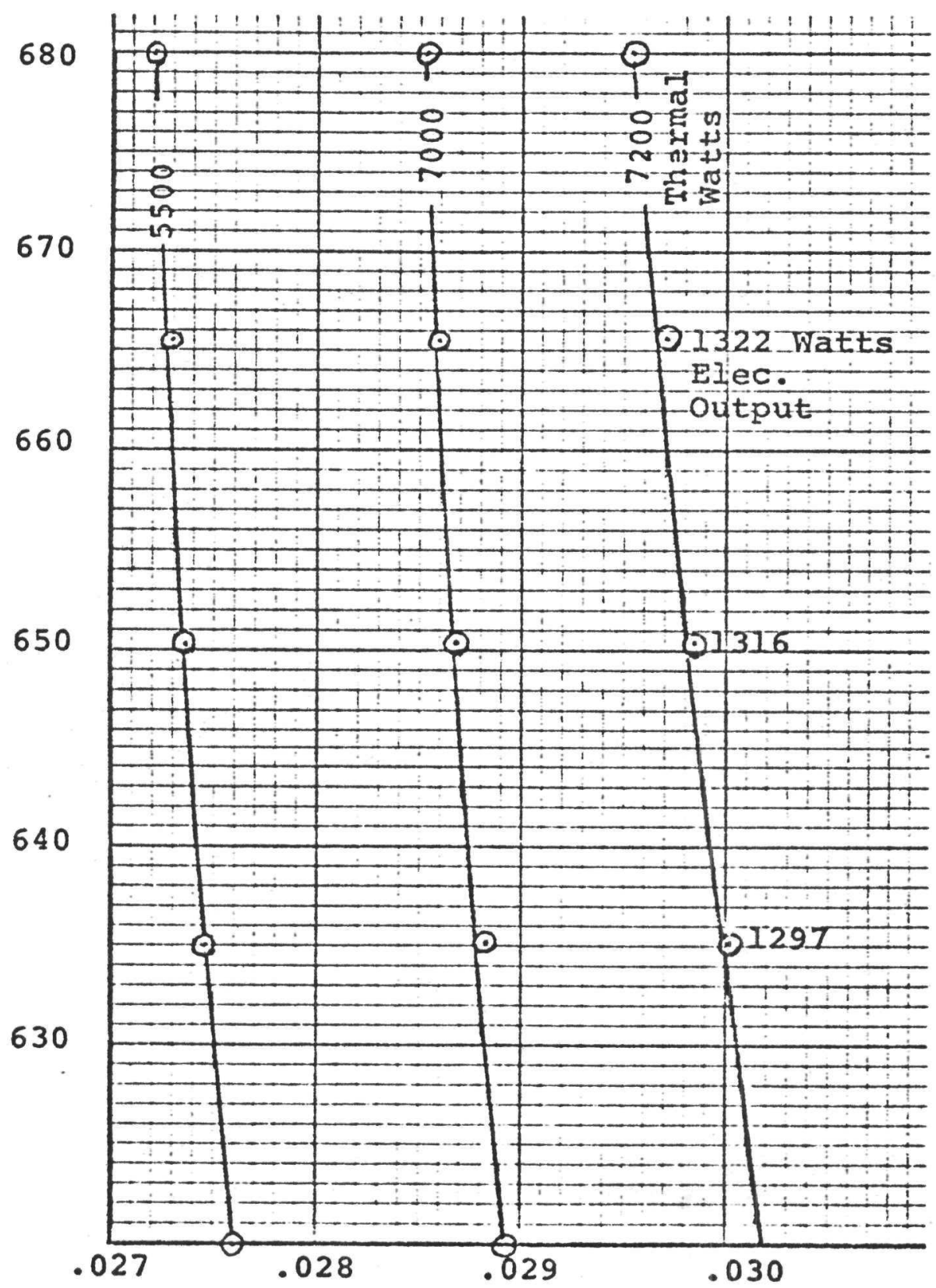

Turbine Mass Flow (16./Sec.) 


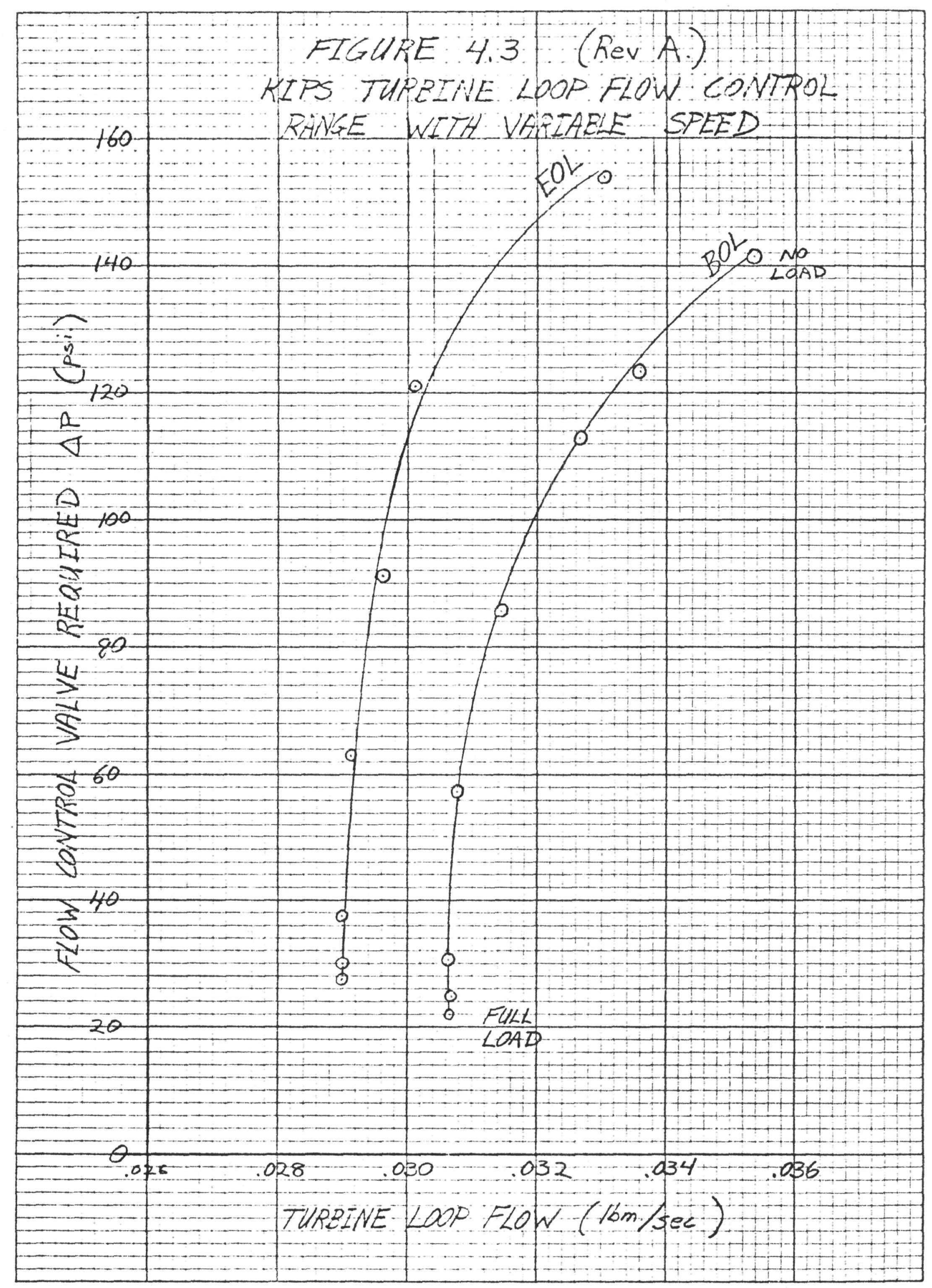




\subsubsection{Tradeoffs:}

With the valve requirements established, several valve candidates were defined and the tradeoff matrix procedure used to select the valve configuration. The completed matrix is shown on Fig. 4.4 .

\subsubsection{Valve Candidates}

4.1.2.1.1 Configuration \#l Fluidic Diverter with Capillary Temperature Sensor

The fluidic diverter valve with capillary temperature sensor consists of a fluidic diverter flow control valve with temperature biasing accomplished by means of a capillary temperature sensor. Figs. 4.5 \& 4.6 are schematic representations of the valve. The fluidic diverter section of the valve consists of three stages of fluidic amplifiers. The temperature sensor is a segment of capillary tube placed on the boiler outlet tubing. The flow resistance of a capillary is a function of viscosity which is, in turn, a function of temperature. Thus, if turbine inlet temperature is constant, the flow resistance of the capillary is constant and a change in turbine inlet temperature causes a change in the flow resistance of the capillary.

Assuming a constant turbine inlet temperature, an increase in pump outlet pressure causes the flow through the flow resistances in the control legs of the first stage amplifier to change. Because of the differing resistance characteristic of the flow resistances, the result of the increase in inlet pressure is the deflection of the output stream toward the output leg of the amplifier which is the "downward" leg on the schematics. This deflection in turn causes the output stream of the second stage amplifier to be deflected upward and, finally, the output stream of the third stage to be defiected downward. The downward deflection of the third stage results in a pressure recovery change in the output leg feeding the turbine loop that effectively cancels the increase in pump outlet pressure.

Temperature biasing is accomplished at the capillary temperature sensor. As temperature increases the flow resistance decreases causing the output stream of the first stage amplifier to be deflected upward. The output stream of the third stage amplifier is deflected upward and the pressure recovery and flow into the turbine loop increased.

Configuration \#2 Bimetallic Washer Valve

The bimetaliic washer valve consists of a single metering orifice with flow area proportional to temperature. Figure 4.7 is a schematic representation of the valve. The metering orifice is a spool valve. The temperature sensor consists of a stack of bimetallic washers placed in the boiler outlet vapor flow stream. The bimetallic washers expand and contract with temperature thereby, stroking the spool valve and metering flow to the boiler. 
SELECTION MATRIX

KIPS FLOW CONTROL VALVE

\begin{tabular}{|c|c|c|c|c|c|c|c|c|c|c|c|}
\hline & & & & & & & & & & & \\
\hline & & $\begin{array}{l}\text { Fluid } \\
\text { Capil }\end{array}$ & lary & $\begin{array}{l}\text { Bim } \\
\text { Was }\end{array}$ & $\underset{r}{a l l i c}$ & $\begin{array}{l}\text { Sing } \\
\text { Ther }\end{array}$ & $\begin{array}{l}\text { Stage } \\
\text { Bulb }\end{array}$ & $\begin{array}{l}\text { Dual } \\
\text { Therr }\end{array}$ & $\begin{array}{l}\text { unct. } \\
I \text { Bui }\end{array}$ & $\begin{array}{l}\text { Rec } \\
\text { Dua } \\
\text { The }\end{array}$ & $\begin{array}{l}\text { ORat } \\
\text { Funct. } \\
\text { al Bul }\end{array}$ \\
\hline CHARACTERISTIC & $\begin{array}{l}\text { Merit } \\
\text { Factor }\end{array}$ & $\begin{array}{l}\text { Value } \\
\text { Rating }\end{array}$ & $\begin{array}{l}\text { actor } \\
\text { Rating }\end{array}$ & & & & & & & & \\
\hline $\begin{array}{l}\text { SAFETY + } \\
\text { RELIABILITY }\end{array}$ & 10 & 8 & 80 & 4 & 40 & 10 & 100 & 8 & 80 & 10 & 100 \\
\hline PERFORMANCE & 9 & 6 & .54 & 6 & 36 & 8 & 72 & 10 & 90 & 10 & 90 \\
\hline RISK & 8 & 6 & 48 & & . & 5 & 40 & 10 & 80 & 10 & 80 \\
\hline WEIGHT & 7 & 9 & 63 & & & 10 & 70 & 9 & 63 & 8 & 56 \\
\hline PRODUCIBILITY & 6 & 5 & 30 & & & 10 & 60 & 9 & 54 & 10 & 60 \\
\hline $\begin{array}{l}\text { DESIGN/OPERATIONA } \\
\text { FLEXIBILITY }\end{array}$ & 5 & 3 & 15 & & & 10 & 25 & 10 & 50 & 10 & 50 \\
\hline $\begin{array}{l}\text { TOTAL } \\
\text { SCORE }\end{array}$ & & & 290 & & & & 367 & & 417 & & 436 \\
\hline
\end{tabular}




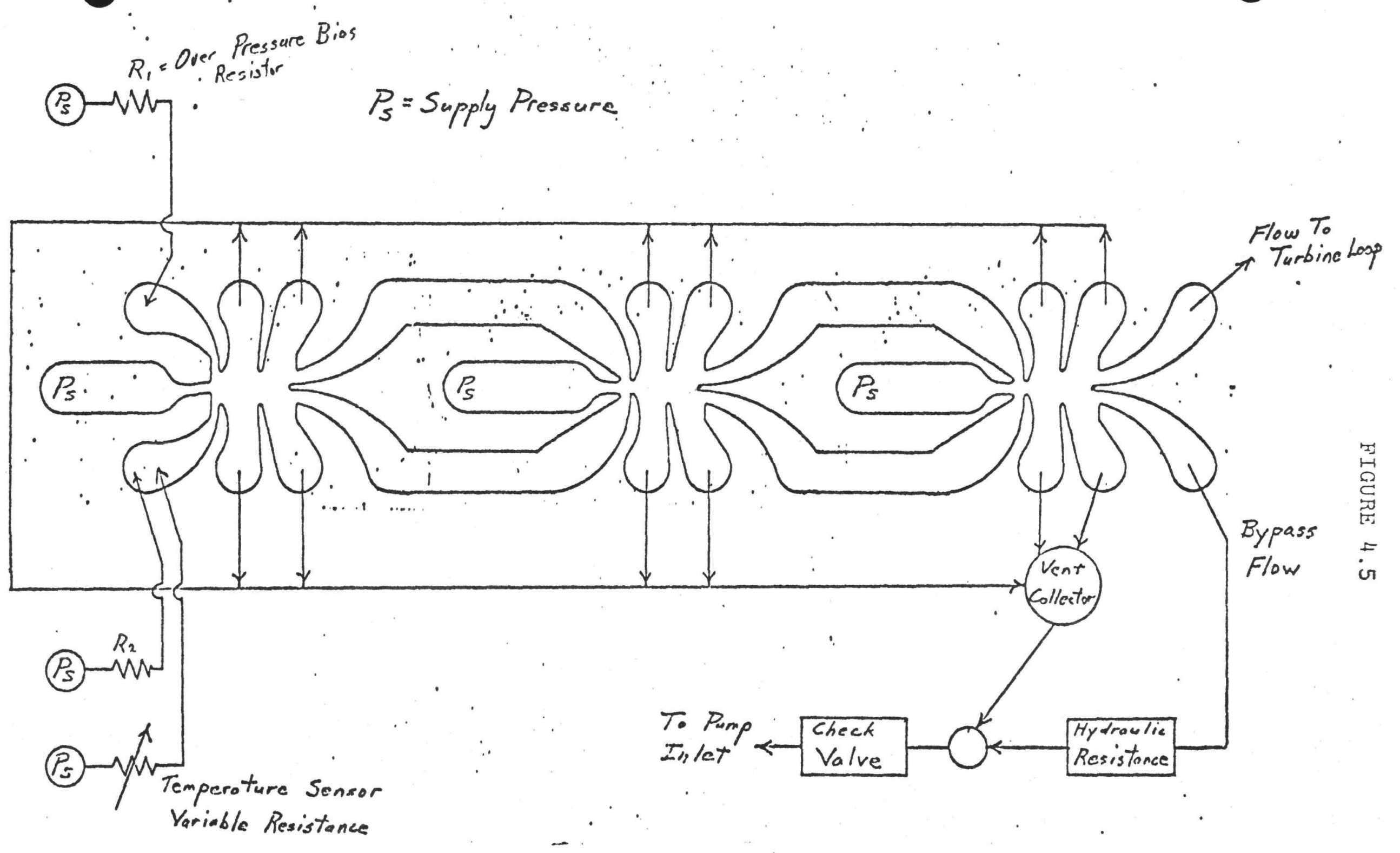




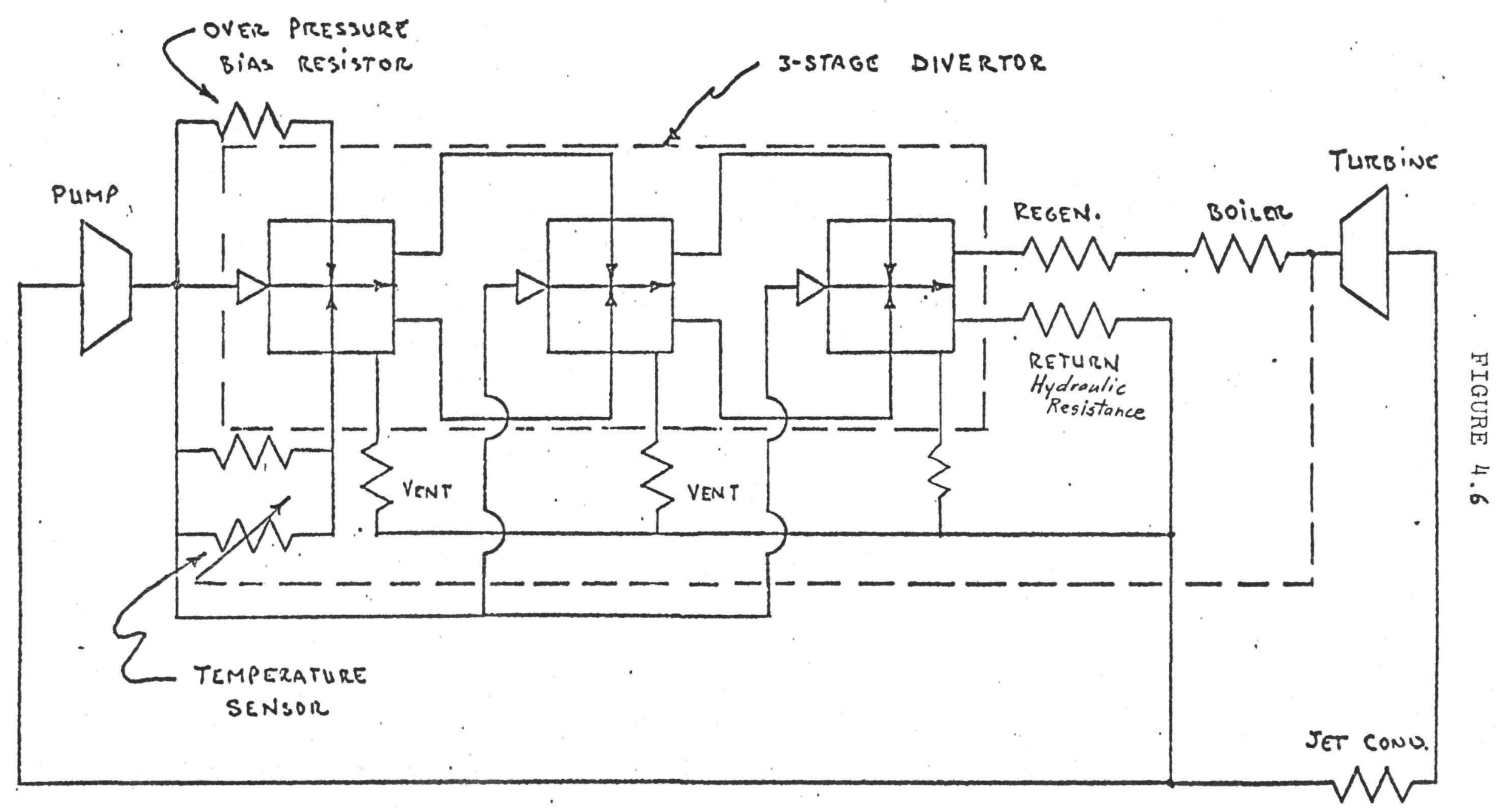

Fluidic TUROHAE TEMPERATURE CONMLOL SCHEMATIC 


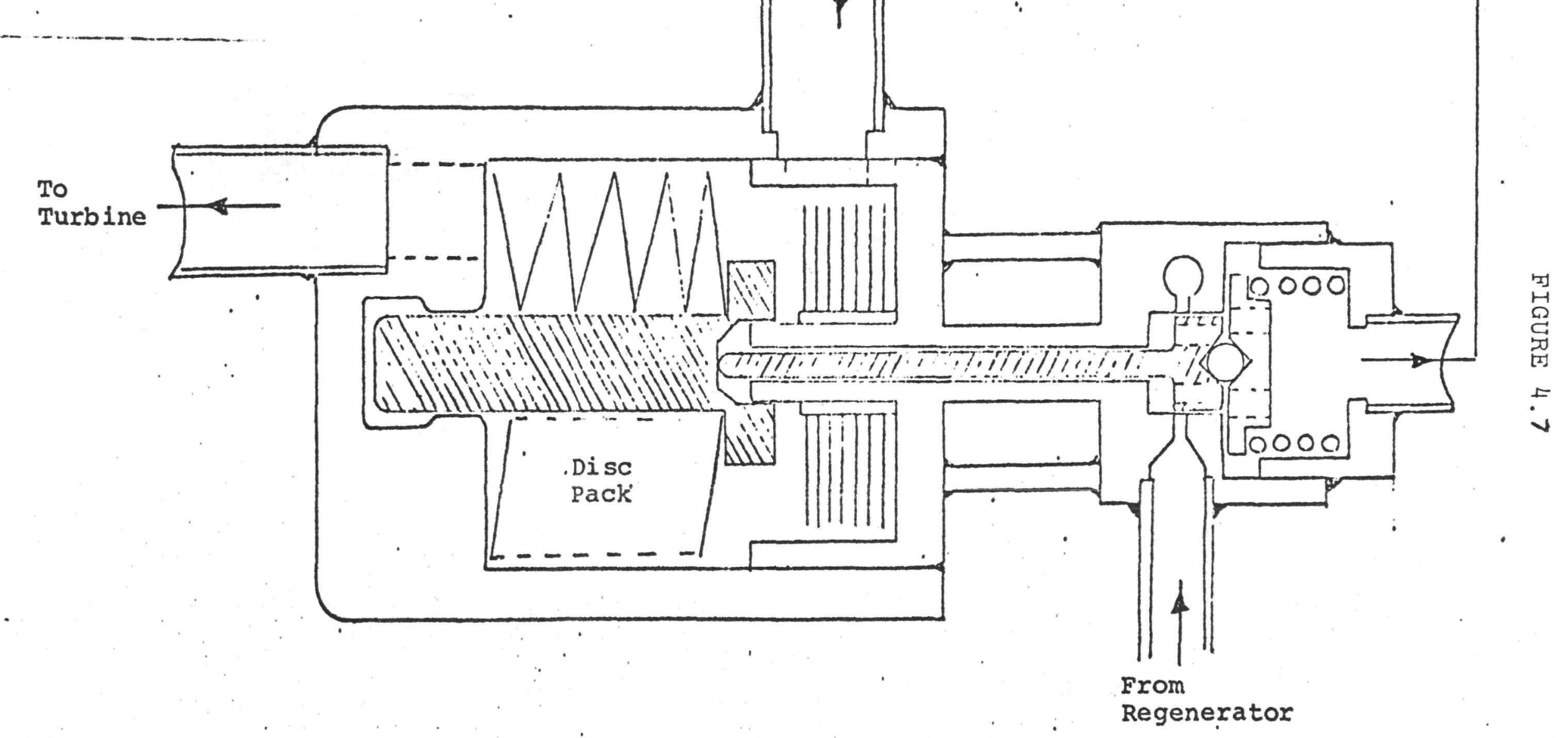

KIPS BIMETAILIC FLOW CONTROL VALVE 
Because of the metering location in the boller inlet and the temperature sensing location in the boiler outlet a leak path around the boiler is introduced. It was intended that this small leakage flow would be vaporized by heat transferred from the boiler outlet flow to the finned seal area of the valve.

Since the pressure drop across the metering area is not controlled, the spool valve must be capable of an area change sufficient to yield the throttling pressure drops required during non speed governed operation. The resulting area change requirement is, therefore, the larger than would be required if the pressure drop across the metering area were controlled. Since the temperature range is fixed, the change in area per degree must be larger than would be necessary if the pressure drop were controlled. As a result the flow change resulting from a given temperature change is relatively large. Configuration \#3 Single Stage Mechanical Valve

The single stage mechanical valve is identical in concept to the bimetallic washer valve. Figure 4.8 is a schematic representation of the valve. The valve consists of a single metering location with area proportional to temperature. The metering orifice is a flapper valve; the temperature sensor is a liquid filled bulb with a welded bellows actuator assembly. The temperature bulb is a helical section of capillary tube brazed in place around the boiler out tube. As the boiler out temperature changes the liquid in the temperature bulb expands and contracts. The changes in volume cause the bellows actuator to change its length and, in doing so, change the metering area.

The single stage mechanical valve improved on some of the shortcomings of the bimetallic washer valve. The leak path around the boiler was eliminated; as was the sliding fit at the spool valve stem.

1.2.1.4 Configuration \#4 Two Stage Mechanical Valve

The two stage mechanical valve adds a throttling pressure drop regulator to the single stage mechanical valve.

Figure 4.9 is a schematic representation of the two stage valve. The pressure drop regulator senses pressure drop across the temperature controlled flapper valve area. The regulator throttles flow as a function of the sensed pressure drop. At a constant turbine inlet temperature the flow area at the temperature controlled flapper valve is constant. An increase in flow across the flapper valve area would increase the pressure drop across this area. The pressure drop regulator would respond to this increase in pressure drop by further throttling flow through the valve by decreasing flow area at another metering location. It is evident that the pressure drop regulator must exhibit some "droop" (i.e., some increase in pressure drop across the temperature controlled flapper valve is necessary before the pressure regulator decreases its flow area). The valve characteristics have been chosen in such a manner that the droop characteristic will have no objectionable impact. 


\section{FIGURE 4.8}

Single Stage Mechanical. Flow Control. Valve

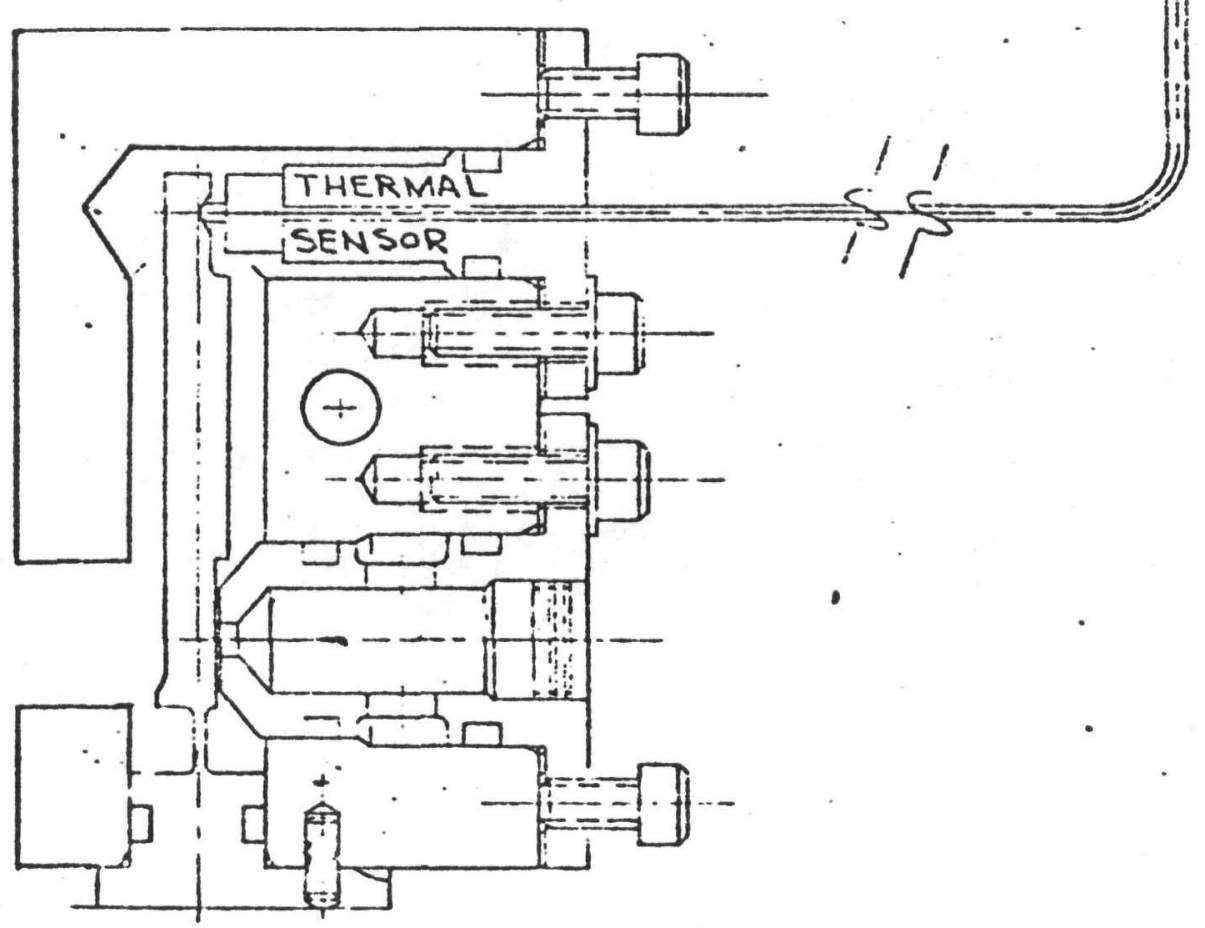


FIGURE 4.9

\section{Two Stage Mechanical Flow Control Valve}


With a controlled pressure drop, flow through the valve is essentially dependent on only the flow area of the temperature controlled flapper valve. This stage of the valve functions as described for Configuration \#3.

Since the pressure drop across the temperature controlled metering area is contrulled the temperature controlled metering area need only vary as required to change flow over the range as defined by Figure 4.3. Since the acceptable temperature range is fixed, the two stage valve requires a smaller area change at the temperature controlled metering area, than does the single stage valve.

The single stage and two stage valves also react differentialy during speed transients. The two stage valve will tend to hold flow constant until a flow change is called for by the temperature sensor. The single stage valve will allow flow to increase or decrease with speed until a temperature change is sensed. For the recovery from overspeed transient, for instance, the two stage valve will hold flow constant at its high value until the unit cools and turbine inlet temperature calls for a flow decrease. The single stage valve, on the other hand, would immediately decrease flow as speed decreased. Since the regenerator stores heat and since the heat released by the isotope does not change, turbine inlet temperature would increase; the valve, responding to increased temperature, would then increase flow to cool the unit. Thus the temperature transients experienced with the two valves would be quite different.

The two stage valve represents an improvement over the single stage valve. The flow change per degree temperature change has been reduced and a more desirable transient behavior attained.

\section{Configuration \#5 Two Stage Mechanical Valve with Redundancy}

Functionally the two stage mechanical valve with redundancy is identical to the two stage mechanical valve described above. Redundant components have been added to enhance system reliability. The pressure regulator bellows have been replaced

A by a flapper valve assembly utilizing redundant bellows. Figure 4.10 is a schematic representation of the valve. Redundant temperature sensors with containment bellows are utilized. The purpose of the containment bellows is to ensure that if an actuator bellows were to leak, the temperature sensing fluid would not be released into the system.

The two stage mechanical valve with redundancy represents an improvement of the two stage mechanical valve. The addition of redundant components eliminates some potential single point failure modes. 


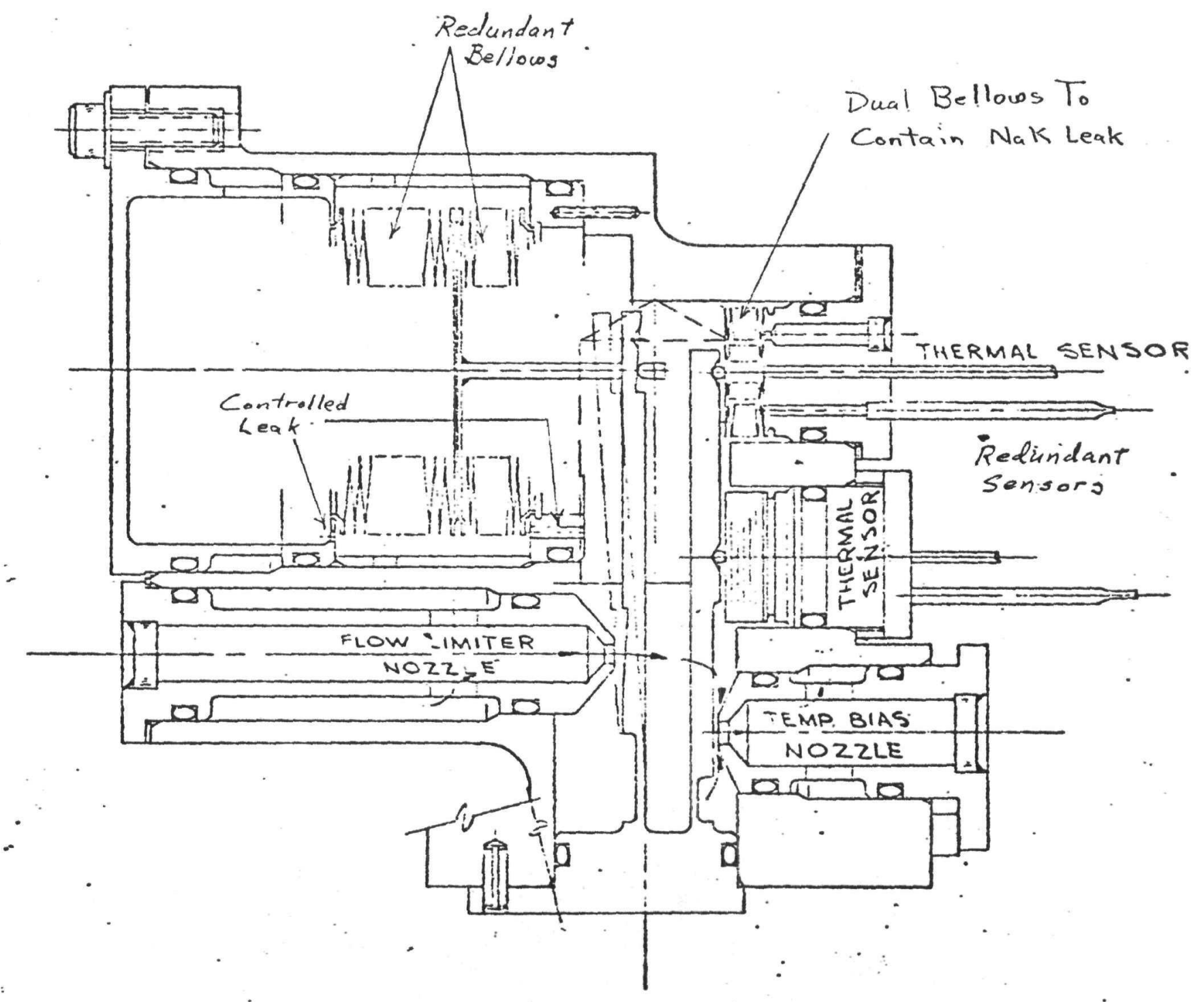

KIPS GDS SYSTEM FLOW CONTROL VALVE FIGURE 4.10 
$4 \cdot 1 \cdot 2 \cdot 2$

1.2 .2 .1

$1 \cdot 2 \cdot 2 \cdot 2$

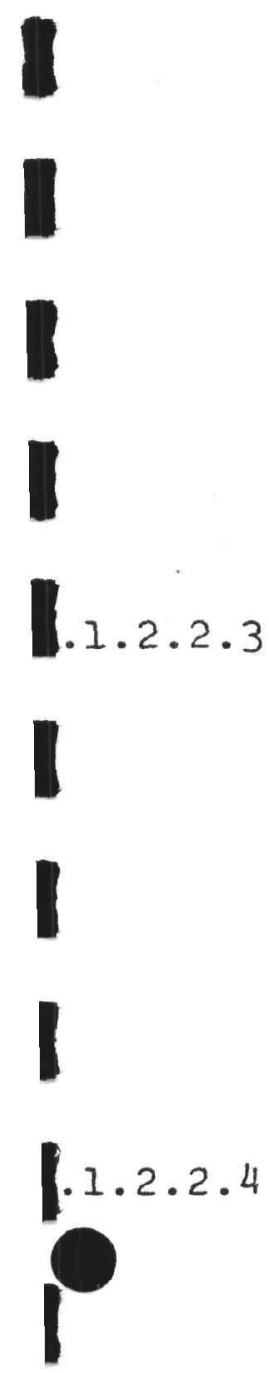

Reiiability

Configuration \# I Fluidic Diverter with Capillary Temperature Sensor

1. The unit has no moving parts.

2. A potential problem of fouling in capillary temperature sensor, (I.D. $=.010)$, exists.

3. Potential for capillary fouling to become positive feedback process, i.e., fouling restricts capillary reducing fiow through capillary, valve response is to reduce flow thereby raising turbine inlet temperature and hastening fouling in capillary.

4. Localized cooler area in boiler exit tube may collect contaminants and restrict flow.

5. Potential susceptability to launch environment an unknown.

6. Limited reliability data for similar components.

7. Bypass line required a check valve.

8. Extra plumbing required for bypass and vent lines.

Configuration \#2 Bimetallic Washer Valve

1. Sliding fits in several locations result in possible failure modes due to sticking. One sliding fit location is also location of high probability of contamination accumulation. Sliding fits also potentially generate wear particles.

2. Low force margins are available to overcome sticking.

3. Relatively large number of parts, complex.

4. Leakage path around boiler.

5. Force balance design is susceptible to launch environment caused problems. Mass of parts makes it difficult to design to have high resonant frequencies. Spool is loose piece located by pressure force.

Configuration \#3 Single Stage Mechanical Valve

1. Bellows uses small portion of available stroke. Margin of safety of two used in working stress diagram.

2. Bellows can be burned in to eliminate "infant mortality" failures.

3. Leaf spring working stresses small in comparison to allowable.

4. Moving parts limited to flexures.

5. Launch environment susceptibility analysis is straightforward.

Configuration \#4 Two Stage Mechanical Valve

1. Bellows uses small portion of available stroke. Margin of safety of two used in working stress diagrams.

2. Bellows can be burned in to eliminate infant mortality problems. 
A 3. Leaf spring working stresses small in comparison to allowable.

4. Moving parts limited to flexures.

5. Launch environment susceptibility is standard analysis problem.

6. Mass of parts susceptible to launch environment problems can be made small to raise resonant frequencies.

7. This configuration is same as Configuration \#3 with a pressure regulator stage added.

$4 \cdot 1 \cdot 2 \cdot 2 \cdot 5$

Configuration \#5 Two Stage Mechanical Valve with Redundancy

1. Leaf spring working stresses small in comparison to allowable.

2. Pressure sensor bellows stresses small in comparison to allowables.

3. One pressure sensor bellows can fail without harming system operation.

4. Temperature sensors incorporate containment bellows to prevent leakage of temperature sensor fluid into system in event of an actuator bellows leak.

5. One temperature sensor can fail without harming system operation.

6. Moving parts limited to flexures.

7. Bellows can be "burned in" to eliminate "infant mortality" failures.

8. This configuration is functionally identical to configuration $\# 4$.

4.1.2.3 Performance

Configuration \#I Fluidic Diverter with Capillary Temperature Sensor

1. High $\Delta \mathrm{P}$ is required for valve operation.

2. Bypass design increases required pump power by $10-20 \%$.

3. Present amplifier gain is not sufficient to compensate for low temperature sensor gain resulting in unacceptable temperature control. Increasing amplifier gain may result in noise problem.

4. Heat shunt at capiliary sensor.

5. Flow controller design concept gives lower temperature loop gain.

6. Contamination susceptible at capillary. 
7. Launch environment susceptibility an unknown.

8. Poor analytical predictability.

9. Poor data base for similar components.

10. Overspeed recovery characteristic an unknown. 4.1.2.3.2 Configuration \#2 Bimetallic Washer Valve

1. Very susceptible to contamination.

2. Very susceptible to launch environment.

3. Tolerant to small leakage.

Configuration \#3 Single Stage Mechanical Valve

1. Single stage valve results in higher gain.

2. Can operate at low $\Delta P$.

3. Launch environment performance amenable to analysis.

4. Small heat loss through liquid filled bulb.

5. Good analytical tools available.

6. Can supply required flow during overspeed recovery.

7. Transient begins in undesirable direction during overspeed and overspeed recovery.

4.1.2.3.4 Configuration \#4 Two Stage Mechanical Valve

1. Flow controller design concept gives lower temperature loop gain.

2. Can operate at low $\Delta \mathrm{P}$.

3. Small heat loss through temperature sensor.

4. Good analytical tools available.

5. Can supply required flow during overspeed recovery.

6. Transients begin in desirable direction during overspeed and overspeed recovery.

Configuration \#5 Two Stage Mechanical Valve with Redundancy

1. The performance of this valve is identical to Configuration \#4. 
4.1.2.4 Risk

2.4.1 Configuration \#I Fluidic Diverter with Capiliary Temperature Sensor

1. Relatively new technology.

2. Cannot predict performance analytically.

3. Significant additional development cost.

4. Problems:

a. Low gain temperature sensor.

b. low amplifier gain.

c. Sundstrand has no production experience with this type of product.

d. Not calibratable.

5. Problems unresolved by GDS.

a. Not calibratable.

6. Problems requiring resolution by rig/lab testing.

a. Temperature sensor development.

b. Amplifier bias resistor design.

c. Amplifier internal pressure drops.

7. Schedule effects - any of above problems.

8. Limited data available.

1.2.4.2 Configuration \#2 Bimetallic Washer

This valve can be dropped from consideration at this point due to low ratings in high weighted categories.

Configuration \#3 Single Stage Mechanical Valve

1. Analytical models are generally available but require knowledge of characteristics that is only available through test. Rig test will supply this information.

2. If required gain is sufficient to cause stability problem, no fix is readily available. Consequence of stability problem is extremely severe.

Configuration \#4 Two Stage Mechanical Valve

1. Analytical models are readily available but require knowledge of characteristics which is only available through test. Rig test will supply this information. 
2. Poppet instability could cause problem at pressure sensor. Valve should be overcompensated however.

Configuration \#5 Two Stage Mechanical Valve with Redundancy

1. The risk of this valve is the same as Configuration \#4.

\subsubsection{Producibility}

.1 .2 .5 .1

Configuration \#I Fluidic with Capillary Temperature Sensor

1. New product to Sundstrand but vendors with experience are available.

2. Complex shapes lead to inspection difficulty.

.1.2.5.2 Configuration \#2 Bimetallic Washer Valve.

4.1.2.5.3 Configuration \#3 Single Stage Mechanical Valve.

1. NaK filled bulb requires fill technique that prevents oxidation of the NaK. This is standard with NaK.

.1.2.5.4 Configuration \#4 Two Stage Mechanical Valve

1. NaK filled bulb requires fill technique that prevents oxidation of the NaK. This is standard with NaK.

2. Pressure motor bellows assembly is difficult to inspect, except by leak check, at the assembly level.

Configuration \#5 Two Stage Mechanical Valve with Redundancy

1. NaK filled bulb requires fill technique that prevents oxidation of the NaK. This is standard with NaK.

\subsubsection{Design and Operational Flexibility}

.1 .2 .6 .1

Configuration \#I Fluidic with Capillary Temperature Sensor

1. The unit is not calibratable.

.1.2.6.2 Configuration \#2 Bimetallic Washer Valve.

1.2.6.3 Configuration \#3 Single Stage Mechanical Valve.

1. The unit is calibratable.

Configuration \#4 Two Stage Mechanical Valve.

1. The unit is calibratable.

Configuration \#5 Two Stage Mechanical Valve with Redundancy. 1. The unit is calibratable. 
Selected Design, Analysis

4.1.3.1 General

The general design procedure is to select three extreme design points and force the valve envelope to pass through these points at the extreme allowable temperature conditions. The points selected are shown on Figure 4.11. It was decided that the valve should operate down to a throttling pressure drop of 10 psi and to split this total into nominal pressure drops of 5 psi across each metering area.

4.1.3.2 Temperature Bias Function

Select Point 1 from Figure $\underline{4.11}$ and apply the following flow formula.

$$
Q=C_{D} A_{1} \sqrt{\frac{2 \Delta P}{P}}
$$

Assume the recommended handbook value for the valve configuration for $C_{D} . Q, \Delta P$, and $P$ are known quantities. Therefore, $\mathrm{A}_{1}$ can be computed. It is known that the valve must decrease flow with decreasing temperature and therefore $A_{I}$ is the area required at $670^{\circ} \mathrm{F}$. Repeating the procedure at point 2 yields $\mathrm{A}_{2}$, the area required at $637^{\circ} \mathrm{F}$.

The metering area for the flapper valve configuration is the curtain area extending above the flapper nozzle edges to the flapper. The area is given by:

$$
A=\pi d h \quad \text { where: } \quad \begin{aligned}
& A=\text { area } \\
& \\
& d=\text { nozzle diameter } \\
& h=\text { gap }
\end{aligned}
$$

A rule of the thumb for flapper design is to make the null gap a maximum of $1 / 16$ the nozzle diameter. Since the maximum area is known the flapper nozzle diameter can be selected.

Given a nozzle diameter and the two required areas, the flapper gap as a function of temperature can be immediately defined. A flapper arm and leaf spring can then be selected and a stress analysis (Appendix A) carried out to ensure that the leaf spring is lightly stressed and to define the required temperature sensor gradient.

The temperature sensor design is quite straight forward. The fluid in the bulb expands with temperature as does the bulb itself. The incremental expansion of the fluid is used to expand a bellows of known effective area (the area of a piston that would displace an equivalent volume of fluid as does a bellows for an equal stroke is defined as effective area). 


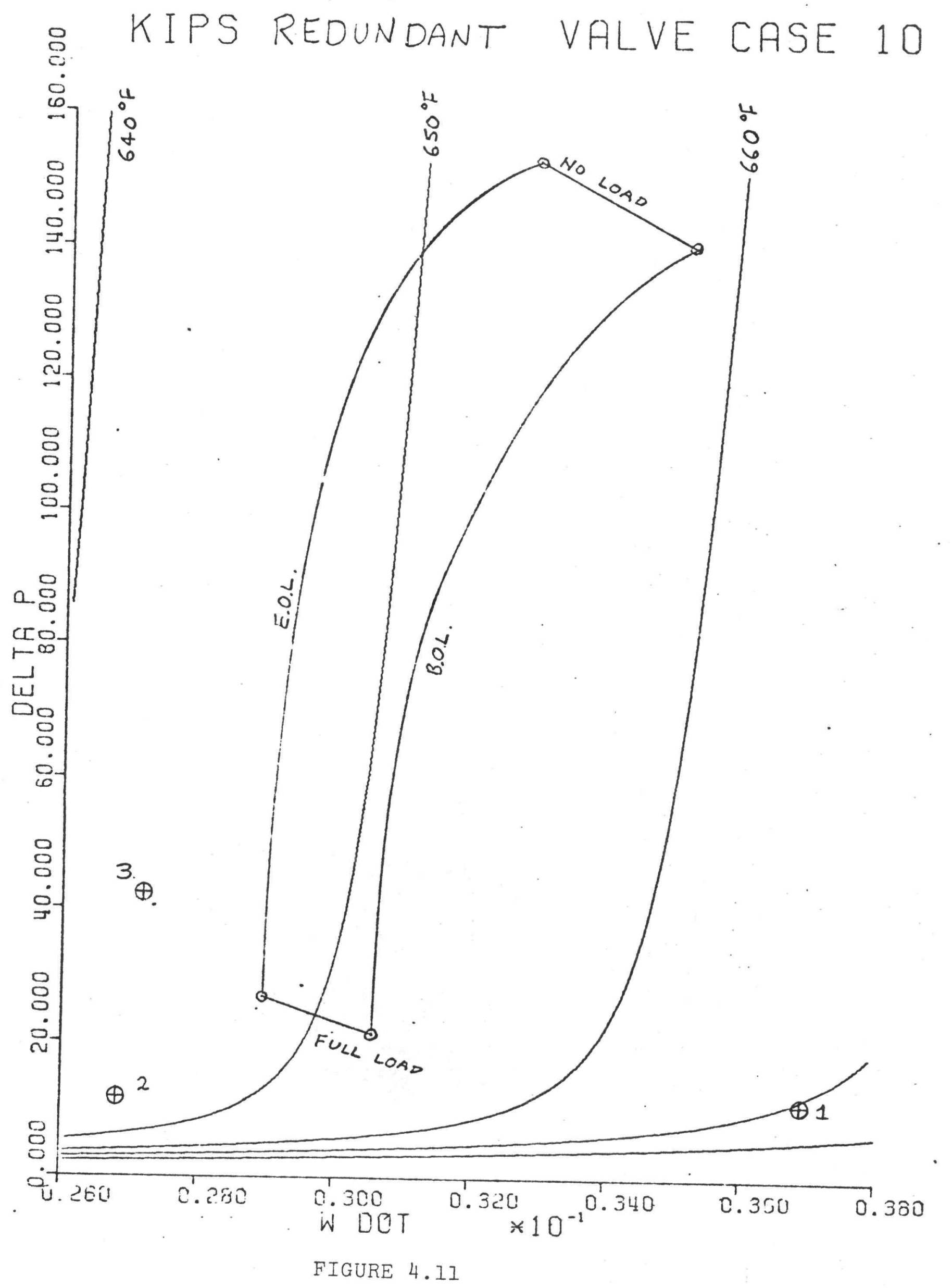


$\therefore \quad$ T.S.Grad. $=\frac{1}{A_{E}}\left\{\left(\frac{\pi d^{2}}{4}\right)(1)\left(B_{f l u i d}-B_{\text {tube }}\right)\right\}$

where I.S.lirad, = Temp Sensor Gradtent $\frac{11 .}{\mathrm{F}}$

$$
\begin{aligned}
A_{E}= & \text { Bellows Effective Area } \\
d= & \text { bulb inside diameter } \\
B_{\text {fluid }=} & \text { Volumetric Expansion Coefficient } \\
& \text { of Bulb Fluid } \\
B_{\text {tube }=} & \text { Volumetric Expansion Coefficient } \\
& \text { of Bulb Material } \\
I= & \text { Bulb length }
\end{aligned}
$$

Several fluids were considered for temperature sensor fluids. Dowtherm A was first considered because of its resistance to thermal breakdown, and because Dowtherm $A$ is the system working fluid. Closed capsule test data on the thermal breakdown was reviewed and it was concluded that the amount of gaseous products that could be expected to form over a seven year period was sufficient to produce an unacceptable calibration shift in the unit. There was insufficient data on the solubilities of the gases to ensure that they would remain dissolved. Since Dowtherm A is at least as stable as any alternative organic fluid considered, metals were considered next.

Mercury was the first metal considered. The problem encountered with mercury was embrittlement of the bellows material. The next metal considered was sodium. Sodium is commonly used in stainless steel containment in nuclear reactors and heat exchangers. Since $\mathrm{Na}$ has been extensively used much data is avallable on its compatability with stainless steel. The problem with sodium for the KIPS application is its high freezing point of $208^{\circ} \mathrm{F}$. It is likely that a sodium temperature sensor would freeze during storage and might cause problems if melted non-uniformly. As an alternative to sodium, the eutectic $N a K$ was considered. The freezing point of $\mathrm{NaK}$ is approximately $10^{\circ} \mathrm{F}$ and therefore the potential freezing problem should be obviated. The question of corrosion was investigated; the results of the investigation are presented in the Appendix. 
The pressure regulator was sized using Figure 4.11 points 2 and 3. Since points 2 ard 3 are on the same temperature line, the difference between the two points must result primarily from a position change of the pressure regulator. Because turbine inlet temperature is the same at both points, the temperature bias metering area is the same at both points. The area of the temperature bias metering area was calculated previously and designated $A_{2}$. At point 2 the pressure drop of the pressure regulator is $5 \mathrm{psi}$ and, since the pressure drop across the temperature bias metering area is also $5 \mathrm{psi}$, the area at the pressure regulator must, therefore, also be $A_{2}$. At point 3 the pressure drop across the temperature bias area, $A_{2}$, will have increased because of the flow increase from point 2 to point 3 . This pressure drop is calculated using Eq. (I). Since the total pressure drop is known the pressure drop at the pressure regulator and finally the area of the pressure regulator can also be calculated. Thus a schedule of pressure regulator area as a function of pressure drop across the temperature bias area has been defined.

Since the pressure regulator flow area at a 5 psi drop across the temperature bias area is a maximum, the nozzle diameter can be based on this area. With the nozzle diameter selected, the pressure regulator area schedule can be converted to a flapper gap schedule.

The flapper nozzle location is adjustable by shimming. The flapper position is determined by the force balance on the flapper arm. Thus the flapper gap can be set to a reference location and by proper selection of the leaf spring and bellows area the desired flapper gap as a function of temperature bias nozzle pressure drop can be attained. Appendix A presents the stress analysis procedure utilized to design the flex pivot leaf spring. 
4.1.3.4 Valve Design Program

The logic described in Sections 4.1 .3 .3 and 4.1.3.4 was incorporated into a valve design computer program and several possible valve selections run. The program was also used to examine the sensitivity of the design to changes in characteristics as would be expected to result from normal manufacturing variations.

\subsubsection{Valve Design Results}

Using the three selected design points, hand calculations were first carried out to define a starting valve configuration. The program was then used to perform a variation of parameters study to refine the valve design. Figure 4.13 presents a table showing the valve characteristics selected. Figure 4.11 presents the expected valve performance. The valve pressure orops as a function of flow through the valve is presented for several different turbine inlet temperatures. The three design points originally selected and used for the original hand calculations are shown for reference only. The valve can be calibrated to adjust the position of the family of constant temperature lines along the flow axis.

Figure 4.11 also shows the system operating lines for beginning of life and end of life isotope heat input rates. During a speed transient flow will initially follow a constant temperature line. As turbine inlet temperature changes, the valve will change the constant temperature line it operates on. The valve will continue to adjust its operating line until the new steady state point is reached. If, for example, turbine inlet temperature increases, the valve will shift to a higher flow line thereby eliminating most of the temperature increase.

4.1.3.6 Further Analysis

Further analytical effort is required for the valve. Dynamic analysis of the valve will be carried out to A verify the design's integrity with respect to accelertion, vibration, and shock loading. Bellows stress analysis will be supplied by the bellows vendor. 
4.1.4 Similarity to Flight System

Figures 4.10 and 4.12 are sketches of the GDS and Flight System two stage mechanical valve with redundancy. The units are interchangeable functionally. The GDS unit is configured in such a way as to allow the unit to be disassembled, if necessary. The flight unit will be a welded assembly with the welding accomplished after the unit is calibrated and tested. The functioning parts (e.g., the bellows, flapper arms, temperature sensor bulbs, temperature sensor actuators) will be identical for the two valves. The GDS valve fittings that the functioning parts are mounted on are altered in such a way as to allow disassembly. Because the GDS unit is a bolted assembly, the GDS unit should be somewhat heavier than the flight unit. In general, the differences between the units are limited to those caused by the anticipated need to disassemble the GDS unit.

\subsubsection{Test Plan}

The two stage mechanical valve concept will be rig tested on the KIFS Dowtherm test loop. The valve utilized for this proof of principle testing will be the two stage mechanical valve. The test loop will be used to define the flow and throtting pressure drop envelope for the desired temperature range. The valve will be calibrated to produce the required flows over the given temperature range. The valve design procedure, of necessity, assumes values of discharge coefficients. The actual value of parameters like discharge coefficients is unlikely to be exactly as assumed. The calibration procedure is used to compensate for differences between these actual and assumed parameters. The capability of the valve to produce the flows required for multi power level operation can also be investigated by determining the envelope of flows and pressure drops that can be attained from a given valve over the required temperature range for various calibration conditions.

The two stage valve will then be altered to simulate the single stage valve. This alteration requires that the two nozzles be replaced. The flow limiter nozzle will be replaced with a nozzle designed so that the motion of the pressure sensor bellows will not result in throtting. The temperature bias nozzle will be replaced with one sized for the required flows and pressure drops.

The valve will then be tested to determine its flow, throttling pressure drop envelope. The valve will then be calibrated to determine the envelope of flows and pressure drops that can be attained from a given valve over the required temperature range for various calibration conditions. 
Redundant

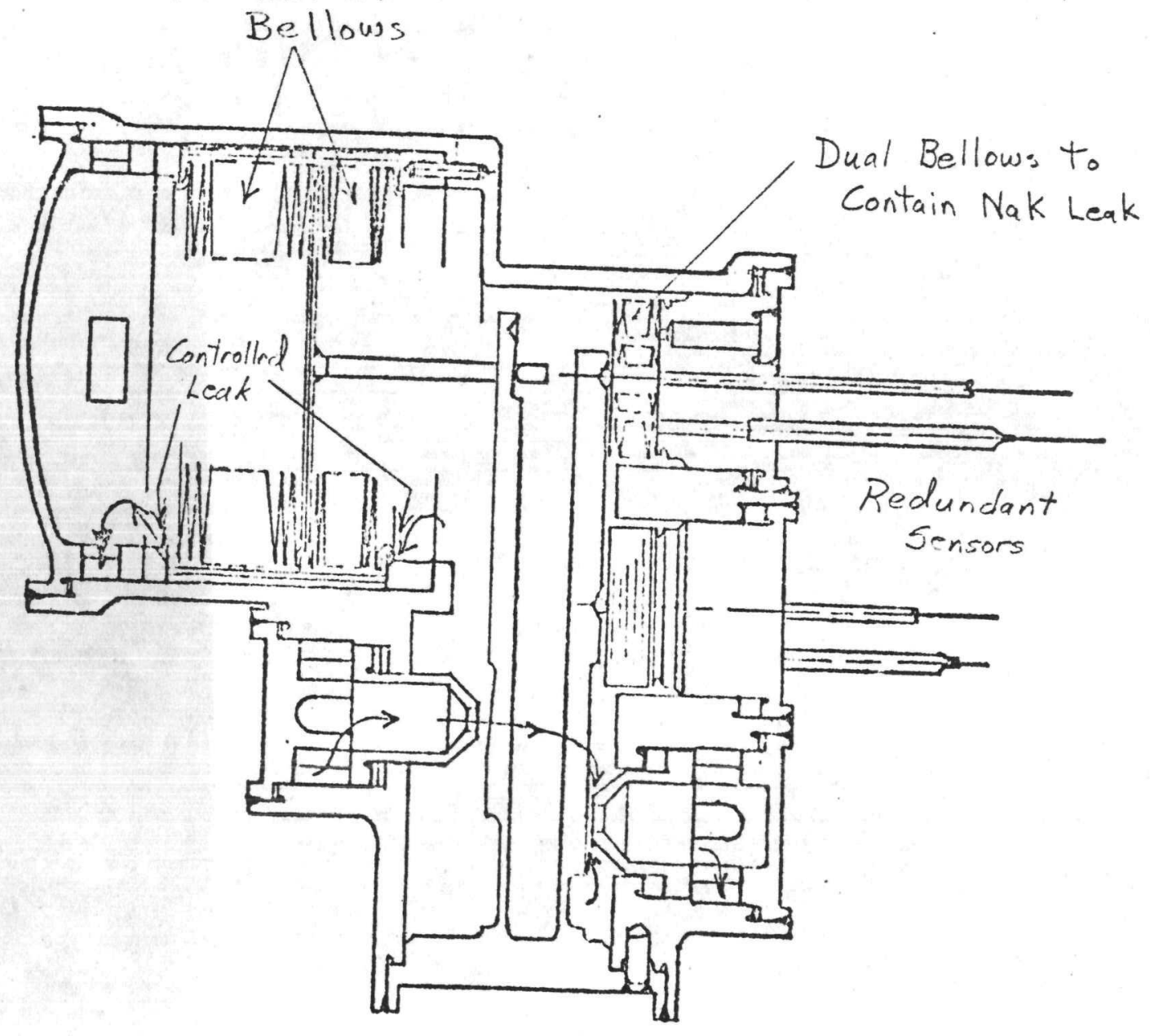

KIPS FLIGHT SYSTEM FLOW CONTROL VALVE FIGURE 4.12 
Fig. 4.13

Valve Characteristics

Temperature Bias Nozzle Diameter $=.125^{\prime \prime}$

Pressure Regulator Nozzle Diameter $=.250 "$

Temperature Bias Nozzle Gap

$\begin{array}{cc}\left.\text { T ( }{ }^{\circ} \mathrm{F}\right) & \text { Gap (in.) } \\ 637 & .0061 \\ 670 & .0082\end{array}$

Pressure Regulator Nozzle Gap

$\begin{array}{cc}\text { Total } \Delta P & \text { Gap (in.) } \\ 0 & .0180 \\ 125 & .0010\end{array}$

Bellows Area $=1.59$ in. ${ }^{2}$

Pressure Regulator Leaf Spring Rate $=53.7 \mathrm{lbf} / \mathrm{in}$. 


\subsubsection{Reliability}

An objective of the valve design was to eliminate single point failures to the maximum extent practical and to demonstrate the reliability of those components which retained possible single point failures by life testing.

The valve incorporates redundant thermal sensors. Either of the thermal sensors may fail without affecting the operation of the valve. The thermal sensors incorporate containment bellows in order to prevent leakage of the thermal sensor fluid into the system in the event of an actuator bellows failure. Helium leak test ports have been incorporated into the thermal sensor so that the containment bellows can be verified to be leak tight. The space between the actuator and containment bellows will be evacuated and cleaned so that a failure of the containment bellows will not release contaminants into the system, and to prevent the NaK from becoming contaminated in the event of an actuator bellows failure.

The pressure regulator section of the valve incorporates redundant bellows. Either of the bellows may fail with only minor consequence. Figure 4-18 illustrates the flow shift resulting from a failed bellows. Failure of a bellows results in a loss of the bellows spring effect and "short circuiting" one of the calibrated leaks. Loss of the bellows spring rate has a small effect on flow because the bellows operates near its free length and has a small spring rate. The shorting of calibrated leak produces a small increase in flow. The failed bellows case is illustrated in Fig. 4-18. The flow change as a result of a $10 \%$ reduction in flex pivot spring rate is also illustrated in Fig. 4-18. If the reduction in spring rate exists at assembly the effect would be removed by calibration.

Single point failures still exist in the flapper valve flex pivots. Five flex pivots will be tested for 2000 lifetimes each. The objective of the test is to demonstrate .9997 reliability for the flex pivots. The flex pivot design utilized margins of safety as specified in the Reliability Volume (Volume 4) para. 2.2.4.5 to achieve a failure probability of (10 ${ }^{-9}$ ).

\subsubsection{Quality Control, Cleaning, Critical Characteristics}

\section{Pressure Sensor Bellows and Pressure Regulator Flapper Arm}

The flapper arm flex pivot spring and the two bellows springs are in parallel when the valve is operating. The flex pivot spring will be controlled by machining the flex pivot in a two stage process. The first stage will machine the thickness and measure to determine the thickness of the pivot within the required tolerance band. Then with the thickness known, machine the pivot to within the width tolerance specified for the known thickness. The table of widths and thicknesses is presented in the flapper stress analysis in the Appendix. A variation of $10 \%$ can be accepted.

The spring rates of the bellows are not critical since the bellows operates near its free length. 
The effective area of the bellows will be experimentally determined by the bellows vendor. A variation of $\pm 10 \%$ will be accepted.

The bellows assembly is configured so as to allow access to both sides of the bellows for cleaning. The bellows cleaning procedure is as yet undetermined. However, a bellows cleaning procedure used by Sundstrand in the past is presented in the Appendix. The bellows vendor will be asked to supply Sundstrand with a manufacturing outline defining the bellows assembly processing. Definition of special procedures utilized by the vendor will be requested. Further definition of manufacturing processing awaits the selection of a vendor.

\section{Thermal Sensor}

The thermal sensor gradient (i.e. change in length per ${ }^{\circ} \mathrm{F}$ ) will be experimentally determined by the thermal sensor vendor. A variation of $\pm 10 \%$ is acceptable. The thermal sensor bellows, fitting, and capillary tubing will all be cleaned as piece parts prior to assembly. After assembly the helical bulb, transition capillary, and actuator bellows will be leak checked by helium mass spectrometer to $10^{-8} \mathrm{scc} / \mathrm{sec}$. The containment bellows will be leak checked to $10^{-8} \mathrm{scc} / \mathrm{sec}$. Prior to filling with $\mathrm{NaK}$, the helical bulb, transition capillary, and actuator bellows will be vacuum baked at a pressure of $10^{-6}$ torr or smaller and a temperature of $500^{\circ} \mathrm{F}$ or greater for a period of $48 \mathrm{hr}$ minimum. The area between the actuator bellows and the containment bellows will have the same vacuum baking process applied. The thermal sensor vendor will be requested to supply a manufacturing outline and definition of special procedures.

\section{Shimming}

The valve is calibrated by shimming. Shimming adjustments may require smaller changes in shim size than are available in standard shim stock. Locations where these small shimming adjustments are required are one of the thermal sensors and the temperature bias nozzle. At other shimming locations standard shim stock is adequate. Where small shimming adjustments need to be made shims will be fabricated and machined as required to attain required valve performance.

\section{Parallelism}

Since the pressure regulator nozzle gap can go to a minimum value of approximately .001 , parallelism between the nozzle face and flapper will be controlled by drilling and pinning the flapper assembly and valve housing at assembly. 


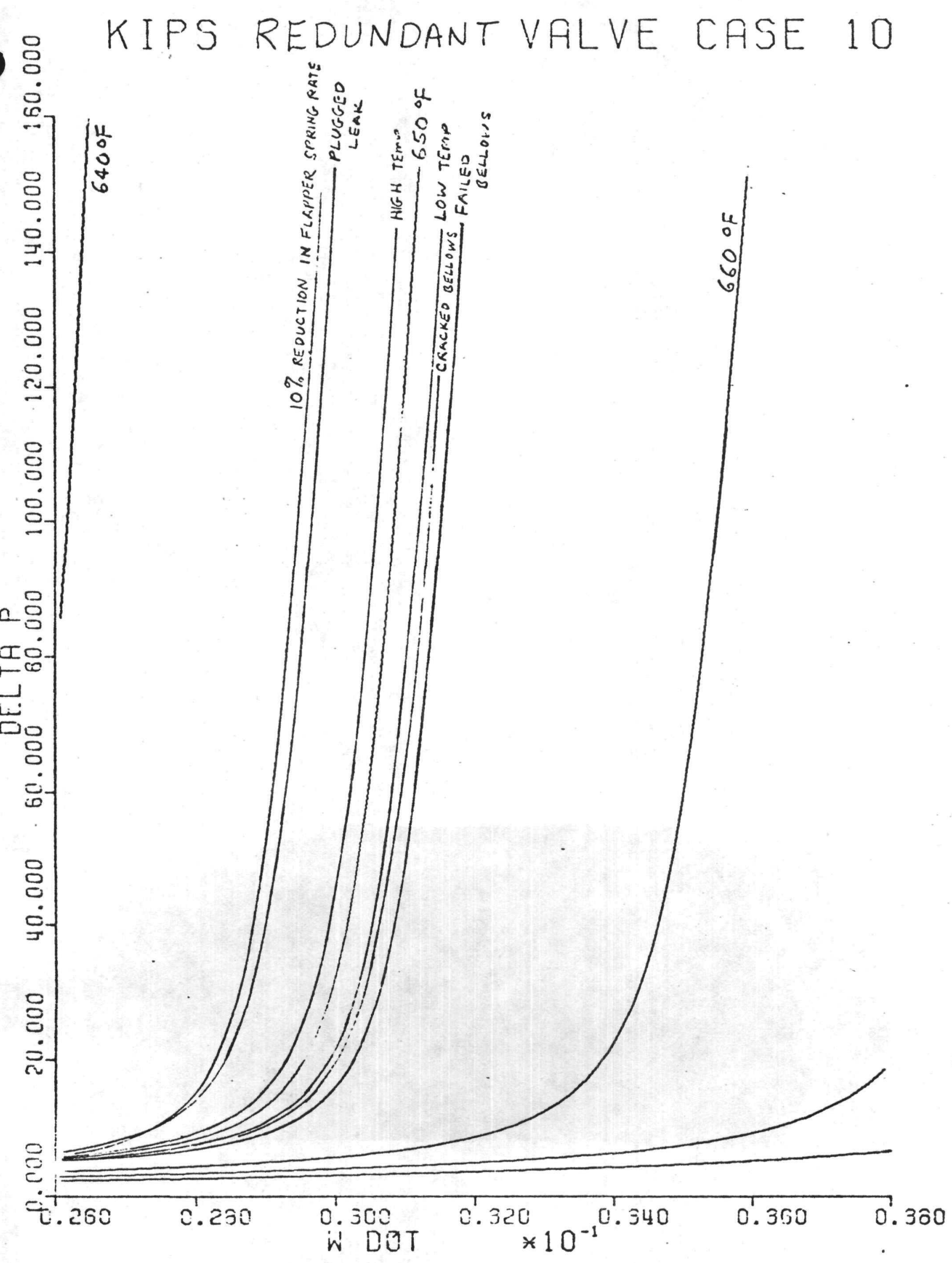

EFFECT OF FAILURE MODES

FIGURE 4.18 


\section{APPENDIX B}

\section{CORROSION OF THERMAL SENSOR MATERIALS BY NaK}

\section{Summary :}

Corrosion of thermal sensor materials by NaK should not present problems. Clean NaK will be introduced into the thermal sensor and complete reduction of the oxide film on the helical temperature bulb surface and the transition capillary tube surface will not liberate sufficient oxygen to cause corrosion problems over a five year period. The temperature of the bellows actuator is sufficiently small to prevent reduction of the oxide film on the bellows.

\section{History:}

Consideration of $\mathrm{NaK}$ as a heat transfer fluid in liquid metal cooled nuclear reactor systems began in 1945. NaK was favored over $\mathrm{Na}$ because the lower freezing point of the NaK prevented potential freezing problems that might occur with Na. The lower freezing point of $\mathrm{NaK}$ was its sole advantage however. In other respects $\mathrm{Na}$ is a superior heat transfer fluid to NaK. A considerable amount of research was done on NaK; but, over the years, emphasis has shifted to $\mathrm{Na}$. Na lines can be trace heated to prevent freezing thereby eliminating $\mathrm{NaK}^{\prime} \mathrm{s}$ sole advantage and making $\mathrm{Na}$ the preferred heat transfer fluid. 
NaK has also found application as a heat transfer fluid in industrial heat exchangers. Several of these applications are described in "Industrial Application of NaK Heat Transfer System," K.R. Barker, MSA Research Corporation. of the systems described, the longest period of operation was eleven years at the time the report was prepared (March 1970). This report also discusses the design, fabrication, and cleaning of industrial $\mathrm{NaK}$ systems. The cleaning procedures discussed are no more elaborate than wire brushing and degreasing.

\section{Discussion:}

The thermal sensor may be divided into two sections on the basis of temperature. The "cold" section is made up of the bellows actuator. The bellows actuator is immersed in a liquid at a maximum temperature of approximately $220^{\circ} \mathrm{F}$. The "hot" section is made up of the temperature bulb at a temperature of approximately $650^{\circ} \mathrm{F}$. The transition capillary will be assuned to be in the hot section.

\section{Hot Section}

The rate of corresion of stainless steel in $\mathrm{NaK}$ is known to be dependent on temperature, speed at which the NaK flows over the stainless steel, and concentration of oxygen in the NaK. One source of oxygen in the thermal sensor NaK is oxygen in the NaK used to fill the unit. The oxygen content of the NaK used to fill the thermal sensor will be monitored by sampling from the fill line and analyzing the sample. The other source of oxygen in the NaK fill is oxygen released by reducing tie oxide film from the inside surface of the capillary tubes. Discussion with W. Reuther, Argonne National Lab., indicates that stainless steel may be conservatively assumed to have a $30 \AA$ coating of $\mathrm{Fe}_{2} \mathrm{O}_{3}$.

Complete reduction of the $\mathrm{Fe}_{2} \mathrm{O}_{3}$ was assumed to take place and the oxygen concentration resulting from the reduction calculated.

For the $.063 \mathrm{in.}$ i.d. capillary temperature bulb:

1. Volume of oxide $=\frac{\Pi I}{4}\left(.063^{2}-\left(.063-30\left(10^{-8}\right)\left(\frac{1}{2.54}\right)\right)^{2}\right) 30$

$$
\begin{aligned}
& =3.51\left(10^{-7}\right) \mathrm{in}^{3} \\
& =5.75\left(10^{-6}\right) \mathrm{cm}^{3}
\end{aligned}
$$

2. Weight of oxide $=\left(5.75\left(10^{-6}\right) \mathrm{cm} \cdot{ }^{3}\right)\left(5.12 \frac{\mathrm{g}}{\mathrm{cm}^{3}}\right)=2.94\left(10^{-5}\right) \mathrm{g}$.

3. Weight of oxygen $=\left(2.94\left(10^{-5}\right)\right)(.3006)=8.84\left(10^{-6}\right) \mathrm{g}$.

4. Weight of $\mathrm{NaK}=\frac{\Pi I}{4}(.063)^{2}(30)(2.54)^{3}(.847)=1.298 \mathrm{~g}$.

5. Concentration $=\frac{8.84\left(10^{-6}\right)}{3.298}=6.81\left(10^{-6}\right)$

$=6.81 \mathrm{ppm}$. 
For the transition capillary a similar calculation yielded an increase in oxygen content resulting from the total reduction of the oxide film of $12 \mathrm{ppm}$. The drawing requirement for oxygen concentration in the NaK used to fill the thermal sensor is less than $25 \mathrm{npm}$. Therefor the maximum total concentration of oxygen in the hot section is $37 \mathrm{ppm}$.

Recent corrosion data for NaK do not seem to be available. However, D.L. Smith, Argonne National Lab, advised that, since $\mathrm{Na}$ and NaK are simlar with respect to corrosion of stainless steel, corrosion data available on $\mathrm{Na}$, be utilized. Corrosion data are not not available for the exact conditions that are present in the thermal sensor. Corrosion data have generally been collected at higher temperatures than are present in the thermal sensor. The reason the data have been collected at higher temperatures is to simulate the conditions seen in service and to produce measurable corrosion rates. The minimum temperature for which data were availabie was approximately $700^{\circ} \mathrm{F}$. The thermal sensor is an essentially zero flow speed situation but the smallest flow speed data was for $.5 \mathrm{~m} / \mathrm{sec}$. Thus the estimated corrosion rate for the thermal sensor should be conservative because of the required assumed temperature of $700^{\circ} \mathrm{F}$ and speed of $.5 \mathrm{~m} / \mathrm{sec}$. Given conditions of $700^{\circ} \mathrm{F}, .5 \mathrm{~m} / \mathrm{sec}$, and $37 \mathrm{ppm}$ oxygen; Figure 1 can be entered and a corrosion rate of $6.16 \mathrm{u} / \mathrm{yr}$. read. Converting to inches the corrosion rate becomes $6.118\left(10^{-6}\right)$ in./yr. If this rate is increased by an order of magnitude to allow for location to location variation in material properties, it becomes $6.118\left(10^{-5}\right) \mathrm{in./yr}$. If a seven year period is assumed the total corrosicn becomes .0004 inches. This is much smaller than the wall thjckness manufacturing tolerance. Assuming the entire bulb loses .0004" wall thickness, the other dimensions at the worgt case tolerance stack up levels, and utilizing the required margins for $\left(10^{-9}\right)$ probability of failure, the maximum allowable pressure in the bulb was calculated to be 1900 psi. Since this allowable pressure is much larger than the maximum bulb pressure of $300 \mathrm{psj}$, the reliability of the sensor should not be affected.

\section{Cold Section}

Discussion with W. Reuther, Argonne National Lab. on the topic of reduction of the oxide film on stainless steel indicated that the rate with which the reduction would take place is greatly dependent on temperature. Reference to the Liquid Metals Handbook confirmed this conclusion. There apparently has been a fair amount of research on this topic. The reason for the research is that the oxide layer increases the resistance to heat flow. Since the primary use of the liquid metals was in heat exchangers, it was highly desirable to remove the oxide layer. A recommended method for removing the oxide was to heat the liquid metal to a temperature where it would rapidly remove the oxide The objective of the research was to determine what temperature was required. Thus although there is research on the topic of interest, there is not much useful information because the objective of the research was to determine a temperature at: which the rcaction would take place rapicly not a temperature below which the reaction would take place extremely slowly. 
Tests carried out at Argome by W. Reuther did lend some information, however. A stainless steel mesh was imnersed in $\mathrm{NaK} 260^{\circ} \mathrm{C}$ after $113 \mathrm{hr}$ no wetting had occurred. At $304^{\circ} \mathrm{C}$ wetting of the stainless steel mesh was completed in less than $1 \mathrm{hr}$. The Arrhenius rate equation is known to model similar reactions and was therefore examined with respect to the available data. Reference to Skoog and West Analytical Chemistry yielded activation energy data indicating that the activation energy for the reactions that might take place is in the range of 3 to 3.5 electron volts. A value of three was assumed since it is conservative. With the value of actuation energy it was then possible to test the Arrhenius rate equation at the two data points.

$$
\begin{aligned}
& \text { Arrhenius Rate Equation } \quad A=A_{0} \exp -\left(\frac{E a}{K T}\right) \\
& \text { where } A=\text { measure of activity or reaction rate } \\
& \mathrm{Ea} \text { = activation energy } \\
& \mathrm{K}=3.29\left(10^{-4}\right) \frac{\mathrm{Cal}}{\mathrm{OK}} \text {, Stefan Boltzman Constant } \\
& \mathrm{T}=\text { temperature }\left({ }^{\circ} \mathrm{K}\right) \\
& A_{0}=\text { constant } \\
& \mathrm{A}_{0} \exp -\frac{(3 \mathrm{ev})\left(3.83\left(10^{-20}\right) \frac{\mathrm{cal}}{\mathrm{cv}}\right.}{\mathrm{CaI}} \\
& \frac{\mathrm{A} 304}{\mathrm{~A} 260}=\frac{0}{\mathrm{~A}_{0} \exp -\frac{\left(3.29\left(10^{-24}\right) \frac{\mathrm{Ca}}{\mathrm{OK}}\right)(304+273)}{3.29\left(10^{-24} ;(260+273)\right.}} \\
& =147.7
\end{aligned}
$$

Therefor if the Arrhenius rate equation holds the reaction should take place 148 times as fast at $304^{\circ} \mathrm{C}$ as it does at $260^{\circ} \mathrm{C}$. Since this agrees quite closely with the test results, the Arrhenius equation was used to estimate the relative speed of the reaction at $104^{\circ} \mathrm{C}\left(220^{\circ} \mathrm{F}\right)$.

$$
\frac{A 260}{A 104}=5.99\left(10^{11}\right)
$$


Therefor the reaction should take place 5.99 (1011) times faster at $260^{\circ} \mathrm{C}$ than it would at $104^{\circ} \mathrm{C}$. Since nowetting occurred in $113 \mathrm{hr}$ at $260^{\circ} \mathrm{C}$, no wetting ghould occur in $6.76\left(10^{13}\right) \mathrm{hr}$. at $104^{\circ} \mathrm{C}$. This is a period of time (1.1 ( $\left.10^{9}\right)$ longer than a seven year mission. Thus the estimate can be in error by a factor of a billion with no ill effect.

It is important to note that the proceding calculation is concerned with only reduction of the oxide film. Corrosion of the stainless steel will take place only after the oxide film is removed.

\section{Welds}

The Liquid-Metals Handbook indicates that welds are as resistant to attack by $\mathrm{NaK}$ as are the base metals. 


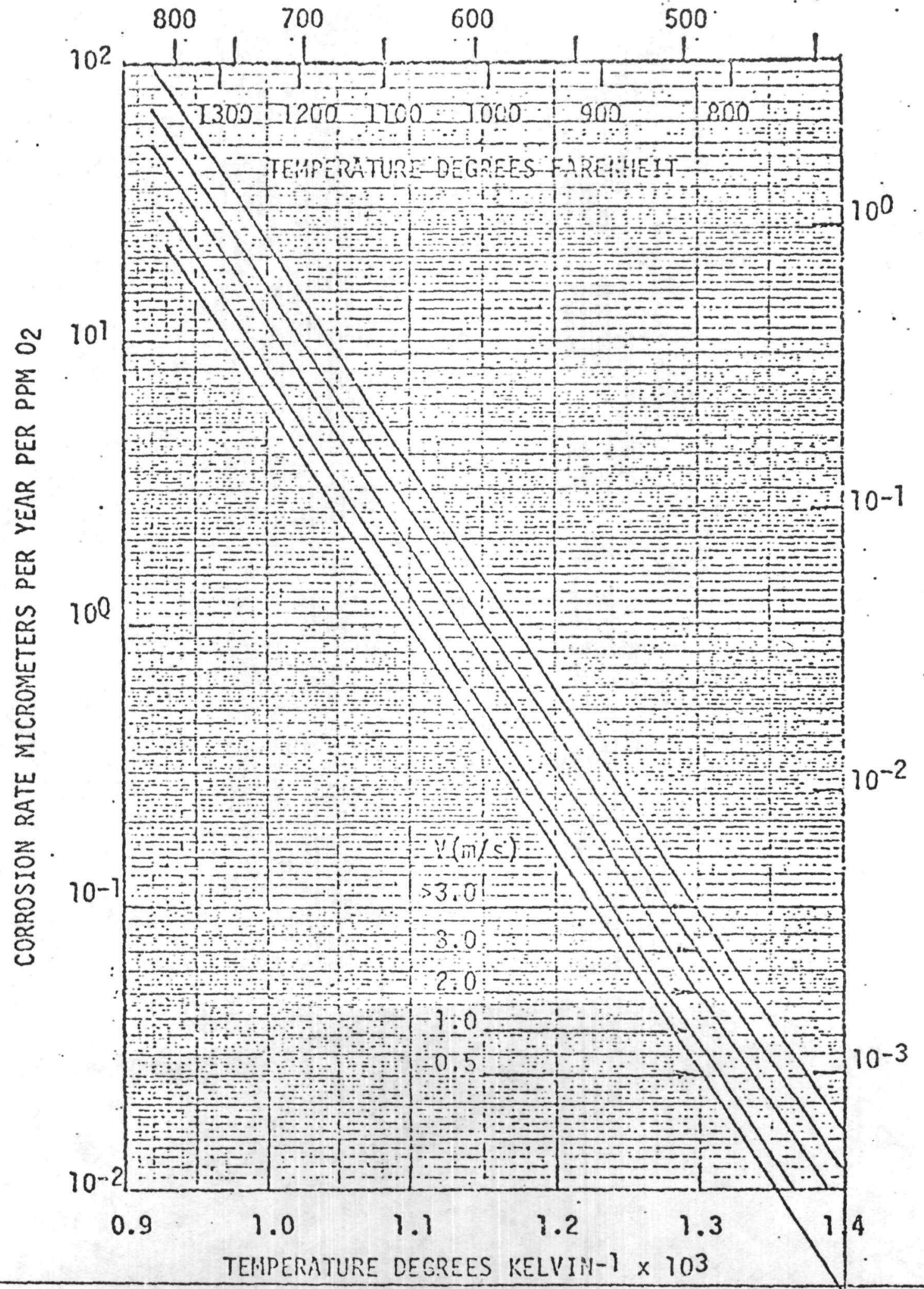

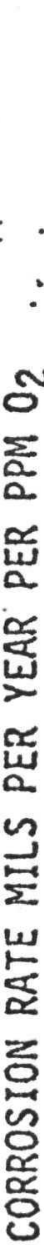

Applicablc Product Forms - All Forms and Hoat Treatments Notes: (1) Read Volune II before using these curves

(2) Mutiply value fren curve by oxjyen level (VHED) to obtain corrosion rate

(3) For high dr/dL conditions i.e., core components, multiply value from curve by 2 . 